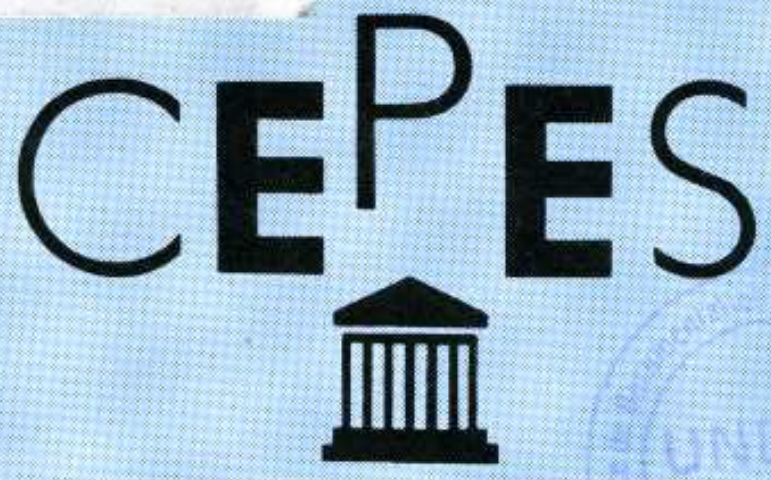
$\begin{array}{llllll}\text { U } & \mathbf{N} & \mathrm{E} & \mathrm{S} & \mathrm{C} & \mathbf{O}\end{array}$

EUROPEAN CENTRE

\title{
FOR HIGHER EDUCATION
}

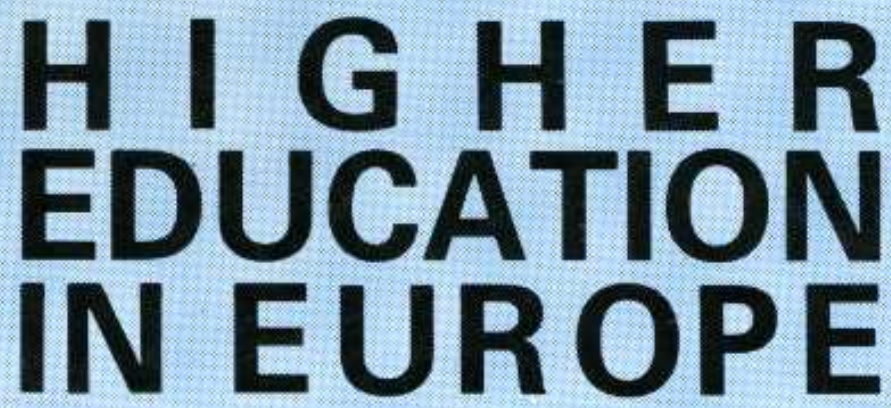

In this issue:

Higher Education and The Labour Market

Vol. XVIII, No. 2, 1993 
Higher Education in Europe is a quarterly review published by CEPES. It deals with major issues and trends in contemporary higher education and presents information on current developments and events in this field. While focussing mainly on Europe and North America, it regularly features contributions from other regions of the world as well.

Director: Carin Berg

Senior Editor: Leland C. Barrows

Guest Editor: Maurice Kogan

Editors:

Mariana Pãtru (English version), Ana Luana Stoicea (French version), Cecilia Preda ("Bibliographical References" and "Calendar") Bernard Cerisier (Subscriptions)

The review appears in English, French and Russian.

The Russian version is published by the Research Centre for the Management of Specialist Training in Moscow.

Authors are responsible for the choice and the presentation of the facts contained in signed articles and for the opinions expressed therein, which are not necessarily those of UNESCO and do not commit the Organization.

The designations employed and the presentation of the material in Higher Education in Europe do not imply the expression of any opinion whatsoever on the part of UNESCO concerning the legal status of any country, territory, city or area or of its authorities, or concerning the delimitation of its frontiers or boundaries.

All correspondence should be addressed to:

The Senior Editor

European Centre for Higher Education

39, Stirbei Vodã Street

R-70732 Bucharest, Romania

Telephone: (40-1) 613-08-39; (40-1) 615-99-56

Telefax: (40-1) 641-50-25

E-mail:CEPES@CEPES.RO

Published texts may be freely reproduced and translated (except when reproduction or translation rights are reserved, indicated by (C), provided that mention is made of author and source.

ISSN 0379-7724

(c) UNESCO 1993 


$\begin{array}{r}\text { UN E S C O } \\ \hline \text { EUROPEAN CENTRE } \\ \text { FOR HIGHER EDUCATION } \\ \hline\end{array}$

\section{H I G H E R} EDUCATION

\section{IN EUROPE}

In this issue:

Higher Education and The Labour Market

Vol. XVIII, No. 2, 1993 
Computer Typeset by Viorica Popa

Printed and bound by "METROPOL" Publishing \& Printing Company Bucharest (Romania) 
Higher Education in Europe

Vol. XVIII, No. 2, 1993

FROM THE EDITORS

\section{Higher Education and The Labour Market}

HIGHER EDUCATION AND THE WORLD OF WORK: AN OVERVIEW

Maurice KOGAN and John BRENNAN

THE EDUCATION MARKET, QUALIFICATIONS, AND EUROPEAN

INTEGRATION

Osmo KIVINEN and RISTO RINNE

DOES THE PROGRAMME MATTER? APPROACH AND

MAJOR FINDINDS OF THE KASSEL GRADUATE SURVEY

Harald SCHOMBURG and Ulrich TEICHLER

CAREER PATTERNS OF FINNISH ACADEMICS AND INTELLECTUALS:

A LONGITUDINAL STUDY OF THE 1965 STUDENT GENERATION

Yrjö-Paavo HÄYRYNEN with Liisa HÄYRYNEN

ACADEMIC DRIFT AND BLURRING OF BOUNDARIES IN SYSTEMS

OF HIGHER EDUCATION

Claudius GELLERT

THE EXPANSION OF EDUCATION IN EASTERN EUROPE:

85

A REGIONAL VIEW

Tamas KOZMA

EDUCATIONAL POLICY AND ECONOMIC POLICY:

THE CASE OF SOUTHERN ITALY

Roberto MOSCATI and Enrico PUGLIESE

THE LOST PROFESSION

Ronald BARNETT and Robin MIDDLEHURST

COMPARING QUALITY IN EUROPE

John BRENNAN, LEO C.J. GOEDEGEBUURE, Tarla SHAH,

DON F. WESTERHEIJDEN, and Peter J.M. WEUSTHOF 
Information

CEPES News

Miscellaneous

Calendar of Events

153

Notes on Contributors

CEPES Publications 


\section{FROM THE EDITORS}

This issue of Higher Education in Europe is another product of the cooperation between CEPES and the Consortium of Higher Education Researchers (CHER), which was established a little over three years ago. It is guest edited by Professor Maurice Kogan, Director of the Centre for the Evaluation of Public Policy and Practice of Brunel University, United Kingdom, and Editor-in-Chief of the OECD-sponsored trimesterly review, Higher Education Management/Gestion de l'Enseignement Supérieur.

The nine articles featured, including a very substantial overview article by Professor Kogan and by Dr. John Brennan, Head of the Quality Support Centre of the Open University (United Kingdom), are part of a set of papers which were presented at the Fifth Annual Conference of CHER, held in London, from 24 to 25 July 1992. The topic, Higher Education and the Labour Market, picks up and develops a number of the themes that were evoked in two previous issues of the CEPES review, The Financing of Higher Education (No.1, 1992), and The Steering of Higher
Education (No. 3, 1992), both of which featured topics and contributors which had been suggested to us by CHER.

Because of the length and number of the articles making up the 'Topic', we have had to leave out or greatly reduce the other sections of this issue. Thus the 'Information' section reproduces the Statement of the CEPES-sponsored International High-Level Consultation on Policy Issues of Quality Assessment and Institutional Accreditation in Higher Education, held in Oradea, Romania, from 5 to 7 May, 1993, and the Declaration of Timisoara resulting from the Soros Foundation-sponsored European Journalism Educators' Conference, held in Timisoara, Romania, from 29 to 30 April 1993. We have included a normal 'Calendar of Events' section in this issue.

The next issue of Higher Education in Europe will feature the full proceedings of the above-mentioned International High-Level Consultation on Policy Issues of Quality Assessment and Institutional Accreditation in Higher Education. 


\section{Higher Education and The Labour Market}

\section{HIGHER EDUCATION AND THE WORLD OF WORK: AN OVERVIEW}

\section{Maurice KOGAN and John BRENNAN}

- This article presents an overview of the state of the art in studies of higher education and the world of work, based on papers, some of which are published in this issue, presented at the 1992 annual meeting of the Consor. tium of Higher Education Researchers. It considers the contributions made to the study of the subject by different disciplines and sketches the range of relationships between higher education and work. It discusses the contribution of higher education to the labour

At the first meeting of the Consortium of Higher.Education Researchers in 1988, Ulrich Teichler presented an overview paper which stated the following:

- the basic questions emerging in the (present) stage of debates on the relationships between higher education and employment, which are well addressed by such value-laden terms as overeducation and overqualification, remain the most important focus of political debates and of research... The qualitative links between the content of education and learning, the impact of unemployment, and the reduction of overall work time on the relationships between higher education and employment, the challenge of new technologies market, its diversity and dynamics, and the employment experiences of graduates. It analyses the different value systems of the two sides, their expressions of needs, and reciprocal impacts. It asks what role government and institutions play in effecting the relationship. It analyses the knowledge and skills content of higher education. And, finally, it offers a research agenda. The emphasis of the paper is on the substantive issues against their institutional and structural aspects.

and... adjustments in the relationships between higher education and work... - all these issues have become the points of emphasis.

Since then, published research (e.g., Boys, et al., 1988; de Weert, 1991), projects mounted by the OECD, in Australia on graduate studies and employment (Moses, 1991) and in the United Kingdom (Jones, 1991) and international seminars (for example, in Uppsala and Florence, 1991), have paid particular attention to the first of these themes, namely, the qualitative content of higher education and its relationship to work, together with the institutional aspects of those relationships.

This overview is an attempt to provide an outline of the current state of the art in studies of the relationship 
between higher education and the labour market and employment. It cannot attempt to make a full survey of the literature of what is already a prodigiously written up field, but rather to highlight the main issues which still remain for detailed exploration. The literature referred to here is mainly, but not wholly, from British sources. The authors also refer briefly to other papers included in this issue of Higher Education in Europe which were presented at the 1992 conference of the Consortium of Higher Education Researchers.

\section{THE DISCIPLINARY BASES}

Higher education and the world of work is an area of study which calls upon a large range of disciplinary and conceptual resources. If undertaken in full, it should draw upon the following:

- labour economics and the study of the behaviour and structure of the labour market;

- the study of complex institutions (higher education institutions and employment organizations) and the connections between them;

- the nature of the curriculum as it is delivered and organized and its deeper bases of learning theory and epistemologies;

- policy analyses and political science studies of the role of government in its regulation of the flow of skilled manpower to the labour market;

- sociological studies of occupational structures and social mobility, including the role of professions and of certification systems.

\section{The Main Issues}

In conceptualizing the connections between higher education and the labour market, one embarks, to a large extent, on a study of inter-institutional relationships. The complexity and multiplicity of relationships between higher education and the labour market make difficult any simple modelling of these relationships. Yet without the overview which a model can provide, there runs the risk of distortion of focus caused by short-term problems and agendas set by the various interested parties.

In viewing current thinking about these relationships and developments within both higher education and the labour market, we note underlying assumptions to be tested as both undergo change. Change in higher education has been assumed to be largely incremental, particularly in the curriculum, effective relationships with the labour market to be created largely through serendipidity and permeability. But policy directions point the other way and towards drastic social engineering. Empirical research must discover whether the changes in the policy frames have altered these modes of development.

The elements and relationships to be addressed are summarized in Figure 1, and elaborated below. 
Figure 1. The Relationship between Higher Education and the Labour Market

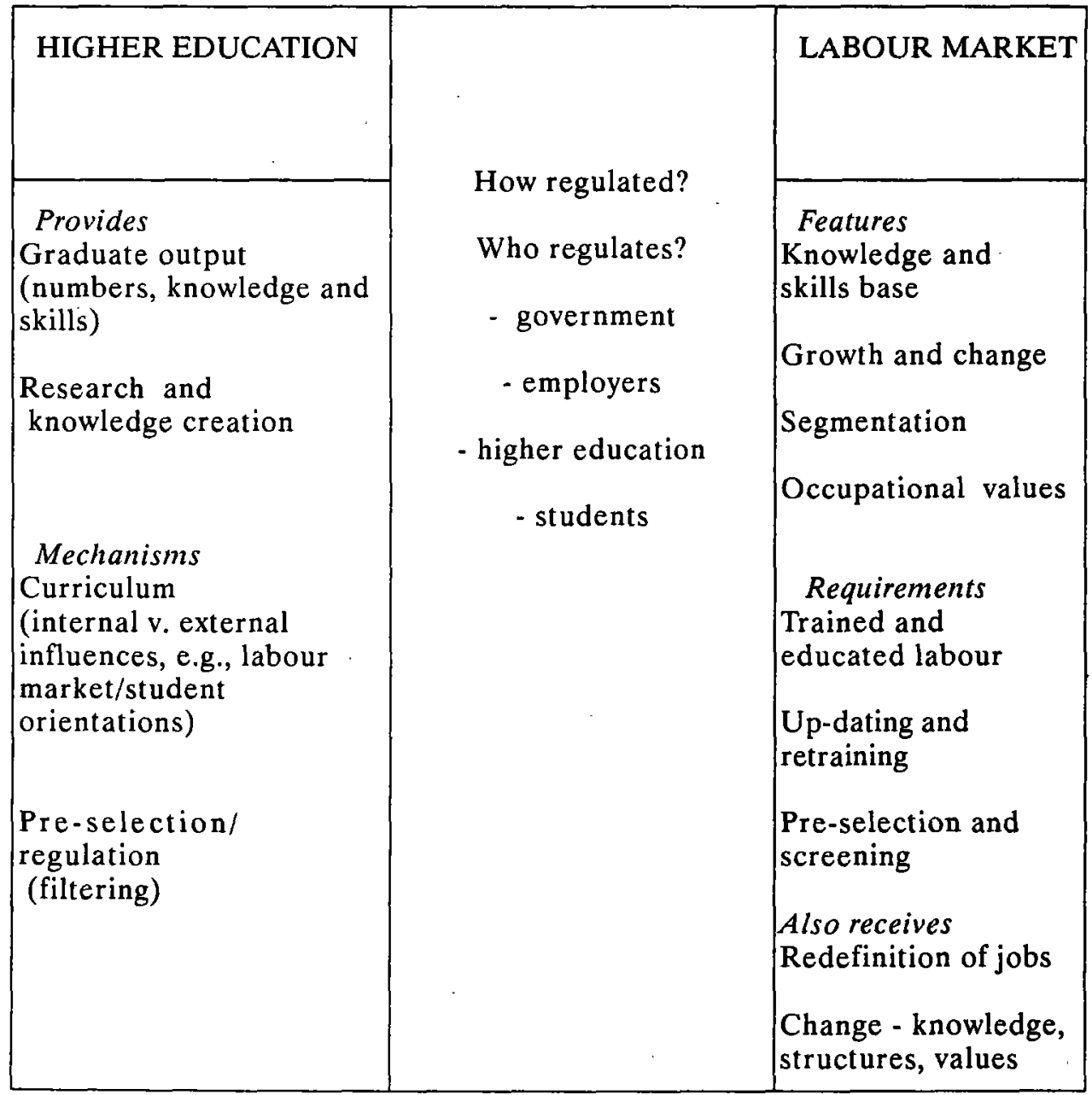

THE NATURE OF THE LABOUR MARKET

The knowledge and skills base of occupations has increased substantially in almost all areas of the labour market. The labour market is also increasingly segmented, both across so- cial variables such as class, gender, and ethnicity, as well as in relation to skills and qualifications. The demand for labour within different segments changes over time, as for example, a shrinkage of the labour market for unskilled male manual work. As well as their knowledge and skills base, 
different occupations are marked by distinctive work cultures, attitudes, and values (frequently related to social and educational background) shared within given occupational groups.

The labour market requires trained and educated labour, and the pre-selection, screening, updating, and retraining of labour. Occupational socialization into the cultures of particular occupations and labour market segments is also necessary. Even though these requirements represent the main features of the demands made by the labour market on higher education, there is no intrinsic reason why they should be met by higher education. Indeed, much training is company provided and probably the bulk of occupational socialization also takes place within employment. The contribution of higher education is variable according to particular occupations and labour market segments, but is frequently on the margins.

In addition to what the labour market requires from higher education, it is affected by the redefinition of jobs and by general occupational and 'cultural change. This relationship is a consequence of the changing attributes (social as well as educational) of the labour which it recruits from higher education as well as a result of the application of the research and development undertaken in higher education.

\section{THE CONTRIBUTION OF HIGHER EDUCATION}

Turning to the higher education perspective of the relationship, its primary contribution is graduate output, variable in terms of numbers, knowledge, and skills.

The higher education curriculum is influenced by the labour market, but certainly not exclusively so. Both inter, nal developments in the curriculum arising from research and knowledge creation, and external influences, most notably student orientations, shape, to a greater or lesser extent, the fórm and content of the curriculum and the characteristics of the graduates produced by it. The relative influence of each varies over time, and much present governmental effort is being expended on changing the balance in favour of the labour market.

The knowledge creation function of higher education has itself a direct influence on the labour market in the creation and redefinition of jobs. This function has been particularly important in recent years as the introduction of new technologies has changed labour market requirements both quantitatively and qualitatively. This factor again is variable according to the zone of activity. It is commonly conceded that in high technology occupations the knowledge frontier is often advanced more in industry than in higher education, whilst in some public sector jobs, for instance, teaching, social work, and planning, the values and working assumptions are not far different from those of higher education.

Finally, higher education acts as a selection or regulation device for labour market recruitment. By using the qualifications and certificates of higher education institutions, employers are sub-contracting a 
large part of the employee selection process to the educational sector. In practice, employers do not distinguish closely between the attributes of graduate labour that are a function of pre-selection and attributes which are a function of the educational process.

The labour market and higher education thus permeate and influence each other. The relationship is best seen, not in terms of needs and demands, but as mutual accommodation to continual social and economic change affecting both institutional sectors. The level of economic activity in society and demographic factors are only two of the extraneous features which exert major influences on the labour market and higher education respectively and, by so doing, change the relationship between them.

If the relationship between the labour market and higher education is interactive, empirical questions arise about the relative strengths of influences, about areas of maximum interdependence and maximum autonomy, and about the mechanisms by which the relationships might be controlled. There are questions about who can and should control it Government? employers? higher education institutions? students? There is a further question of whether or not it should be controlled and how much should be left to the creative development of each sector of society.
THE DIVERSITY AND THE DYNAMICS OF THE LABOUR MARKET AS A CONTEXT FOR HIGHER EDUCATION

We turn now to more detailed descriptions of the labour market. Higher education must contend with labour market characteristics such as shifting employment rates and demands for higher education, including skills in graduates. It must also form a view, or a range of views, about what its contributions to usable research and development should be.

In all, there have been increased flows of graduates to the labour market, in spite of temporary reductions and levellings off in the 1970's and 1980's (Teichler, 1988). But graduate unemployment has been a source of increasing concern since the 1980's, even if it is lower than that of non-graduate unemployment. The incidence of unemployment varies according to field of study. Graduates in engineering, economics, and the legal and medical fields do not generally face problems. It also varies according to the type of institution from which the graduate receives his or her degree: university versus polytechnic; IUT, grande école, or university. This effect is not constant universally or over time. The institutional differences have, for example, faded in Germany but appear to remain important in the United Kingdom. The unemployment of women is more serious than that of men. The average period of the search for work has increased. It is uncertain whether these trends have been mitigated by recruitment to further full- or part-time study and that, 
too, is variable according to field of study, a point recently reinforced by a Dutch study (de Weert, 1990) of social science students and employment.

Yet, despite these difficulties, only in the USA has there been clear evidence of a dramatic shift of student options towards marketable fields of study. They remain devoted to what Geoffrey Squires has called essentialism in higher education. That may be, of course, because students cannot be sure what will remain marketable for ever. A recent British study (Brennan, et al., 1993) points to the importance of "altruistic", "intrinsic" and "leisure" as well as "careerist orientations" in students, orientations which vary significantly according to subject fields, types of institutions, and social backgrounds of students.

Several researchers have analysed the extent to which the labour market depends on general or specific forms of higher education (e.g., Teichler, 1988; Boys, et al., 1988; de Weert, 1990). In considering the preparation of students for employment, Silver and Brennan (1988) have defined a hierarchy of eight relationships between course programmes and potential employment with an ordering of specificity and explicitness in the design and presentation of course programmes. They point out that irrespective of a liberal-vocational dichotomy, academic qualifications are being used to regulate entry into employment. "From the employer's standpoint, a degree in a particular subject is essential, desirable, or irrelevant for selection". They then note three possible rules for degree qualifications in the regulation of entry to an occupation: a specified degree as sole regulator; a specified degree as partial regulator, and an unspecified degree. They also note the relevance of the extent to which courses achieve different amounts of completed job preparation.

For the most part, these concerns have not been strongly present in the thinking of curriculum makers, who largely feel able to respond to intuition and the hidden hand of employment demands, except in those areas in which specific qualifications are required and professional bodies exert a certification role. Higher education is less concerned with occupational tasks than are other types of pre-career training. Moreover, as higher education questions existing concepts and practices, it is unlikely, therefore, to be too sympathetic to the promotion of particular work styles or doctrines, enterprise philosophies included.

Similar themes are reinforced by studies of the perceptions of students and of graduates of the relevance of studies to work (Brennan and Mc Geevor, 1987; Teichler, 1988; Boys, et al., 1988; and Brennan, 1991). In general, graduates, even in vocational subjects, do not appear to have found their studies especially useful in actually doing a job. Yet their perceptions of work-related benefits are generally high, and more in selfawareness, personal confidence, and general intellectual and critical growth and development.

Two-thirds of graduates in the United Kingdom enter fields not related to their undergraduate studies 
(Pearson, 1985). Once they enter employment, what happens to them? Here career theory displays two competing views (Robinson*, et al., 1992, reporting Arthur, et al., 1989). The functionalist approaches support systems already in place as does conventional human resources planning. The second approach challenges the existing system. Trait factor theories take characteristics of the individual and of the work environment and examine the appropriateness of the fit or the match between the two sets of characteristics (congruence). We have to note that much of the discussion is normative, dealing with desired states, rather than objective, dealing with actual states. For example, Ginsberg, et al. (1951) and Super (1957) argue that discrete decisions are made at particular points of time and propose a continuous process of career development. Work on expectancy theory (Vroom, 1964) distinguishes between "preferred occupation", "chosen occupation" and "attained occupation". Much sociological thinking on careers has concerned itself with the relationship between individuals and institutions and with situational/structural aspects of career opportunities.

One tendency is to view careers as vertical structures in which the journey is ever upward. "... [R]esearchers overlook the empirical fact that meaningful careers exist that involve no movement through a hierarchy of power of control" (Robinson, et al., 1992). From the point of view of higher education institutions concerned with providing relevant education, one might ask whether there are critical periods in individual development. Do graduates go through phases in which their knowledge and skills grow and are consolidated but then need to be broken down into different patterns as they reach a new stage in their careers? For example, in technologies, for some the starting point of a career might be specific technical knowledge which increasingly has to give way to a grasp of organizational structures, marketing, etc. No continuous modelling across the whole range of higher education and employment exists with regard to what happens to the whole range of higher education employment and to what happens to people as they pass through the system from higher education and the labour market through many stages of the latter. Such studies for broad study areas could be helpful to institutions and departments trying to analyse their portfolios.

Kivinen and Rinne consider the European dimension to the relationship between higher education qualifications and the labour market. They sound a skeptical note about this relationship in general and about the aspirations of the European Communities in particular. Not only might a more highly qualified workforce not

* Much of the discussion of career theory contained in this section depends on a review of literature in Sarah Robinson, et al., The Careers of Nurses and Midwives, Project Report 1 , Nursing Research Unit, King's College, London (1992). 
be the key to economic prosperity, but it might be a contributory factor to greater social inequalities inasmuch as a social reward system based on the possession of qualifications is not matched by equal access to these qualifications.

\section{EMPLOYMENT EXPERIENCES OF GRADUATES}

Brennan (1991) has described the employment experience of British graduates from different but matchable institutional backgrounds. More polytechnic students remain unemployed whilst more also enter the labour market - because more university students stay on for full-time study. "The destination statistics suggest a better market situation for university graduates but a more complete employment preparation for polytechnic graduates". After five years, more polytechnic students are self-employed. University students were earning $\mathfrak{f 2 0 0 0}$ more a year than polytechnic students, except in computing. They were also holding employment traditionally regarded as appropriate for graduates, whilst polytechnic graduates were more frequently in "new" graduate jobs.

Polytechnic students, however, were more likely than university graduates to say that they would have taken the same course programme again, given the choice. The figures display a high level of dissatisfaction with course programmes. More polytechnic students felt they were regarded as possessing expertise based on their degree courses, but of the groups who followed the most employment related courses, Brennan writes that "engineers - from whatever type of institution - are less likely to wish to repeat their choice of degree course than other groups of students, the only exception being university accountants". Student preferences, however, do not tend to push the curriculum either to more academic or to more vocational treatments. A student survey (Boys, et al., 1988) suggested that students are motivated primarily by personal interest and that employment considerations vary in importance according to the subject.

From these findings, Brennan concludes that "there is a discrepancy between success in the labour market and success in the way higher education prepares students for employment". But this discrepancy is also partly explained by the fact that university students tend to get into fast track management positions in which specific knowledge from courses becomes more distantly relevant.

The results of a major German study are reported in the article in this volume by Schomburg and Teichler. The relative importance to be attached to field of study differences, to institutional differences (universities versus Fachhochschulen), and to gender differences is explored. The authors believe that the results of their study challenge the widely-held views in Germany on the relationship between higher education and employment. Most studies, in fact, do. Conventional wisdom on higher education and labour market relationships - whether held by academics, employers, or governments - is rarely based on evidence or systematic inquiry.

Results from a major Finnish study are reported in this volume in the ar- 
ticle by Häyrynen. The long-lasting impact of social origins and cultural capital are emphasized in this study as is the importance of gender. The study also illustrates how objective characteristics of employment are distinct from the perceptions of graduates and the satisfaction felt by them.

A further element of labour market dynamics concerns the rapidity of technological change and consequent skills requirements, seen most spectacularly in the impact of information technology on job specifications of all kinds. As the nature of employment changes, as enforced mid-career redirections become increasingly the norm, so new requirements for continuing professional education appear. As recent OECD project papers point out, these requirements are frequently met outside mainstream higher education institutions. Other studies have pointed to a widespread lack of interest by higher education institutions in the educational needs of adults (e.g., Soljan and Schutze, 1989). Even if these requirements continue to be met elsewhere, higher education institutions need to take them into account in the design of initial education and training. These developments would seem to imply a greater concentration on general intellectual or at least transferable skills at the initial stage of education/training rather than attempts at specific vocational preparation. There may be important consequences here for the direction of those non-university sectors geared to the meeting of employer needs as has been recognized within at least one of those sectors (Stoddart, 1991). Some systems, for instance, of Japan, provide largely general education in the first degree on the assumption that employers will provide advanced training and education related to careers.

\section{RELATIONSHIPS AND DIFFERENT VALUE SYSTEMS BETWEEN THE LABOUR MARKET AND HIGHER EDUCATION}

In some countries, the labour market must contend with an increasing diversity of institutional forms of higher education. The traditional dominance of universities is being challenged by non-university institutions, for instance, the IUT's (France), the HBO's (the Netherlands), and the Fachhochschulen (Germany). They may be seen as producing closer forms of relationships with the labour market. Course offerings are directed to specific vocational fields; and academic staff are recruited as much for their work experience as for their academic credentials. Consultancy rather than research form the staff agendas. Students and graduates may be distinguished by different entry and exit qualifications from their university counterparts. The claims of these institutions and forms of their labour market relationships have been subjected to critical scrutiny (Teich́ler, 1992).

In his article in this volume on "Academic Drift and Blurring of Boundaries in Systems of Higher Education", Gellert reviews trends in institutional differentiation and asks whether these are needed to sustain functional differentiation. In other words, if societies and labour 
markets require higher education to take on new, mainly applied, functions, do these require separate institutions with different normative stances with regard to academic work, teaching, research, and service priorities?

A major research concern has to do with the ways in which two very complex and variable sets of institutions form or do not form relationships. Higher education institutions are essentially public institutions with publicly known and accepted formats yet remarkedly varied in style, objectives, and operation, while serving different social constituencies. Labour market institutions are entirely idiosyncratic yet reveal regularities in structure and behaviour. How do/can such different structures effect any kind of relationship? Policy assumptions tend to look for preconceived and structured working relationships, whereas all the evidence points to far more complex behavioural patterns. These complexities can be observed at several levels. Does an examination of the two value systems indicate whether connection is possible?

The value systems of the labour market are likely to be as diverse as the employment activities in which it engages. The profit-led sectors, of industry, commerce, and privately provided services are essentially concerned with optimizing unique and idiosyncratic opportunities and not likely therefore, except in Marxist demonology, to have a single set of values which can be read off by higher education. Its values are to some extent expressed in its demands with regard to higher education for the inculcation of certain instrumental skills and for moral and operational support of such value sets as belief in enterprise. The public sector, by contrast, is concerned with such values as those encapsulated in accountability and equity. But even within local authorities, social workers and housing managers evince somewhat different values. Thus higher education in trying to fashion employment values in students is in for a tough job. Presumably it is struggling to find a generic core of moral qualities and behavioural propensities that all kinds of work require. Such a quest would be an objective of the British Enterprise Initiative Project (Jones, 1991).

Perhaps less various, but still various enough, are the values of higher education. All higher education unites in its stated belief in autonomous thinking and the critical search for new truths. But we have moved a long distance, over a wide range, of what is now considered higher education, from the pure academic models expressed by Cardinal Newman and Humboldt. These depended on assumptions of the importance of excellence and independence of disciplined thought. The newer ranges of values depend upon social policy considerations of interactiveness, and of concern with advancing causes. The more sophisticated employers themselves give credit to much in both models, to an ability to relate and to lead and to intellectual flexibility, good self-expression, and independence of judgment, rather than callow instrumentalism and reiterative training producing tightly focussed skills. 
Nevertheless, we must recognize new forms of higher education provision which are prepared to be more directly led by considerations of employment relevance. Thus, courses in geography become courses in tourism; courses in economics become courses in business administration; and courses in hotel and catering emerge from no clear disciplinary background. How far traditional values of intellectual inquiry confront more alien workplace values and with what result in such courses and institutions is an interesting question deserving of research. The research agenda here would be to analyse the range of values implicated in programmes and recruitment practices on both sides, and then to see whether they really result in conflict and disjunction.

The uncertainty of fit between the two sets of institutions could be a harsh operational reality as employers seek to maximize economic advantage and young people seek to develop their own interests. Yet even here, Teichler tells us, "a growing number of graduates take positions that lack some elements of the jobs traditionally considered typical for graduates in general or considered typical for graduates in a particular field of study...." But, he goes on, "the number of graduates in European countries taking jobs that are strikingly inappropriate by all standards for graduate employment has increased much less in the 1970's and 1980's than pessimistic statements widespread in the 1970's had predicted. In addition, the values of students and graduates have seemed to change with regard to desirable jobs".

\section{EXPRESSION OF NEEDS BY THE LABOUR MARKET}

But if students and higher education are uncertain, so are employers, in the ways in which they articulate and express their needs. In the most powerful economy in the world, Japan, employers virtually use higher education as a screening system and expect to train their recruits themselves in work knowledge and attitudes. For the most part, British employers express the need for quite general and even humanistic qualities directed to producing flexible, clear minded, and co-operative team workers and leaders. Some are concerned with standards in certain basic skills of communication and calculation. But the notion that there can be any systematic method of analysing the needs of employers and of gearing higher education to them is an episodic fantasy of politicians and the occasional planner. This view also flies against current beliefs in the hidden hand of the market. To look for sustained examples of such planning, we would have to do research on the monumental failures of the command economies of eastern Europe.

Indeed, all of the studies of the situation in the United Kingdom (Roizen and Jepson, 1985), in Japan, and in Europe generally, as reviewed by Teichler (1993), have shown the great variety of employers' criteria and recruitment procedures. Nor could Teichler find that the variations were related to the logic of technology or economy. We cannot therefore 
draw from research any clear picture of the changing receptor function of the labour market and of its ability to exploit the resources offered by higher education.

\section{RECIPROCAL IMPACTS}

This question leads one into territory not often examined by students of higher education, namely, some of the characteristics of the labour market as they affect higher education. Both Roizen and Jepson and Teichler have depicted internal recruitment structures in which different power structures and presumably value systems hold sway. Is recruitment undertaken by the operating division according to its own specialist needs or by a central unit that might evince a concern for the career trajectory over the longer term? There are indeed different degrees of centralization of the use of specialist personnel and training roles.

A related issue is the extent to which higher education affects the labour market. Several perspectives could be followed. At one level, the connections are obvious. The results of knowledge created by R\&D undertaken in higher education institutions affect the productive capacity of the labour market (DNA, areas of social reform affecting the public sector, science parks, etc.); even though increasingly state-of-the-art technology is developed by industry itself. Secondly, higher education is itself a large service sector generating employment and economic activity in the areas where it is located (Mallier and Rosser, 1986). Thirdly, however, are there more insidious contribu- tions, such as the changing concepts of organization and social relations largely deriving from the social sciences, also to be taken into account? An official Dutch (HOOP) statement (de Weert, 1990) maintains that institutions should provoke signals from the labour market and act on them critically. Thus the institutions should try to make their own judgments with regard to the ways in which the economy and society are moving, create their own prospective portfolios, and test them actively with client groups. Some such process is indeed demanded of those who provide courses in social work.

One way in which higher education may affect the labour market is through the subject mix offered by institutions and systems. The subjects studied help determine employment. The changing balance between particular disciplines and subject fields as well as moves towards multi-disciplinarity affect who is recruited in higher education, the nature of their socialization, their aspirations, and their preparation for different forms of employment.

In general, the assumption is that the labour market is the active partner, and higher education, the passive partner in this relationship. Is this characterization empirically true?

THE CAPACITY OF GOVERNMENTS TO AFFECT RELATIONSHIPS BETWEEN LABOUR MARKET INSTITUTIONS AND HIGHER EDUCATION INSTITUTIONS

If we are uncertain about the capacity of higher education and the labour market to affect each other in any 
systematic way, we can look at the role that might be played by governments. The only clear fact is that governments act as if they can affect the outcomes, doing so by regulating the amount of higher education provided in broad subject categories. In the past, and now once again, to a lesser extent, they have engaged in explicit manpower planning in areas such as medicine and teacher training, and less specifically elsewhere.

In the United Kingdom, the government has expressed explicit requirements to the effect that higher education should move closer to the needs of business (1987) and has said nothing about the needs of the public sector.

No competent research has indicated how all of this happens. We are left to assume that whatever prescriptions a government makes are based on guesswork which often differs from that of employers. We would like to know more about whether and how government and the funding councils aggregate and express demands as policies. To what extent do they articulate economic, social, and regional needs, and on what information do they depend? Do they in fact allocate higher education resources in response to the labour market? The answer is that the funding councils on the whole do not do so and that it has been central initiatives such as the British government's Enterprise in Higher Education projects which represent big shifts in the relationships of government with higher education. Research results are available on the creation of institutional frames and connective mechanisms by the centre, starting with the Manpower Services Commis- sion (Ainley, 1990), and the shift of power from the Department of Education and Science to the Department of Employment. No research results exist on the monitoring of relationships between higher education and the labour market by the centre.

Room exists here for analysis which is both more descriptive and more conceptual. It could begin by outlining the difficulties of government in formulating and implementing policies in this field. There is the difficulty of applying means to prescribed ends, that is, acting as rationalistic government, whilst sustaining a belief in market behaviour. It would be possible to model relationships in terms of quite a large repertoire of choice. Are relationships between government, institutions, and the labour market those of the free market, or of the hidden hand and of serendipity? Are they an exchange relationship in which explicit quids are given for explicit quos? Or are there still residues of the deficiency grant in which higher education institutions are permitted to find their own way on the premise that they will do good by. doing what they like best? Are elements of a communal relationship still in place?

The role of governments, and the limits to that role, are featured in several of the other contributions to this issue of Higher Education in Europe. Kozma reminds us of significant geographical differences in the rate of expansion of higher education systems, differences which relate strongly to developments at other levels of education. Geographical factors are also evident in the article 
by Moscati and Pugliese. In this case, the suggestion is made that an undifferentiated and centrally controlled education system in Italy is unable to adapt to the distinctive economic and social needs of, in this example, an underdeveloped area.

\section{THE ROLE OF HIGHER EDUCATION INSTITUTIONS IN FORGING LINKS WITH THE LABOUR MARKET}

In the United Kingdom, from the time of the first cuts in the early 1980 's, policy pronouncements emphasized that the institutions, rather than the departments and the individual academics, should generate and control educational practice. The reductions in public funding placed new burdens on, and elicited new responses from, the individual institution and its leadership. The Jarratt Report (1985) placed upon the Vice-Chancellors of Universities the explicit role of Chief Executive rather than that of primus inter pares within a collegium of scholars and advocated strong corporate planning.

The United Kingdom Enterprise Initiative is an example of an attempt to reinforce these changes. It invites institutions to persuade departments to externalize their teaching away from the singular demands of the discipline and towards the inculcation of qualities and skills outside those traditionally demanded by the academy. This request elicits all the dormant politics of academic life. The Brunel study of nine very different higher education institutions in 1984-1987 (Boys, et al., 1988), noted some of the potential shifts in power and behaviour which were al- ready taking place without the benefit of Enterprise in Higher Education.

In the period covered by the study, no academics, at any level within any institution, could doubt that changes in the environment were affecting their ways of working. The formal structure as much as the frames of action determined responsiveness to the labour market. Responses varied according to institutional status, which helped determine degrees of vulnerability, and their histories, as well as the linking of styles of leadership with the other forces operating within and on institutions. Because of this complex combination of factors, generalizations cannot easily be made, but some are offered as follows:

- The setting of objectives by institutional leaders, new to many institutions, promoted change only when the threat from the outside was severe. This threat opened the way for determined leadership, or allowed a consensus to build up between leadership and the basic units. Otherwise the setting of objectives tended to remain largely rhetorical.

- Institutional responsiveness was not markedly influenced by the activities of lay governors even though their part in the appointment of institutional leaders might critically affect institutional style and responsiveness. Generally, governors doubted the extent to which they could or should attempt to influence policy, even though the chairman emerged as significant in manag- 
ing meetings and in his relationships with senior officers. Governors expected to follow the recommendations of the officers and committees and to confine themselves to "giving advice, warning, and consent" and not to being interventionist. The key event by which they influenced the future was the appointment of the head of the institution or other senior personnel.

- Industrial members were often drawn from a wide range of work and not necessarily from local firms. Thus they had difficulty in developing any kind of group perspective. Most members also doubted that the governing body was an avenue through which they could put forward views about the needs of industry. Overall, although the laymen appeared to be growing in power, they were not a primary source of external influence.

- As institutions responded to external pressures, they centralized power, sometimes through an increase in leadership influence, but also through the strengthening of the intermediary, usually faculty, level. The sovereignty of individual disciplines came under challenge, and it was at the faculty level that proposals for the combination, modularization, or combining of teaching or research disciplines could be considered. The means employed were associated with the size of the institution and its vulnerability and need to respond to external influences. The agenda of the institution became greatly. expanded with the setting of supra-departmental objectives and the handling of an environment both prescriptive and volatile. But external bodies continue to assume departmental autonomy in course planning and academic development. It is doubtful whether the institution can influence the development of specific courses. The curriculum becomes a matter for institutional decision-making only in terms of the overall balance of courses and in responding to system level requirements or restrictions.

- But managerial patterns are changing rapidly, and the Brunel study, now five years old, may not have captured some of the more heroic examples. New bidding procedures are requiring institutions to make a searching inspection of what will pay and will not pay.

- At the same time, if basic units, in some subjects and institutions, were changing, little evidence existed, at least in 1988, that heads of departments exercised much power in setting departmental priorities, even if there were decisive individual initiatives. Most changes resulted from more or less democratic processes, often prompted by curriculum review, perhaps initiated from the outside. Departments might still remain guardians of their subject interests, for example, through their control of student assessments.

- The performance of institutional leaders helped determine how well institutions sustained their positions during the period of 
contraction (Sizer, 1987). In eight institutions, that is excepting an ancient collegial university, the quality of leadership was viewed as affecting the direction of institutional change. In the case of at least three (one vicechancellor and two directors) of the five recent appointments among the nine higher education institutions in question, the criteria included not only academic qualities but also leadership, public relations, and institutional representation, and an entrepreneurial and a strong managerial approach. For the most part, the leaders in our sample did not adopt a simple hierarchical style: leadership lay as much in the exercise of co-ordination, team building, committee skills, and a sense of overall vision in policy setting.

- The leaders of three higher education institutions initiated such changes as organizational restructuring to strengthen the centre; or faculty restructuring to facilitate devolution; and changes in the committee strueture to give the vice-chancellor a more decisive rolc. They introduced research and finance committees to give more prominence to research and to resource allocation. Moves to strengthen the leader's hand in committees and in the administration, to build a top team or directorate, to establish closer links with the chairman of the governing body or council, all indicated attempts to promote active and authoritative leadership.
- The larger and most prestigious institutions in both sectors displayed the most diffused patterns of leadership. Leaders of institutions offering more vocationally oriented courses or with expressed community objectives were more likely to look to external relationships. The institutions most under pressure from lost revenue or courses displayed strong leadership. Yet even here, with one exception, the basic units remained the originators of the bulk of the curriculum and of the research programme.

- There were responses to external changes. Institutions encouraged basic units, through financial inducements and sanctions, to increase external earnings through, for example, industrial liaison, research contracts, consultancies, new postqualified courses, and science parks. Higher education institutions were thus increasingly being forced to adjust to the environment, to become more outward looking, and to recognize the influence of the consumer.

- But at the time of the Brunel study, whilst there was certainly an atmosphere of change, there were "still large gaps between the dominant government rhetoric and the ways in which institutions themselves operate". The classic and autonomous model of academic government was giving way, but only in part, to the concept of the responsive and dependent institution. 


\section{KNOWLEDGE AND SKILLS CON- TENT OF HIGHER EDUCATION}

We turn next to the knowledge and skills content of higher education and to its relevance to employment. For the most part, academics remained true to their own values in developing and delivering the curriculum but there were important concerns about skills desirable for employment which varied according to the subject area. The Brunel study (Boys, et al., 1988) traced curriculum change in six subject areas, including history, economics, engineering, and physics. In summary the findings were as follows:

- History remained strongly "internalist" in its development, but budget cuts caused some rearrangements, even in the stronger departments, including closures. An emphasis on employability was internalized by teachers who were concerned about the prospects of employment of students. The logic of the discipline continued to prevail, but movement was evident towards more thematic treatments and socially relevant topics, including the economic plight of the United Kingdom. Some teachers ensured attention to development of oracy, self-presentation, and the use of information technologies. But individual development continued as the main claim of the subject to employability.

- Physics was under pressure. Physicists remained in control of the taught discipline but had to take account of external pressures and constraints. The agen- da of research was subject to external pressure from funders, but the rules of scientific enquiry were not affected. However, economically-led research might begin to affect the undergraduate curriculum. There was a growing demand for inter- and multi-disciplinary scientists and for work in areas shaped by both academic science and industry. Physicists were concerned to preserve a distinct identity from engineering whilst taking note of external demands.

- In electrical engineering, there was broad consensus between academics and employers. Differences concerned questions of emphasis. The departments were directed to produce graduates for the engineering profession, even if all graduates would not be working in this field, and not all graduates proved satisfied about their preparation (Brennan, 1991). Employers influenced curriculum through research funding rather than through guidance offered through committees or other explicit mechanisms. Departments had difficulty in interpreting the wishes of 'employers', and there were differences with regard to the proper division between academic and employment skills.

- The strong sense of disciplinary identity on the part of economics might have made it unresponsive to external influences. Yet its subject matter was relevant to the world of work and, for some persons, application was the main thrust. They seemed able to make 
strategic changes in their courses without losing academic authority and recognized that opportunities lay in business or financial institutions whilst sustaining the belief that good "academic" economists were valued in the labour market. They did not act, or find it necessary to do so, on messages received in any coherent form from employers. But labour market considerations played a part in shaping developments in undergraduate teaching.

One can observe, therefore, that whilst the four subject areas were certainly responding to employment considerations, they were able to do so without shifting from their own value bases. But both physics and history were less secure than in the past. Electrical engineering was a growth area. Some traditionally strong subjects, (economics was an exception), were losing ground to newer subjects in the organization of degrees. Subjects varied in self-confidence according to their status and paradigmal certainties; some of them (e.g., economics and history) felt able to meet the demands of employability by sustaining their disciplinary stances, whilst others, such as physics, if making no concessions on scientific standards, felt constrained to respond to the perceived demands of the market. Except for such subjects as engineering and business studies, however, most subjects did not receive and act on direct messages from employers about curriculum content.

Curriculum development was predominantly incremental and continuous; however, there were cases of substantial restructuring or innovation, including one college in which the directorate virtually destroyed discipline-based courses in favour of new employability themes. There was growth in multi-disciplinary, interdisciplinary, combined, and modular courses and undergraduate programmes which linked across traditional disciplinary boundaries. Physics provided several such links; for example, with biological, geological, and medical sciences to offer courses in bio-physics, geo-physics, and medical physics, in response to a demand for technologists who can work together on problems which cannot be tackled within one discipline.

Thus re-orderings of the boundaries and "kinships" between subjects are occurring involving the regrouping of departments according to vocational or disciplinary links. Some such redefinitions may respond to newly defined needs for trained manpower. Those institutions which most need external earnings or more students are perhaps more likely to pursue this path, but the objective of relevance appears to gain strength as economic pressures mount, even in high status and long established academic departments.

The concerns of government and employers about the development of skills are reflected in many course programmes. The spectrum of skills that academics were concerned about promoting includes generic study skills, intellectual skills, experimental and technical skills, and general and specific work skills. Within this range, there was increas. ing interest in identifying and 
promoting transferable skills. Institutions also recognized the demand for the literate scientist, the numerate arts student, the socially aware engineer, for computer literacy, and for communication and social skills.

Almost everywhere, institutional concerns about graduate employment formed an important part of the atmospherics. These concerns were not, however, equally strong everywhere, and the evidence suggests that they partly reflected the degree of vulnerability and traditional differences in institutional mission. Application and vocationalism, which have been part of the ethos of the polytechnics and the technological universities since their foundation, were well established among the nine institutions under study.

These developments do not usually derive from considered institutional policies but emerge opportunistically as individuals and departments pursue what they see as their best interests: to secure survival, to maintain academic status and identity, to secure resources, to fend off external threats, and to sustain individual and collective disciplinary advancement.

A rather different perspective, however, is offered in the article in this volume by Barnett and Middlehurst. They describe what they see as the failure of academic professionalism and with it the readiness of the state to intervene to shape curriculum developments. Intervention may take the form both of direct regulation and/or evaluation or of opening up higher education institutions to the forces of external markets.
Although the thesis is somewhat at odds with the main thrust of the developments described by Boys, et $a l$., one must note that the empirical work for this study was carried out in the early 1980's. Certainly, the pressures reported by Barnett and Middlehurst are increasingly apparent. What may be more open to dispute is the robustness or otherwise of the academic community to resist or at least to deflect them. As Barnett and Middlehurst point out, there are probably large institutional differences in the balance reached between internal and external influences on the curriculum.

Seen from the graduate end, perspectives on the employment relevance of courses and course programmes vary substantially according to field of study. A recent study found a range from $94 \%$ of polytechnic graduates in estate management who felt their course programmes to be useful in their current employment to only $29 \%$ of university graduates in history and English literature (Brennan, et al., 1993). The data were collected two years after graduation. Nor were the history and English graduates confident of future usefulness, $41 \%$ expecting their degree courses to be of some use to future employment, again the lowest figure in 33 subject fields.

And yet, $89 \%$ of these same university history and English graduates expressed themselves either satisfied or very satisfied with their courses; $74 \%$ would do the same course programmes again if given the opportunity. Compare, for example, the case of polytechnic quantity surveys of 
graduates according to which $93 \%$ found their degree courses useful in employment but only $63 \%$ would choose to do the same course again.

Such figures are selective. Most graduates, in this and other studies, state that they are satisfied with what they received from higher education. In the above study, only in four subject fields (all in the area of art and design) did more than $20 \%$ of the graduates express actual dissatisfaction with their course programmes. On the other hand, there were 17 subject fields in which more than $20 \%$ wished they had taken a different course programme in higher education.

How do we interpret such data on customer satisfaction in our increasingly market driven systems of higher education? The messages coming from our graduates are no less ambiguous than those from employers. But they certainly do not suggest that higher education is failing to meet the needs and aspirations of its students in any substantial way.

It is worth noting how the graduates in the study felt that higher education had improved certain abilities. At the top of their list were the abilities of critical thinking, independence, organization of one's own work, the application of knowledge, self-confidence, and logic. But again, different course programmes and subjects appear to produce different results: do employers recognize these different results in their recruitment strategies? Do students anticipate them when selecting courses and institutions? Or is it all a random process?
To institutional and curriculum differences must, with the advent of the single European market, be added national system differences. Will employers pick and choose among the differentiated products emerging from the contrasting educational systems within the European Communities? Student mobility across Europe is growing, supported by schemes such as ERASMUS, as is labour market mobility. However, the comparative study of economics courses in the European countries reported on in the article by Brennan, et al. suggests that curricular differences may not be so great, notwithstanding the vast differences in duration of study between different national systems. The conclusions of the study are perhaps less sanguine, however, on the subject of equivalence of standards of student attainment. There is a general point of some importance here: how far can educational differences (whether at subject, institutional, or system level) be related to diversification of educational purpose and how far do they reflect relative success in attaining universal educational goals? Whereas conventional wisdom among many educators, at least in the United Kingdom, may be tending towards the former, it is not so clear that employers are prepared to accept the trade-offs in competencies and skills which the fitness for purpose approach seems to imply.

\section{A RESEARCH AGENDA}

The issues raised in this article are not exhaustive of all possibilities. The other articles in this volume pose their own research questions. Many 
topics for future research, however, which are evoked in this overview, are listed below:

- the relative strengths of different influences on the relationships between the labour market and higher education and the mechanisms by which the relationships can be controlled;

- continuous modelling, across the whole range of higher education and the labour market, of what happens to people as they pass from higher education to the labour market, and through stages of the labour market;

- an analysis of values implicated in programmes and recruitment practices on both sides directed at the identification of conflicts, disjunctions, and convergences;

- testing of the extent to which the labour market is the active and higher education, the passive partner in generating relationships and joint work;

- the capacity of governments to affect labour market-higher education relationships;

- changing power and authority within higher education institutions with the onset of both managerialism and market practices;

- the extent to which curricula are changing under the pressures of labour market demands.

\section{REFERENCES}

AINLEY, P., and M. COMEY, Training for the Future: The Rise and Fall of the Manpower Services Commissions (London: Cassell, 1990).

ARTHUR, M. B., D. T. HALL, and B. S. LAWRENCE, "Generating New Directions in Career Theory: the Case for a Trans-Disciplinary Approach", in, Handbook of Career Theory (Cambridge: University Press, 1989).
BRENNAN, J., and P. McGEEVOR, Graduates at Work: Degree Courses and the Labour Market (London: Jessica Kingsley, 1987).

BRENNAN, J., Graduate Experiences in the United Kingdom Labour Market, 1991, Mimeographed paper written for the Council for National Academic Awards given at a joint seminar held at Sigtuna, Sweden, June, 1991, by the Department of Education, Uppsala University, and the Centre for the Evaluation of Public Policy, Brunel University, United Kingdom.

BRENYAN, J., et al., Students, Courses, and Jobs: the Relationship Between Iligher Education and the Labour Market (London: Jessica Kingsley 1993).

BOYS, C. J., J. BRENNAN, M. HENKEL, J. KIRKLAND, M. KOGAN, and P. YOULL, IIigher Education and the Preparation for Work (London: Jessica Kingsley Publishers, 1988) [Summarized under the same title in CNAA Development Services Project, Report 23].

DEPARTMENT OF EDUCATION AND SCIENCE, WIITE PAPER, Higher Education: Meeting the Challenge (London: H.MSO, 1987), $\mathrm{Cn} 114$.

EMPLOYMENT DEPARTMENT, Enterprise in IIigher Education: Key Features in Enterprise in Higher Education, 1990-1991 (1991). [This report, collated by the Employment Department of the United Kingdom, is based in part on reports of independent evaluations made by the Tavistock Institute of Human Relations (1989) and the National Foundation for Education Research (1990). It is difficult, however, to ascertain which parts of the document derive from these independent studies, and which parts from other academic works to which inadequate reference is made in the text.]

GINSBERG, E., S. W. GINSBURG, S. AXELRAD, and J. L. HER.MA, Occupational Choice: an Approach to General Theory (New York: Columbia University Press, 1951).

IENKEL, M., "Higher Education and the Preparation for Work", Iligher Education Policy 3 4 (1990).

JONES, S., The Enterprise in Higher Education Initiative. Mimeographed paper given at a joint seminar held at Sigtuna, Sweden, June, 1991, by the Department of Education, Uppsala University, and the Centre for the Evaluation of Public Policy, Brunel University, United Kingdom.

MALLIER, T., and M. ROSSER, "Economic Impact Studies and Higher Education Institutions", in, International Journal of Institutional Management in Higher Education 101 (1986). 
MOSES, I., and K. TRIGWELL, Factors Shaping Postgraduate Course Work Programmes: Aims and Significance. Mimeographed paper given at a joint seminar held at Sigtuna, Sweden, June, 1991, by the Department of Education, Uppsala University, and the Centre for the Evaluation of Public Policy, Brunel University, United Kingdom.

PEARSON, R., "The Demands of the Labour Market", In, D. JAQUES and J. RICIIARDSON, eds., The Future Ior Higher Education (Guildford: SRHE/Nelson, 1985).

PRATT, J., and S. SILVERMAN, "Responses to Constraint in Higher Education: the 1984-1985 NAB Planning Exercise in the English Public Sector", International Journal of Institutional Management in Higher Education 103 (1986).

Report of the Steering Commlttee for Efficiency Studies In Universilies [Jarratt Report] (London: CVCP, 1985).

ROBINSON, S., J. HAYWARD, C. KIPPING, L. MARSLAND, H. OWEN, and K. JACKA, The Careers of Nurses and Midwives, Project Report No. 1, (London: Nursing Research Unit, King's College, 1992).

ROIZEN, J., and M. JEPSON, Degrees for Jobs: Employer Expectations of IIigher Education (Guildford: SRHE/Nelson, 1985).

SILVER, H., and J. BRENNAN, A Liberal Vocationalism (London: Methuen, 1988).
SIZER, J., Institutional Responses to FInancial Reductions in the University Sector, Final Report (London: DES, 1987).

SOLJAN and SCHUTZE, Higher Education and the World of Work (Zagnet: Andragogical Centre, 1989).

STODDART, J., Higher Education in the 1990's. Paper presented at the Conference of the Confederation of British Industry, London, 1991.

SUPER, D.E., The Psychology of Careers (New York: Harper and Row, 1957).

TEICHLER, U., Research on Higher Education and Work in Europe. Paper presented at the first CIIER Conference, Kassel, 1988.

TEICHLER, U., "Higher Education and Occupational Structures", in B. R. CLARK, and G. NEAVE, eds., The Encyclopaedla of Higher Education, Vol. 2 (Oxford: Pergamon, 1992), pp. 375-392.

VROOM, V. H., Work and Motivation (New York: John Wiley, 1964).

WEERT, E. de, Higher Education and Employ* ment: the Case of the IIumanities and the Social Sciences in the Netherlands (Twente University, Centre for Higher Education Policy Studies, 1990). 


\title{
THE EDUCATION MARKET, QUALIFICATIONS, AND EUROPEAN INTEGRATION
}

\author{
Osmo KIVINEN and Risto RINNE
}

This article examines the relationship between the development of the education market and the demand for qualified personnel in the context of European integration. To begin with, a model portraying the relationships between the education and the labour market is introduced, following which the old but still topical qualification discourse with its theses with regard to overqualification and

\section{INTRODUCTION}

In the Twentieth Century, belief in education has been an important factor in consolidating society, the school serving as a crucial instrument for the State in the formation of ideology. By attending school, people become integrated into the nation, become accustomed to the routines of everyday life, and grow to be lawabiding citizens. New generations are guided, from the family, through the filters of the education and labour markets, to take their positions in society just as self-evidently as the members of a congregation were once allotted their own pews in churches (Kivinen, Rinne, and Ahola, 1989).

Education has become an increasingly important means of matching the supply of labour to the demand. In an increasingly meritocratic society, education is expanding, but access to more and more occupations is becoming restricted to those who underutilization, is discussed. Despite the modern European Communities' educational ideology of technological progress and of the thesis of increasing qualifications, questions which are still worth asking are what kinds of demands actually exist in the labour market for increasingly highly trained labour and what kinds of educational policy the new United States of Europe should have.

hold specific educational qualifications.

\section{THE EDUCATION MARKET AND THE LABOUR MARKET}

With technological progress and the increasingly differentiated division of labour, education has become more and more closely linked, both in a practical and in an ideological sense, with economic growth and working life. The division of labour and education have developed along parallel paths, and the hierarchy of social positions now largely corresponds to the hierarchy of educational qualifications and certification.

One can analyse the placement of the more educated into working life in two stages: firstly, the matching of those seeking education with the places available on the education market, and secondly, the matching of educationally qualified persons with the jobs available on the labour market. In this view, education 
qualifies a person primarily for the labour market (i.e., for the sale of one's labour) and only secondarily, if at all, for the work task itself.

The labour market consists of those institutions and processes that relate to the buying, selling, and pricing of labour, and of those structures that determine the placement, mobility, and distribution of the rewards and sanctions in relation to work (see, for example, Kallenberg and Sörensen, 1979:351-352). From the point of view of the individual, the question is one of the placement in the hierarchy of social positions; from the societal point of view, it is more a general question of matching of educationally qualified people and jobs on the labour market, both in terms of occupation and of geographical location.

The market analogy enables us to examine the placement of individuals in the education system, and the matching of places with those seeking education at the various interfaces of the school system. Like the labour market, the education market too is subject to problems of matching (Kivinen, Rinne, Ahola, and Kankaanpää, 1989).

The interests of employers in the demand for labour are portrayed on the right-hand side of Figure 1 (p. 26), which gives the positions of the education and labour markets in relation to each other. These interests are reflected more or less accurately in education planning, through the dimensioning of the number of people to be trained for any one oc- cupation at any educational level. The supply of people to be trained is based on a concept described as the talent reserve, which has recently been assigned major importance. The meritocratic ideal of an educational system is one which, while favouring equal opportunities for all, will promote the most talented and enterprising individuals above the rest.

On the left-hand side of the figure, the demand for education, manifested as educational preferences, and the supply of education, exemplified in the number of starting places, are portrayed as merging on the education market. Placement and selection for education are determined very much by the various forms of capital and the reproduction strategies of the family (cf., Bourdieu and Boltanski, 1981). Preferences concerning employment and the supply of jobs meet, above all, in the labour market. Employment preferences are formed partly during education and partly through family social status (Kivinen, Rinne, Ahola, and Kankaanpää, 1989).

Since the educational preferences of families and the interests of employers (partly mediated by the State) do not correspond, there are imbalances in the education and labour markets. The numbers of those seeking education and the numbers of places available in the education system do not match any more accurately than do the numbers of prospective employees and the numbers of jobs available. 


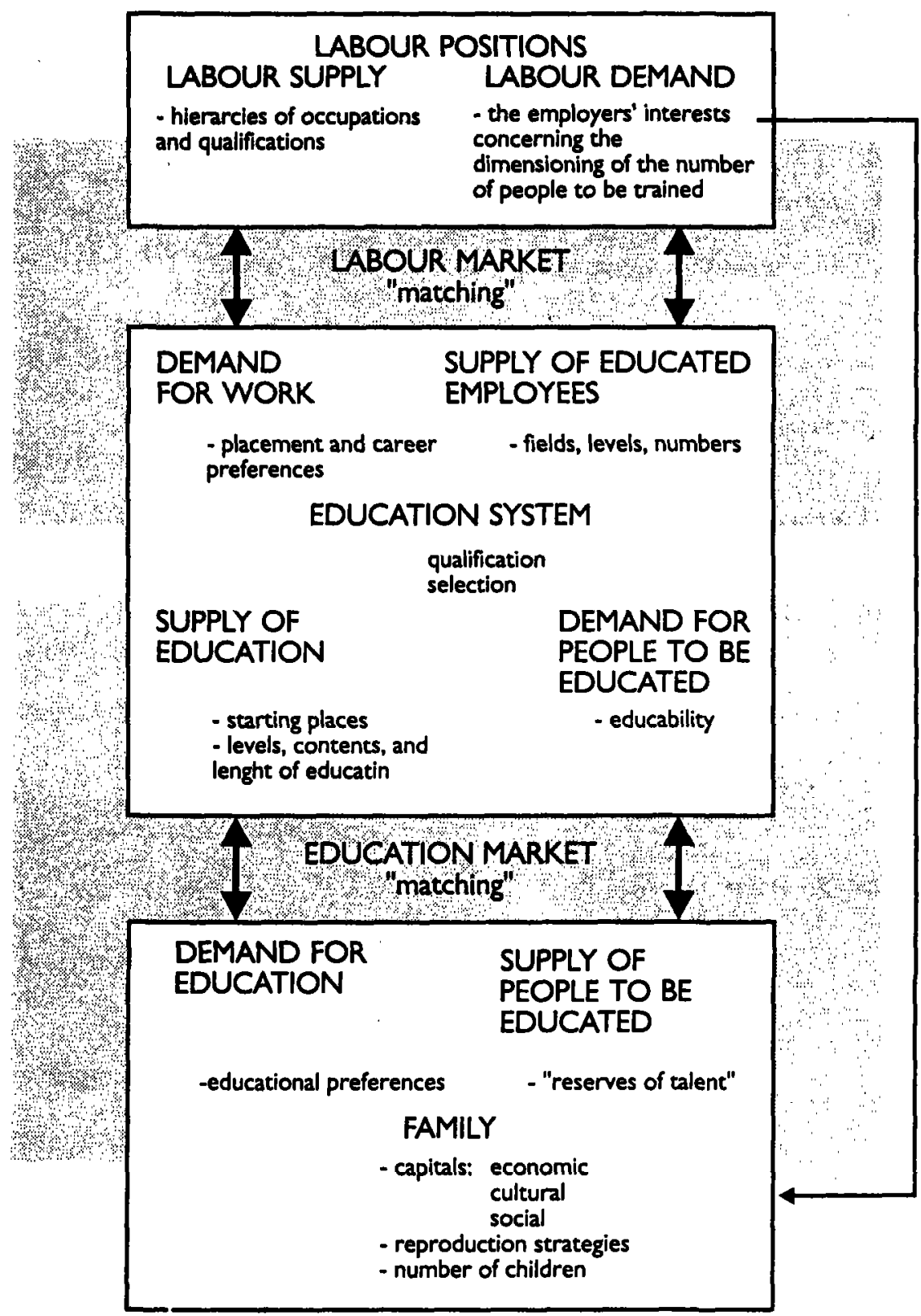

Fig. 1 Labour and Education Markets 


\section{FEATURES OF EDUCATION DETERMINED BY THE LABOUR MARKET: THE QUALIFICATIONS DEBATE}

The matching of education with working life has not only been an objective of educational policy, but also a central target of research. In recent decades, extensive attention has been paid to the questions of matching educational qualifications with the qualification demands of the labour market and working life, and to the effects of the resulting match or mismatch (e.g., Berg, 1970; Freeman, 1976; Rumberger, 1981; 1987; Duncan and Hoffman, 1981; also Smith, 1986; and Teichler, 1987; 1989). One thread in the discussion on the relationship between education and work has been called the qualifications debate (cf., Psacharopoulos, 1986).

The qualifications debate deals with the matching of the qualifications generated by education with those required by the job. It has been particularly concerned with vocational training, but the focus has also been extended to higher education. Some of the key issues relating to the links between the educational and vocational structures are the following: What kinds of qualifications does the work require? How, in cultural and economic terms, can they be produced? How and to what extent can qualifications generated by education be translated into determinants of labour market status, and how does the final matching between education and work take place? For example, according to Granovetter (1981:12), matching is determined by the qualities of the jobseeker, the demands of the employer, and structural factors involved in the market.

The output of education consists of both technical qualifications (the actual knowledge and skills required for performing tasks) and formal qualifications (the certificates, degrees, and titles required for career mobility). In the latter case, the correspondence between education and work is not primarily a correspondence between know-how gained through education and the requirements of the job, but a correspondence between hierarchies of educational certificates and hierarchies of social positions (Bourdieu and Boltanski, 1981; Kivinen, 1988; Silvennoinen, et al., 1988).

In an increasingly meritocratic society, the role of formal educational qualifications is constantly increasing. The distinction between the educated and uneducated work force is becoming a crucial watershed. Paradoxically, a highly skilled, but formally untrained craftsman is thus attributed unskilled status. If the exclusionist strategies of the new middle classes are strong enough, lack of formal educational training becomes equated with lack of skill, and will be understood as a manifestation of the ability deficiencies characteristic of the marginal lower strata of society.

A major terminological problem in this debate is how to define what skill 
refers to in different contexts (Wood, 1987:7; Spenner 1983:827) ${ }^{1}$. Qualifications can mean the totality of skills required for the job, or the skills possessed by the worker. In examining the concrete links between education and working life, one has to keep in mind that skill is realized in practice in the matching of qualifications produced by education and training with those required by the job in a particular social context, which also involves social labelling.

The skills required of an occupation are often taken for granted in relation to the specific tasks in question, even though in practice, many tasks can be carried out in very different ways and with different knowledge bases. The idea that students should learn their work tasks within the educational system is reversed: "the learning objectives embodied in a training programme are not a body of knowledge which an individual acquires about work, but a profile which provides 'work' with what it (in the mythical form of the 'ideal employer' implicit in the rationality assumptions of the market economies) needs to know about the individual" (Moore, 1987:233).

The concept of "tacit skills" 2 emphasizes that many important qualifications are social in nature. It is impossible for educational training to encompass the collective nature of the work process, for it is formed and exists only within the work process itself. On the other hand, the concept also implies that workers cannot easily be made into mere extensions of machines (Wood, 1987).

\section{DEMAND FOR HIGHLY TRAINED LABOUR?}

The traditional education system is not a very efficient means for the generation of technical qualifications for work, at least not in a rapidly changing environment. Likewise, one cannot be completely certain as to

\footnotetext{
${ }^{1}$ The concept of skill needs careful analysis. Littler (1982:7-9), for example, classifies three concepts of skill. First, skill can be seen as a feature objectively inherent in the job in question, and can be defined by the time taken to learn the job or by the type of knowledge required for the occupation. This view matches the functionalist concept of occupations: each occupation can be operationalized as a number of tasks, the performance of which requires certain abilities. Secondly, skill can be defined in terms of the degree of autonomy in the work: a worker who makes a product from beginning to end without continuous guidance or direct supervision, from this perspective, is skilled. On a more universal level, what is important is the extent of the worker's possibilities to control his own work in relation to the level of external control. In this view, the conflict between skilled and unskilled originates in fundamental social divisions such as mental versus manual labour or men's versus women's work (cf., Littler and Salaman, 1982:262). Thirdly, skill can be seen in terms of social status. A job may be defined as skilled, regardless of the (objective) character of the work itself, on the basis of traditions, social conventions, organizations, and on the basis of the role of trade unions in controlling access to jobs, wages, etc. (cf., Lee, 1981:69-71; Wood, 1987:8).

${ }^{2}$ The concept of tacit skllis is similar in many ways to the concept of the hidden curriculum, and is intended to express the fact that the realities of work praxis are far removed from the ideal of formal intentions of rationalized work procedures, just as the realities of school praxis are very different from the rationalized curriculum. This quotation is taken from a recent report by the Industrial Researchers and Development Advisory Committee of the Commission of the European Communities (IRDAC) on "Skills Shortages in Europe".
} 
how well the educational system succeeds in its tasks of socialization and of helping students embark on their chosen career pathways.

In addition to the fact that the demand for highly trained labour is proving to be smaller than what has been widely forecast (see Carnoy, 1987), the constantly rising educational standards of the population as a whole could well lead to the emergence of a discontented, over-educated generation (Silvennoinen, Kivinen, and Rinne, 1992). The concept of over-education has generally been used to refer to a situation in which the labour market status of the highly educated weakens markedly, due to a mismatch between the supply of educated people and the demand for them. This situation may result in graduate unemployment and in the placement of educated people further down in the professional hierarchy than has usually been the case (see Freeman, 1976). Rumberger (1987:92) argues, for instance, that personnel who are overqualified for their tasks will be discontented and that their productivity will be lower than that of those engaged in similar tasks but without formal training (see also Rumberger, 1981).

According to another point of view, a person can never be "overeducated", the problems in fact being that the person's education is "underutilized" in working life (Bailey, 1991).

In many occupations, technological progress and the complexity of tasks have increased the need for formal education. The rising level of educa- tion and training among workers has led to pressures for more highly developed work organization. As tasks become more sophisticated, they are in danger of being monopolized by people with specific forms of training, whose interest is to prevent task boundaries from opening up to permit upward mobility for lower levels of employees.

On the other hand, the implementation and the manner of application of new technology is a matter of optimizing a firm's economic operations, and

whether technology reduces skills depends on what tasks are mechanized and what new tasks are created by the use of new machines. Many people believe that machines are used primarily to perform the least skilled tasks and that to use more complex machines workers require more complex skills. Yet employers can achieve greater cost savings by mechanizing complex tasks performed by high-wage labor than by mechanizing simpler tasks performed by low-wage labor. In other words, General Motors has more incentive to replace highwage automobile workers with robots than MacDonalds has to replace workers who earn minimum wages (Rumberger, 1987:78).

It is, of course, true that high-tech tasks are increasing relatively rapidly. In terms of the occupational structure of society, however, the numerically significant increase in jobs created as a result of the spread of 
new technology is taking place within highly traditional fields. For example, according to the forecast of the occupational structure in the USA in 2000 by Levin and Rumberger (1989:211), although the fastest relative growth is predicted for various semi-professional occupations and for certain occupations related to information, the largest quantitative increases will nevertheless be in the numbers of sales assistants, waiters and waitresses, nurses, and cleaners. While the ten relatively fastest growing occupational groups account for less than $4 \%$ of the net growth in employment, the ten groups that are quantitatively increasing most make up about a third (e.g., Forester, 1987; Kutscher, 1987; Wirth, 1987).

In a survey of the effects of technology, the United States Academy of Sciences concluded that the research results are so sporadic and contradictory that no valid conclusions can be drawn about changes in qualification requirements in the occupational structure as a whole. It is, however, evident that there are no very sharp net changes. On the other hand, qualification profiles may undergo crucial change with regard to various social skills and communicative abilities (Levin and Rumberger, 1989:213).

Moves towards the development of common educational policies are now being developed within the framework of the European Community. In the field of higher education, one of the most recent documents, at present being circulated for comments, is the Memorandum on Higher Education in the European Community (Com., 1991).

\section{HIGHER EDUCATION IN THE SERVICE OF TECHNOLOGICAL PROGRESS: HIGHER EDUCATION POLICIES IN THE EUROPEAN COMMUNITIES}

Guy Neave (1990) argues that higher education institutions in Europe passed through three major phases of change during the 1980's. In the first stage, governments (especially in the United Kingdom and the Netherlands) cut back on their higher education expenditure, and the position of the university as a self-evident component in the welfare state was questioned in a new way. Two decades of continuous expansion, which had conferred "mass status" on higher education, were now subjected to critical re-evaluation.

Secondly, the output, costs, and operations of universities have been brought under public scrutiny. Governments have begun to impose conditions and priorities on higher education development, placing an emphasis on engineering, information technology, administration, and support for productivity in the private sector, in contrast to the traditional emphasis on training for expanding numbers of jobs in the public sector. This stage was accompanied by the construction of new systems for assessment: the Evaluative State seemed to withdraw to the background role of steering the new mechanisms. At the same time, higher education funding was rearranged on a more market-oriented basis, and the universities themselves were entrusted with implementing cost-effective, output-driven management. 
Towards the end of the 1980's, the role of supranational organizations in the governance of higher education in Europe has become increasingly evident ( $c f$. Neave 1990:118). One of the cornerstones in this development was the 1988 Directive requiring the mutual recognition between the member states of the European Community of all higher education professional qualifications requiring more than three years of training. As Neave himself comments, however, "standardisation may be an excellent thing for wine and pigmeat", but it is not necessarily equally beneficial in educational matters (Ibid.:119).

Indeed, the attempts being made by some European nation-states to implement both greater university autonomy and greater responsibility for output within higher education may well be in conflict with the moves being made by the European Communities to introduce at least some measure of standardization within higher education and thus promote graduate mobility. A situation would now appear to be emerging in which power is increasing at two foci: within the universities themselves and their hinterland markets, on the one hand, and at the level of supranational government and market forces, on the other hand. In this new situation, national agencies for the governance of higher education can no longer, even if they wish, exercise their accustomed sovereignty of jurisdiction.

"Preparing for markets", whether this is meant at the national or supranational level, can easily become merely a fashionable slogan of the moment; but as Neave (1990:120-
121) argues, it does nevertheless represent a phenomenon which needs to be taken seriously, and which is radically changing the face of European higher education.

The recent Memorandum of the European Communities (Com., 1991) on common policies in higher education is a good example of the intentions and political will of the Communities. It is also an outstanding example of higher education policy built on a business-friendly orientation, and predicated on continuous economic growth. It is characterized by a passionate belief in the benefits which technological development can bring to society. The possible disadvantages are hardly discussed. The central function of institutions of higher education, in this view, is to produce appropriately qualified labour. In order to meet the tasks assigned to them in the Memorandum, however, the universities would need to undergo profound reorientation, for the production of graduates with a pluridisciplinary training and all-around skills would be a tall order within existing structures.

The Memorandum lists a number of steps which the various partners within the European Communities could successfully carry out, either independently or in collaboration, in order to meet the challenge. The existing European programmes are dealt with, and a broader agenda is proposed, in the context of which arguments are put forward for a strengthening of the European dimension. Although no requirement is being put forward that member states should adopt a common educational policy, the argument is made 
that an enlarged European component should be involved in the planning and implementation of higher education throughout the Community.

The success and competitiveness of the Single Market will depend upon the availability of people who can operate across national and cultural frontiers. In the Memorandum, a European dimension in higher education is therefore seen as a practical necessity for specifically economic reasons. The free mobility of persons guaranteed by the treaties, and the mutual recognition of professional qualifications brought about by EC directives, mean that a Single Market for highly educated workers is already taking shape; and this in turn means that the framework within which undergraduate and postgraduate education and research are regulated and planned is also, in its turn, inevitably expanding on a European scale.

The key message in the Memorandum is contained in the following quotation: "The output of education and training systems (including in particular higher education), in terms of both quantity and quality of skills at all levels, is the prime determinant of a country's level of industrial productivity and hence, competitiveness" (Com., 1991:4). What this principle leads to in practice is an emphasis on the provision of engineering, science, and technology skills, but also of hybrid, interdisciplinary skills (such as those achieved through a wide-ranging study of societal and technological questions raised by information tech- nology and environmental protection).

The Memorandum identifies a -worldwide concentration on the development of technology and its applications. The tools for improved access to knowledge provided by information and communication technologies (ICT's) are increasingly penetrating all sectors of the economy and of social existence. By the beginning of the Twenty First Century, information technology and telecommunications are expected to form the largest sectors of production, with two-thirds of all forms of work being concerned with ICT products and/or services.

Insofar as freedom of mobility and the mutual recognition of occupational qualifications on the labour market do in fact become realized, the problem of mismatch between supply and demand will need to be examined not only within national contexts but also in a European perspective. The drafting and implementation of employment and economics policies, by means of which the balance of the labour market can be maintained, is likely to become increasingly difficult as market forces begin to operate in a steadily widening context.

The prediction has been made that the proportion of professional occupations in the labour force will increase; yet even here, problems of mismatch between supply and demand are becoming more prominent. Manpower shortages are in fact highly specific to particular regions and to particular fields. Those who lose their jobs because 


\section{Osmo KIVINEN and Risto RINNE}

their skills have become obsolete will need to be retrained through adult education programmes.

The Memorandum poses the question (particularly with respect to the universities) as to whether there is a danger of a widening gap between a professional/technical and an academic/scholarly orientation. Such a trend would be considered undesirable, since the modern economy and modern society need generalists as much as specialists. A most acute need exists for graduates who are căpable both of solving complex problems and of communicating effectively. A further question is the extent to which general education should be maintained as part of professional training and also the degree to which it is feasible to establish post-degree technological and professional training for graduates in the humanities, in order to facilitate their employment in the growing service sector. All of these factors point to a blurring of the boundary between what is considered general education and what is considered professional training, and the need to find a new approach to drafting balanced curricula.

The Memorandum argues very forcibly in favour of increased participation in higher education, on the following grounds:

- Technological development and its applications in industry have brought about a significant rise in the level of knowledge and skills required of the European workforce. Intensifying competition necessitates higher educa- tion which can respond to the challenge.

- The European Community, with its rich variety of languages and cultures, necessitates a higher level of educational achievement in order for its citizens to be in a position to exercise their citizen's rights of mobility more widely within the Single Market.

- Changes in society and in cultural values, in conjunction with the accumulative effects over several generations of increased participation in higher education, will lead ("automatically") to increased demand.

- The implementation of structural policies is to a great extent dependent upon the availability of a highly skilled labour force.

- Increased participation in higher education is an essential factor in the achievement of the Community's goal of "equal access to all forms of education".

- Economic, societal, and cultural progress within an increasingly integrated European Community supports a significant rise in the educational standards of the population.

The changing composition of the student population will create demand for a wider range in the organization of educational supply, including both full-time and part-time study, intensive short courses, continuing education, and retraining. The institutions of higher education will need to be able to offer all of these with maximum customer-orientation. The scenario sketched by the Memorandum is thus one of "the 
emergence of a learning society, where an individual's daily activities, in and out of the workplace, constitute part of a learning process" ${ }^{\prime 3}$. Such a learning society will therefore need to overcome the hindrances to learning, whether they be rigidly demarcated boundaries in educational institutions, or obstacles experienced at work.

\section{FINAL COMMENT}

Comparing the optimistic message of the EC Memorandum as regards technology with, for example, Levin and Rumberger's more critical views as quoted above, one can clearly see the extent to which the prospects sketched by the European Communities are based on expectations of continuing economic growth and rising levels of qualification requirements. The EC Memorandum must of course be seen as an ideological document, based on a policy of integration. As such, it contains numerous points which are worthy of consideration and guidelines for a rational policy on higher education with the target of ensuring the success of the European Communities in international competition through the centralization of the production of high-tech commodities and services requiring a high level of education.

It is another matter altogether how these ideas are to be implemented in practice and what will happen to that part of the population which fails to find suitable tasks in the upward surge of high technology. Even though the EC documents speak eloquently of human and educational equality, it seems unlikely that everyone will be able to find a promised place in the sun. The gap between the highly educated part of the population and the rest may even widen in the future, and the percentage of the population which drifts into the labour reserve may increase. It seems likely that there will be plenty of scope not only for educational policy but also for social policy in the European Communities as outlined.

In the international context, there is no guarantee as to how successful the EC's policy of "education in the service of technological progress" will be. Can the whole of Europe survive as a zone specializing in high technology and be able to compete with the economic superpowers of North America and Asia (cf., Neave, 1991a; 1991b; Kivinen and Rinne, 1991)? Will the countries with low labour costs be willing to specialize in industrial mass production and restrict themselves to tasks requiring a low level of education? Will the European higher education system be able to improve its quality to any significant extent, and how will the 3,500 small higher education institutions scattered throughout the European Communities, with less than seven million students, be ableto compete, for example, with the 3,300 institutions of higher education and 13 million students in the USA? At all

\footnotetext{
${ }^{3}$ This quotation is taken from a recent report by the Industrial Researchers and Development Advisory Committee of the Commission of the European Communities (IRDAC) on "Skills Shortages in Europe".
} 
events, the top-ranking universities of the United States will, for a considerable time, continue to present a serious challenge to their European competitors.

As Clark Kerr (1990:16-17) has commented, "the EC endeavour is the greatest of all intentionally planned experiments with the internationalisation... of learning ever undertaken". Surveying the situation from his American perspective, however, what strikes Kerr is the fact that a "European identity" or a "European dimension" sound more like a cosmopolitan than a universal approach to learning. It cannot be taken for granted that the currently prevailing ideological assumptions are in fact any sounder than those which have now been widely discarded.

\section{REFERENCES}

BAILEY, T., "Jobs of the Future and the Education They Will Require: Evidence from Occupational Forecasts", Educational Researcher 2 (1991): 11-20.

BERG, I., Education and Jobs: The Great Training Robbery (New York, 1970).

BOURDIEU, P., and L. BOLTANSKI, "Titel und Stelle", in Bourdieu et al., eds., Titel und Stelle: Über die Reproduktion sozialer Macht (Frankfurt am Main, 1981).

CARNOY, M., "High Technology and Education: an Economist's View", in, $K$. BENNE and S. TOZIER, eds., Society as Educator in an Age of Transition, 86th Yearbook of the National Society for the Study of Education (Chicago: University of Chicago Press, 1987, p. 88-111).

COMMISSION OF THE EUROPEAN COMMUNTTIES, Memorandum on Higher Education in the European Community (Brussels: Commission of the European Communities, 1991).

DUNCAN, G. and S. HOFFMAN, "The Incidence and Wage Effects of Overeducation", Economics of Education Review 1 (1981): 75-86.

FORESTER, T., High-Tech Society: The Story of the Information Technology Revolution (Oxford: Basil Blackwell, 1987).
FREEMAN, R. B., The Overeducated American (London, 1976).

GRANOVETTER, M., "Toward a Sociological Theory of Income Differences", in, I. BERG, ed., Sociological Perspectives on Labor Markets (New York, 1981).

INDUSTRIAL RESEARCHERS AND DEVELOPMENT ADVISORY COMMITTEE OF THE COMMISSION OF THE EUROPEAN COMMUNITIES, Skills Shortages in Europe (Brussels: IRDAC, n.d.).

KALLENBERG, A., and A. SÖRENSEN, "The Sociology of Labor Markets", Annual Review of Sociology 5 (1979): 351-379.

KERR, C., "The Internationalisation of Learning and the Nationalisation of the Purposes of Higher Education: Two 'Laws of Motion' in Conflict?" European Journal of Education 251 (1990): 5-22.

KIVINEN, O., "Koulutus kulttuuripääomana", Kasvatus 6 (1988): 445-452.

KIVINEN, O., and R. RINNE, "Changing HigherEducation Policy: Three Western Models" Prospects 213 (1991): 421-429.

KIVINEN, O., R. RINNE, and S. AHOLA, Koulutuksen rajat Ja rakenteel (Helsinki, 1989).

KIVINEN, O., R. RINNE, A. KANKAANPÄÄ, and S. AHOLA, Työelämä, koulutus ja ennusteet, Opetusministeriön suunnittelusihteeristön julkaisuja 6 (Helsinki, 1989).

KUTSCHER, R., "The Impact of Technology on Employment in the United States: Past and Future", in, G. BURGE and R RUMBERGER, eds., The Future Impact of Technology on Work and Education (London: The Falmer Press, 1987, pp. 33-54).

LEE, D.J., "Skill, Craft, and Class: a Theoretical Critique and a Critical Case", Sociology 1 (1981): 56-78.

LEVIN, K., and R. RUMBERGER, "Education, Work, and Employment in Developed Countries: Situation and Future Challenges", Prospects 192 (1989): 205-224.

LITTLER, C., The Development of the Labour Process in Capitalist Societies: A Comparative Study of the Transformation of Work Organization in Britain, Japan, and the USA (London, 1982).

LITTLER, C., and G. SALAMAN, "Bravermania and Beyond: Recent Theories of the Labour Process", Sociology 2 (1982): 251-269.

MOORE, R., "Education and the Ideology of Production", British Journal of Soclology of Education 2 (1987): 227-242. 
NEAVE, G., "On Preparing for Markets: Trends in Higher Education in Western Europe, 1988-1990", European Journal of Education 252 (1990): 105-122.

NEAVE, G., "On Visions of the Market Place", Higher Education Quarterly 451 (1991a): 25-40.

NEAVE, G., "A Changing Europe: Challenges for Higher Education Research", Higher Education in Europe 163 (1991b): 3-27.

PSACHAROPOULOS, G., "Links between Education and the Labour Market: a Broader Perspective", European Journal of Education 4 (1986): 409-415.

RUMBERGER, R., "The Changing Skill Requirements of Jobs in the U.S. Economy", Industrial and Labor Relations Review 4 (1981): 578-590.

RUMBERGER. R., "The Potential Impact of Technology on the Skill Requirements of Future Jobs in the United States", in, G. BURKE and R. RUMBERGER, eds., The Future Impact of Technology on Work and Education (London: Falmer Press, 1987, pp. 74-95).

SILVENNOINEN, H., O. KIVINEN, and R. RINNE, "Rakennemuutoksen koulutusstrategiat", Lähtökohtia "uuden" aikuiskoulutuksen tutkimukseen ja arviointiin. Turun yliopisto: Sosiologisia tutkimuksia 120 (Turku, 1988).
SILVENNOINEN, H., O. KIVINEN, and R. RINNE, "New' Educational Strategies: Managing Structural Change on the Labour Market", in, $O$. KIVINEN and R. RINNE, eds., Educational Strategies in Finland in the 1990's, University of Turku, Research Unit for the Sociology of Education: Research reports 8 (Turku, 1992): 37-84.

SMITH, H., "Overeducation and Underemployment: An Agnostic Review", Sociology of Education 59 (April, 1986): 85.99.

SPENNER, K., "Deciphering Prometheus: Temporal Change in the Skill Level of Work", American Sociological Review (December, 1983): 824-837.

TEICHLER, U., Higher Education in the Federal Republic of Germany, Werkstattberichte vol. 16 (New York and Kassel, 1987).

TEICHLER, U., "Research on Higher Education and Work in Europe", European Journal of Educa. tion 24 3 (1989): 223-247.

WIRTH, A. G., "Contemporary Work and the Quality of Life", in K. BENNE and S. TOZER, eds., Society as Educator in an Age of Transition, The 86th Yearbook of the National Society for the Study of Education (Chicago: University of Chicago Press, 1987, pp. 54-87).

WOOD, S., "The Deskilling Debate: New Technology and Work Organization", Acta Sociologica 1 (1987): 3-24. 


\title{
DOES THE PROGRAMME MATTER? APPROACH AND MAJOR FINDINGS OF THE KASSEL GRADUATE SURVEY
}

\author{
Harald SCHOMBURG and Ulrich TEICHLER
}

This study attempts to establish the extent to which study programmes and study conditions within selected fields of study vary among institutions of higher education in the Federal Republic of Germany and the extent to which diversification has an impact on the careers and work assignments of graduates. All persons who graduated during the 1983-1984 and 1984-1985 academic years in mechanical engineering, economics/business, and social work from seven institutions of higher education were surveyed during their final year of

\section{AIMS AND DESIGN OF THE STUDY}

\section{Key Questions}

The Kassel Graduate Survey was conducted at the Centre for Research on Higher Education and Work, Comprehensive University of Kassel, Germany, from 1982 to 1991. Compared with other studies on this subject, the Kassel Graduate Survey focussed on an investigation of the impact of study programmes and study conditions on the professional success of graduates. The Survey asked four main questions:

1. To what extent do study programmes and study conditions vary among institutions of higher education within the same field of study?

2. To what extent do the employment and the careers of study, again in a longitudinal study two years after graduation, and finally, four to five years after graduation. The authors come to the conclusion that the vertical diversification of higher education in the Federal Republic of Germany has had a less pronounced effect on the careers of graduates, over the last few years, than had been expected. No dominant elements of study programmes and study conditions could be identified which might explain study outcomes, careers, and job assignments.

graduates vary according to the institutions of higher education and the departments from which they have graduated?

3. To what extent might differences in the employment and the careers of graduates, to the extent that these differences might be attributed to individual institutions and departments, be causally attributed to study programmes and study conditions, and what other factors (student intake, the regional labour market, etc.) come into play?

4. Which elements of study provisions and study conditions are most influential as regard study outcomes as well as employment and careers? 


\section{Approach of the Study}

The Kassel Graduate Survey was not only much more costly than others in terms of time, labour, and expense, but also with regard to the methodical work involved in elaborating the concept and a means of evaluation. This effort was necessary, for the study goes beyond a mere stocktaking of the professional situation of graduates in three ways:

1. While most analyses of study programmes and study conditions are based only on the views of graduates, the framework of this study included the application of other methods of inquiry. For every field of study considered, detailed information was collected with the help of document analyses, on the spot observations, and interviews with deans, key lecturers, and several students. Thus the study programmes and study conditions could be recorded in a more detailed way and could be compared with the impressions of graduates.

2. A three-step panel study was carried out: enquiries were made during the examination period, two years after graduation, and four to five years after graduation. Thus only the study programmes, the start of professional life, and the settling into the latter could be analysed in a more detailed way, (and more importantly) a retrospective view of the study experience could be ascertained before it had been eclipsed by professional experience. Moreover, contrary to the usual method of retrospective inquiry, the graduates interviewed could record their impressions of their transition from study to profession before these impressions had been distorted by professional consolidation.

3. This study is special in that it stresses such questions as the degree to which differences in individual fields of study in given institutions or departments from which a student had graduated were reflected in differences in positions and careers and the aspects and conditions of study programmes which were most important for the future professions of graduates. Although having been viewed for some time as highly significant in discussions of higher education policy, these questions have rarely been the objects of detailed analyses.

The themes of major debates on the relationships between higher education and work have changed over the last three decades. From the second half of the 1960's to the beginning of the 1970's, a central question had referred to the extent to which the increase in the student enrollment quota should be matched by the establishment of various types of institutions of higher education and courses of study which reflected very different relationships between work and study. In this context, Fachhochschulen were created as a second type of institution of higher education, and several comprehensive universities were also established. From the beginning of the 1970's through the beginning of the 1980 's, a period characterized by 
many experiments and the creation of a study reform commission, one question came very much to the foreground: how could insights with regard to the structuring of course programmes and fields of study be gained by an analysis of the work/professional lives of graduates? A point of discussion as well was whether or not the courses in given subjects should be standardized to a large degree or whether they should stress different aspects of the preparation for different professional fields. Since the beginning of the 1980's, a question of increasing significance referred to the extent to which a differentiation of institutions and course programmes of the same type had come about or was desirable.

This study tries to clarify the degree to which a differentiation exists within selected subjects and the extent to which it might be significant for the future employment/professions of graduates.

Four aspects of this fundamental question could be identified.

The first point to be clarified was the degree to which in a given field of study differences between study programmes in different institutions affect conditions of study, study behaviour, and ultimately, study results and professional success. Thus, it was possible, at the same time, to check the evolution of the configuration which the system of higher education had acquired. In the previous decades, had the relative homogeneity of the institutions of higher education of the Federal Republic of Germany given way to an evident hierarchy, or had increasing variety led to the placing of different emphases on course programmes and study conditions so that the graduates of a given institution might seem very competent with regard to certain qualifications and less competent with regard to others?

Secondly, and regarding a point which had been absolutely minor in other surveys, an analysis was made of the aspects of study programmes and conditions which might influence study results and are momentous for careers and positions of graduates. Consequently, a wide range of possible factors was recorded, drawn from public discussion, scientific surveys, and even frequently from evoked single aspects, for example, the research reputations of lecturers, an element often stressed, even when very little is known about the effectiveness of such factors.

Thirdly, an attempt was made to settle the question as to whether or not special emphases in study programmes are useful for later professional life. For example, to what extent are the graduates of a faculty having a special subject-related emphasis more likely to be found in subject-related professional fields? Do they frequently accept employment which corresponds to the main emphases of their studies?

Fourthly, the degree to which differences in the study results, the careers, and the positions of graduates in the same subject but from different institutions was examined in an effort to ascertain the extent to which the differences could in fact be attributed to the institu- 


\section{DOES THE PROGRAMME MATTER?}

tions from which they graduated. However, one cannot rule out the possibility that differences in the individual bio-data of graduates might also be of great significance, and that the graduates themselves might have greatly structured the effects on them of their institutions by the way they acted as students. It might also be true that the labour market - e.g., the regional employment situation, the recruitment policies, and the personnel policies of the employing organizations might have proven to be an important filter for the possible effects of institutions.

\section{Concept and Methodical Proceedings}

The Kassel Graduate Survey was conceived at the start of the 1980's. Its central aspect was a longitudinal analysis of qualification attainment and transition to employment \profession as well as to career and professional positions, which was carried out from 1983 to 1989.

Mechanical engineering, economics/business studies, and social work/social education were included in the analysis. For each subject, seven institutions of higher education (universities, comprehensive universities, and Fachhochschulen) were selected in such a way that a variety of study programmes and study conditions was represented. All examinees completing their study programmes during the 1983-1984 and 1984-1985 academic years were polled in writing during their examination periods about their study programmes and study results. About 2,500 graduates participated in the first sampling, comprising 50\% of the target population. Two years later, these persons received a further questionnaire which referred mainly to their searches for employment and their initial positions. About 1,600 graduates participated in this second poll, e.g., $75 \%$ of the graduates making up the first sampling. Finally, between the summer of 1988 and the autumn of 1989 the third questionnaire was sent out - about five years after graduation for the 1983-1984 graduates and about four years after graduation for the 19841985 graduates. The rate of response of those who had participated in the second poll was $77 \%$, and the analyses were based on the answers of a total of 1,420 graduates, including some graduates who had only taken part in the first poll.

Additional institutional analyses were conducted. Prior to an initial interview, descriptions of study programmes and conditions at individual institutions or faculties were collected with the help of document analyses, interviews with key personnel, and direct information. In addition to the second inquiry, regional labour market conditions in the localities of given institutions were investigated. Documents were analysed, press advertisements were examined, and representatives of the employment offices and organizations were interviewed.

The interviews of the examinees or graduates were conducted with the help of a very extensive, standardized questionnaire ( 80 to 100 questions with about 700 to 800 variables). The individual questions were formulated mainly in general terms (i.e., not related to a single subject). Specific questions concerning a particular 


\section{Graph 1. The Design of the Kassel Graduate Survey}

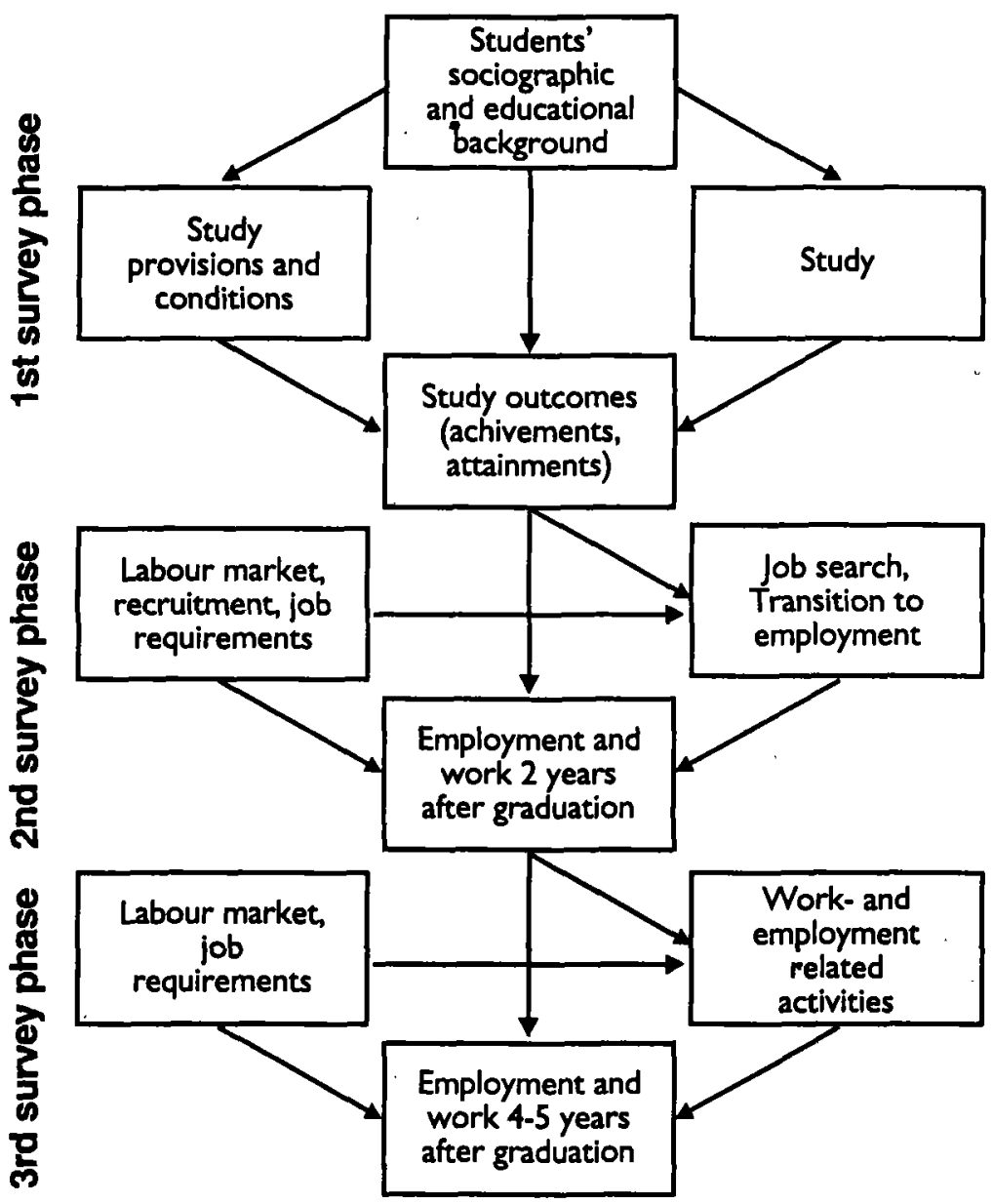


subject referred above all to professional fields and duties as well as to the utilization of competencies acquired as a result of having been enrolled in the given study programme. As to the selection of subjects and institutions of higher education, we do not wish to claim representativity in the sense of any generalization with regard to careers and positions for all graduates in the Federal Republic of Germany. A comparison of the graduates who took part in the survey and the respective total number of graduates in the three subjects according to age, gender, and study period (official examination statistics) did not reveal major differences. Therefore, the results can definitely be regarded as representative of the three-subjects in question.

\section{SELECTED FINDINGS OF THE SURVEY}

\section{Study Programmes and Study Conditions}

The examinee-interviewees were asked to state in detail how they perceived their study programmes and conditions, notably the physical study/learning environment, the administration of their programmes and institutions, and the approaches of the staff to questions of education, research, and examinations. In this context, one cannot clearly establish in all cases whether or not the university environment is a precondition for the behaviour of students or whether the students shape their environments themselves, either through selection, e.g., choice of courses, or actively, for example in conversation with the teaching staff. As on top of this diversity, perceptions vary, one is not surprised to find that the statements of graduates with regard to identical departments vary substantially.

If one considers the importance attached to the uniform quality of institutions of higher education in the Federal Republic of Germany - based on the tradition of the German system of higher education - the differences as to physical study/learning environment and administrative study conditions as perceived by the examinees seemed remarkably great.

To cite a few examples: $18 \%$ of the interviewees considered the localities of their universities as being stimulating for human relations. In mechanical engineering, the percentage varied from $0 \%$ to $15 \%$, and in economics/business, from $2 \%$ to $35 \%$. In social work, judgments contrasted. In four departments, only $1 \%$ to $6 \%$ of the students gave the above response, while in three other departments, the figures ranged from $46 \%$ to $78 \%$ percent.

Among the interviewees, $21 \%$ complained about the deficiencies of library facilities (with regard to opening hours, reading rooms, lending facilities, etc.). This percentage varied according to institution: $0 \%$ to $33 \%$ in mechanical engineering, $3 \%$ to $35 \%$ in economics/business, and $11 \%$ to $33 \%$ in social work.

Some $67 \%$ of the students complained that the overcrowding of courses led to a reduction in work intensity. The proportions varied from $22 \%$ to $57 \%$ in mechanical engineering, from $34 \%$ to $91 \%$ in 
economics/business, and from $41 \%$ to $97 \%$ in social work.

Some $40 \%$ of the interviewees rated the administration favourably: $21 \%$ to $53 \%$ of the students in mechanical engineering, $23 \%$ to $74 \%$ in economics/business, and $12 \%$ to $93 \%$ in social work agreed with the statement: "I think the administration makes an effort to facilitate our orientation at the university."

\section{Higher Education and Employment}

The search for employment turned out to be a complex procedure - 22 job applications on average by each economics/business graduate, 16 by social work graduates, and 13 by mechanical engineering graduates; however, the transition to employment was smoother than generally expected. The average durations of job searches were 3,4 , and 6 months respectively.

The period from graduation to initial employment was about four months long on the average. In mechanical engineering, this transitional period took an average of 3.7 months. It was longer for graduates of Fachhochschulen (4.5 months) than for those of universities (2.7 months). The transitional period for economics/business graduates took 4.0 months. No clear differences between the experience of graduates of the two types of institutions turned up. For social workers, the average length of the initial job search was 5.6 months. Thus the average transition period varied according to the individual institutions from 2.0 to 6.3 months for mechanical engineers, but only from 3.6 to 4.5 months for economics/business graduates and from 4.5 to 6.6 months for social workers.

In the case of the mechanical engineers and of the economics/business graduates, the first $25 \%$ was employed immediately after graduation. Another $25 \%$ of graduates in these subjects was already employed after two months. After five months, the third $25 \%$ was pursuing professional activities. Employment included probationary periods, if respondents were regularly employed. In the case of social workers from one-phase studies (i.e., the initial professional training phase being integrated into the course programme), the first $25 \%$ was also employed immediately after graduation. The second $25 \%$ was employed three months after graduation at the latest. The third $25 \%$ was regularly employed after eight months at the latest. The respective figures of about 14,16 , and 20 months for social workers, who had completed their initial training phases after graduation (so-called two-phase studies), illustrate that the double transition to employment - from studies to initial professional training and from initial professional training to regular employment - prolonged the search period by about one month.

The rate of unemployment for those no more than two years beyond graduation was unexceptional: $16 \%$ of the mechanical engineers and $17 \%$ of the economics/business graduates had been unemployed at least once. The respective quota for social workers was substantially higher: $35 \%$ for graduates of one-phase studies and $52 \%$ for graduates of two- 
Graph 2. Duration of job search (months), by field of study and type of higher education institution (mean)

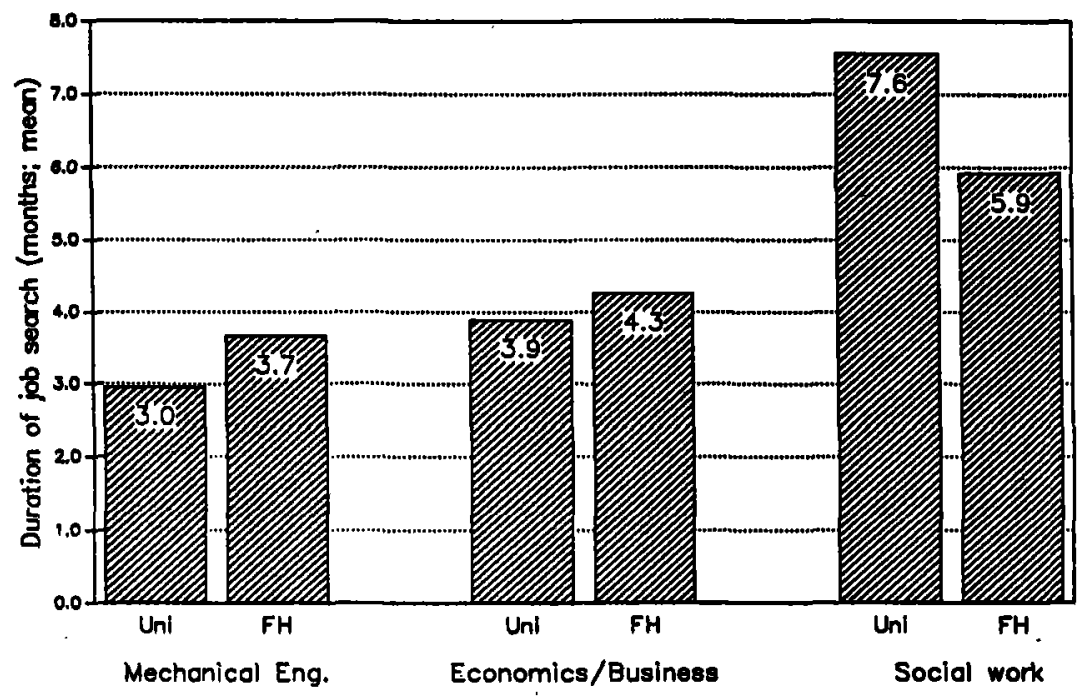

Graph 3. Indicators of job search, by field of study and type of higher education institution (mean)

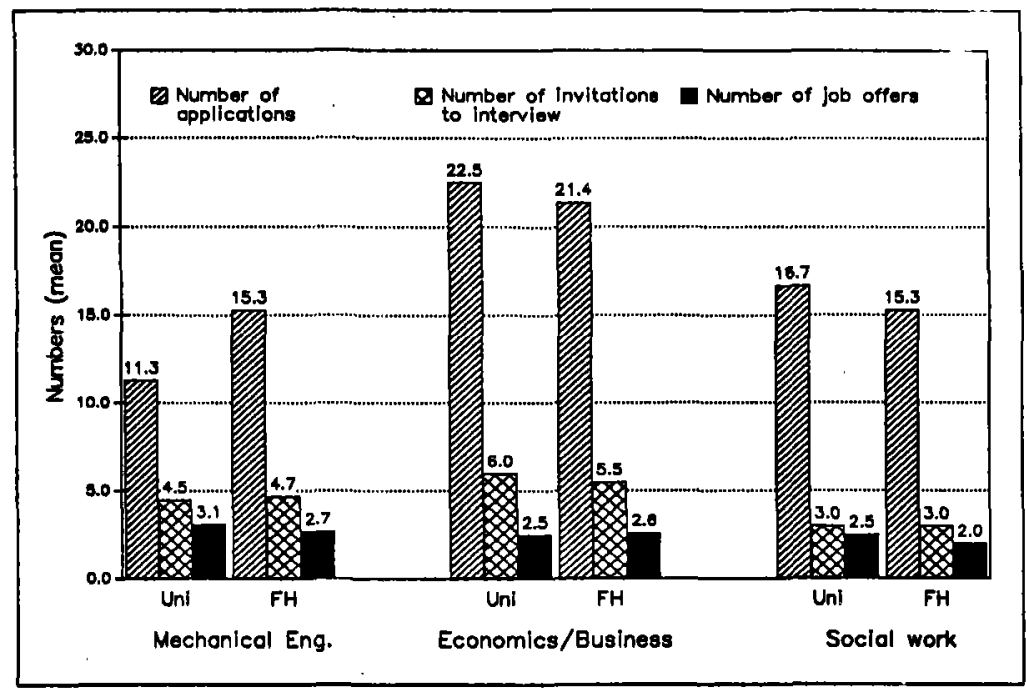

Source: Kassel Graduate Survey; Qvestionnaire 2 years after graduation. 
Graph 4. Employment during the first four years after graduation graduates from mechanical engineering (percentage)

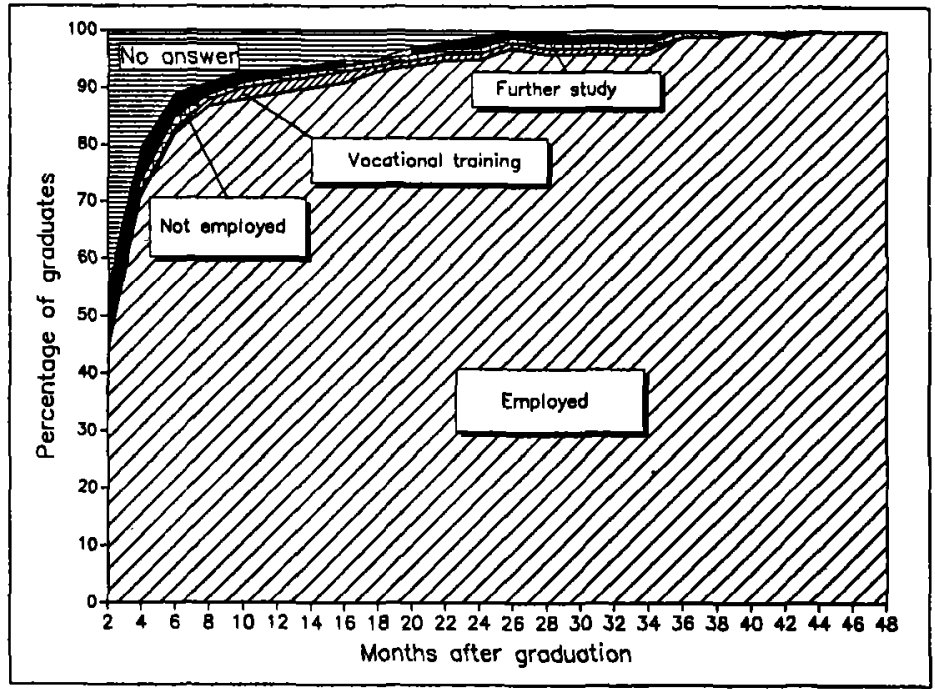

Graph 5. Employment during the first four years after graduation graduates from economics/business (percentage)

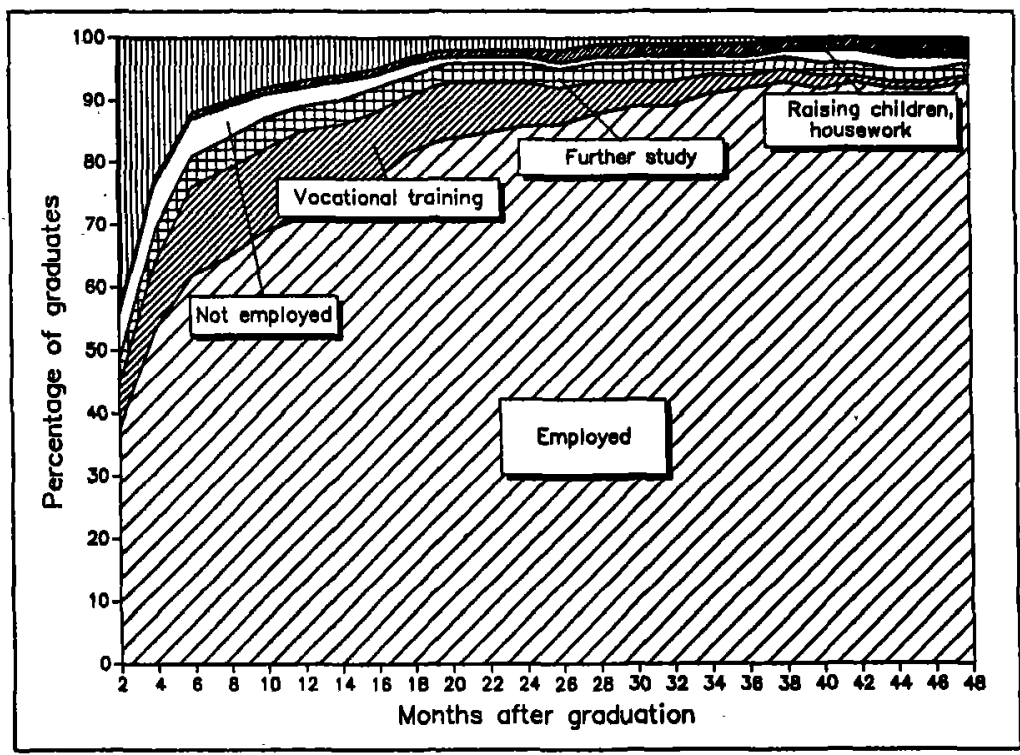

Source: Kassel Graduate Survey; Questionnaire 4-5 years after graduation. 
Graph 6. Employment during the first four years after graduation graduates from social work - "two phase-study" (percentage)

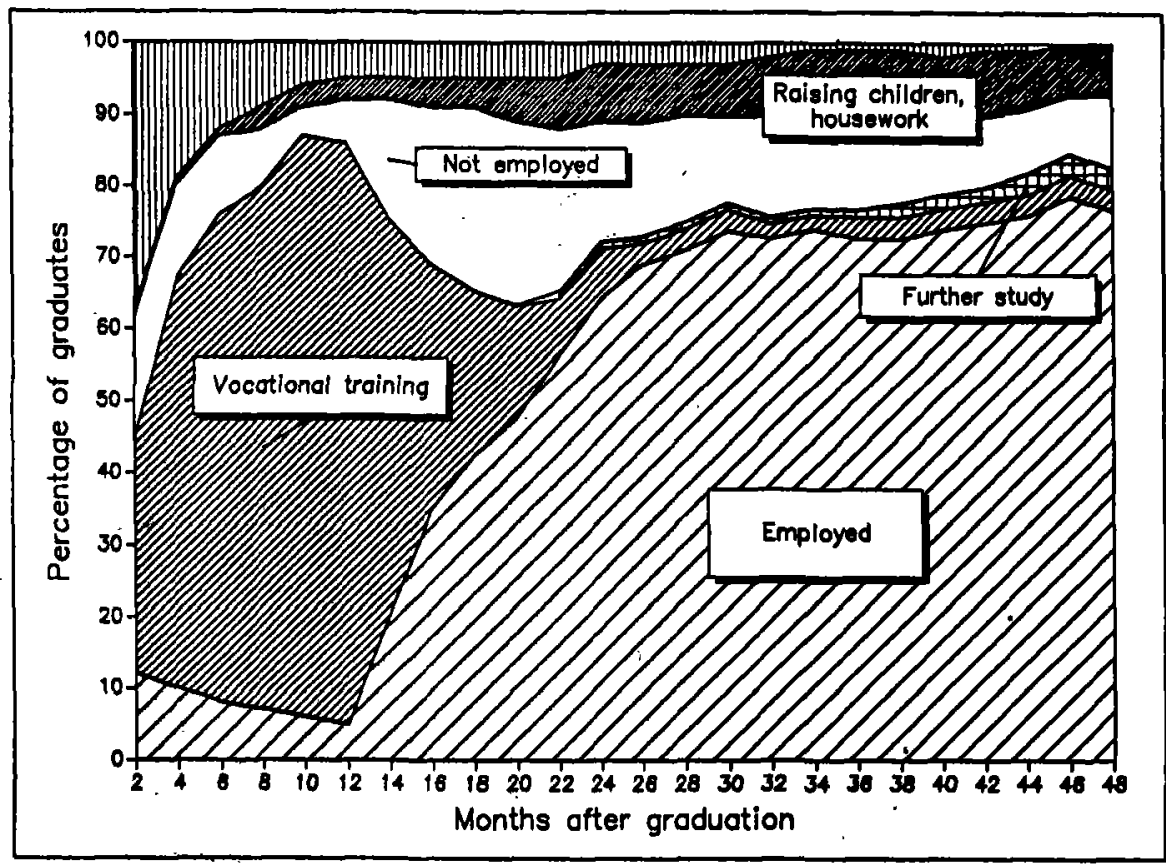

Source: Kassel Graduate Survey; Questionnaire 4-5 years after graduation.

phase studies. Most of the interviewees had experienced only a short period of unemployment while hunting for their initial positions. The unemployment rate for social work graduates remained constant over the early career period at about $12 \%$. Almost as many graduates took transitional jobs during the first two years after graduation (14\% of the mechanical engineers, $15 \%$ of the economics/business graduates, and $28 \%$ of the social workers).
A typology of links between education and employment based on a cluster analysis of the job characteristics of graduates gives the following distribution:

- privileged job for graduates (25\%);

- normal job for graduates (26\%);

- job for graduates comprising substantial routine tasks $(21 \%)$;

- academic position (8\%);

- socio-political engagement (8\%);

- dissatisfying job (12\%). 
Table 1. Typology of graduate employment and work two years after graduation (percentages)

\begin{tabular}{|c|c|c|c|c|}
\hline & $\begin{array}{c}\text { Mech. } \\
\text { engineering }\end{array}$ & $\begin{array}{c}\text { Economics/ } \\
\text { business }\end{array}$ & Social work & Total \\
\hline Privileged graduate job & 25 & 31 & 8 & 25 \\
\hline Normal graduate job & 29 & 26 & 21 & 26 \\
\hline $\begin{array}{c}\text { Graduate job with substantial } \\
\text { routine tasks }\end{array}$ & 22 & 23 & 17 & 21 \\
\hline $\begin{array}{c}\text { Academic jobs } \\
\text { Socio-political engagement }\end{array}$ & 12 & 8 & 4 & 8 \\
\hline Dissatisfying job & 9 & 11 & 32 & 8 \\
\hline Total & 100 & 100 & 18 & 12 \\
\hline
\end{tabular}

Source: Kassel Graduate Survey; second survey 1985-87

Differences between the Experiences of Graduates of Fachhochschulen and Graduates of Universities

Although Fachhochschulen are supposed to offer practical training and although Fachhochschule graduates in engineering and economics/business studies are generally supposed to be in greater demand than university graduates, university graduates from those fields reported a higher level of use of knowledge which they had acquired during their courses of study (see Table 2).

Fewer social work graduates reached positions generally con- sidered appropriate for graduates of institutions of higher education, but slightly more of them reported a proper utilization of their knowledge than graduates in the other fields surveyed.

University graduates in mechanical engineering were earning only $3 \%$ more than Fachhochschule graduates 4-5 years after graduation. The respective income differences were $10 \%$ for economics/business graduates and $6 \%$ for social work graduates - i.e., substantially lower income advantages than usually provided for in civil service salary scales (about 20\%). 
Table 2. Graduates' perception of the links between study and work: utilization of competences acquired during the course of study and appropriateness of position (percentages)

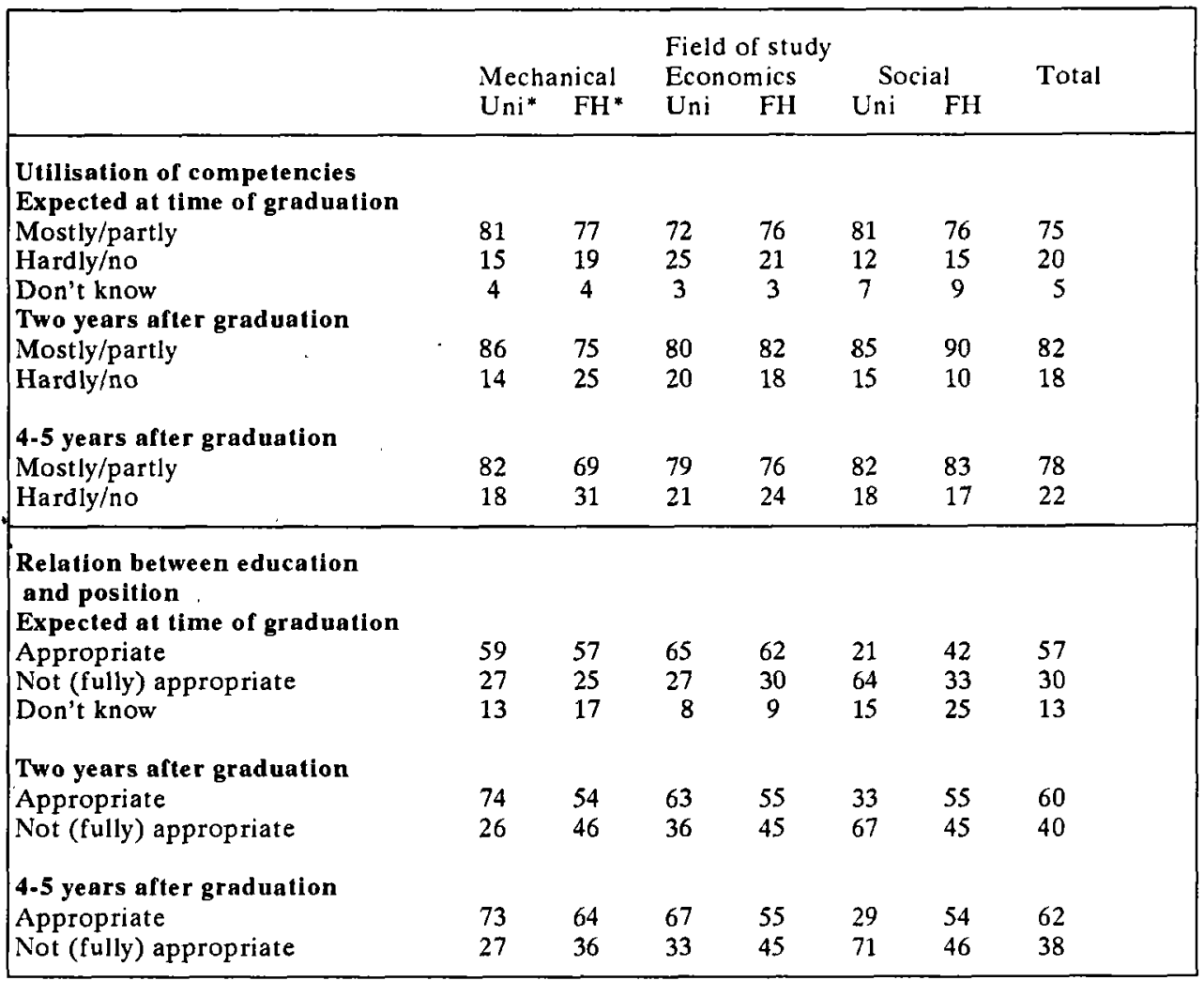

* Uni = university graduates, $\mathrm{FH}=$ Fachhochschule graduates; surveys conducted from 1983 to 1988.

- Source: Kassel Graduate Survey. 


\section{Differences between Institutions of Higher Education with Respect to the Professional Success of Their Graduates}

Since the end of the 1970's, the question as to differences between institutions of higher education in the Federal Republic of Germany with regard to the professional success of their graduates has been raised time and again. The answers to these questions, of course, are perceived as having an important bearing on the prospects of graduates for gaining employment. Such matters as the academic reputation of staff, their research productivity, and preferences of employers have a bearing in this respect. This survey embodied a complex attempt to measure the impact of the institution on the career and the employment of graduates during the first five years following graduation.

Ten criteria were chosen for measuring professional success two years after graduation (see Table 3), and eight, four to five years after graduation. A variance analysis helped to determine the extent to which differences in professional success could be attributed to the higher education institution from which one had graduated.

Based on an average of the ten criteria for initial employment, the institution of higher education was held responsible for $5.5 \%$ of the variance for mechanical engineering, $1.5 \%$ for economics/business, and $4.7 \%$ for social work.

Based on an average of the eight criteria for the professional situation four to five years after graduation, the institution of higher education was held responsible for $3.7 \%$ in the case of mechanical engineering, $1.6 \%$ for economics/business, and 3.5\% for social work.

On the whole, professional success seemed to be only slightly dependent on the higher education institution from which one had graduated. Notably in economics/business, the relationship was close to zero. In the other two subjects, the higher education institution attended was of less importance for the status of graduates four or five years after graduation than it had been for initial employment.

The variance, however, is explained differently according to the criterion of success examined. As regards the start of a career, it varies from:

- $2 \%$ to $10 \%$ in mechanical engineering; highest with regard to the income and the extent of the utilization of competencies;

- $1 \%$ to $4 \%$ in economics/business; highest with regard to the utiliza- tion of competencies;

- $2 \%$ to $11 \%$ in social work; highest with regard to the duration of the job search.

Regarding professional success four to five years after graduation, it varies from:

- $1 \%$ to $8 \%$ in mechanical engineering; highest with regard to the extent of the utilization of competencies;

- just $1 \%$ to $2 \%$ in economics/business; 
Table 3. Differences between institutions of higher education with respect to career and work assignments of their graduates two years after graduation

(percentages, range and explained variance)

\begin{tabular}{|c|c|c|c|}
\hline & from & Range & $\begin{array}{l}\text { Explained } \\
\text { variance }(\%)\end{array}$ \\
\hline \multicolumn{4}{|l|}{ Mechanical engineers } \\
\hline Duration of search (mean) & 2.5 & 4.2 & $4.9^{*}$ \\
\hline Income ${ }^{2}$ (mean) & 45.4 & 55.7 & $9.3^{*}$ \\
\hline Utilization of competencies ${ }^{3}$ & 73 & 91 & $9.5^{*}$ \\
\hline Appropriate position ${ }^{4}$ & 78 & 93 & $4.3^{*}$ \\
\hline Job satisfaction in general ${ }^{5}$ & 57 & 81 & 2.1 \\
\hline Status/career possibilities ${ }^{6}$ & 10 & 33 & $3.1^{*}$ \\
\hline Work involvement/relation to study ${ }^{6}$ & 44 & 76 & $8.5^{*}$ \\
\hline Work autonomy ${ }^{6}$ & 29 & 71 & $6.0^{*}$ \\
\hline Utilization of competencies in the future ${ }^{3}$ & 70 & 100 & $4.9^{*}$ \\
\hline Appropriate position in the future 4 & 67 & 86 & 2.7 \\
\hline \multicolumn{4}{|l|}{ Economics/business studies } \\
\hline Duration of search (mean) & 3.0 & 4.7 & $2.3^{*}$ \\
\hline Income (mean) & 47.2 & 52.5 & 1.1 \\
\hline Utilization of competencies & 71 & 85 & $3.6^{*}$ \\
\hline Appropriate position & 78 & 87 & 1.1 \\
\hline Job satisfaction in general & 60 & 74 & 0.7 \\
\hline Status/career possibilities & 20 & 41 & 1.0 \\
\hline Work involvement/relation to study & 53 & 68 & 0.9 \\
\hline Work autonomy & 37 & 54 & 0.8 \\
\hline Utilization of competencies in the future & 76 & 85 & 1.2 \\
\hline Appropriate position in the future & 67 & 88 & $1.9^{*}$ \\
\hline \multicolumn{4}{|l|}{ Social work } \\
\hline Duration of search (mean) & 4.4 & 8.9 & $10.8^{*}$ \\
\hline Income (mean) & 28.1 & 32.6 & 2.0 \\
\hline Utilization of competencies & 78 & 98 & $4.8^{*}$ \\
\hline Appropriate position & 50 & 83 & $5.8^{*}$ \\
\hline Job satisfaction in general & 37 & 64 & $4.2^{*}$ \\
\hline Status/career possibilities & 0 & 15 & 1.8 \\
\hline Work involvement/relation to study & 43 & 61 & 1.6 \\
\hline Work autonomy & 45 & 75 & $5.3^{*}$ \\
\hline Utilization of competencies in the future & 62 & 82 & 2.5 \\
\hline Appropriate position in the future & 38 & 64 & $3.3^{*}$ \\
\hline
\end{tabular}

* significant $(\mathrm{p} \leqslant 0.05) ;{ }^{1}$ in months; ${ }^{2}$ Income in the years $1985-87$; in thousand DM; ${ }^{3}$ mostly and partly utilization; 4 appropriate and not fully appropriate position; 5 Values 1 and 2 from a 5 point scale $\left(1=\right.$ very satisfied, $5=$ not at all satisfied); ${ }^{6}$ Values 1 and 2 from a 5 point scale $(5=$ not at all)

Source: Kassel Graduate Survey; second survey 1985-87 
- $1 \%$ to $8 \%$ percent in social work; highest with regard to the appropriateness of the position.

However, more striking differences leap to the eye, if we look at the ranges of responses made by former students from individual institutions of higher education ( $c f$. Table 4); a few examples:

- At one extreme, only 7\% of the graduates of the departments of mechanical engineering described their professional positions four to five years after graduation as being inadequate; however, at the opposite extreme, the figure was $21 \%$. Two years after graduation, we noted a range from $7 \%$ to $22 \%$. In the case of economics/business, the respective range was $10 \%$ to $27 \%$, and in social work, $13 \%$ to $42 \%$.

- At one extreme, $72 \%$ of the mechanical engineers considered that they had high professional autonomy four to five years after graduation, and at the opposite extreme, only $43 \%$ held that view. The corresponding range was $61 \%$ to $38 \%$ for economics/business graduates and from $73 \%$ to $48 \%$ for social workers.

- Four to five years after graduation, the largest differences between institutions of higher education were recorded with respect to the professional utilization of competencies acquired during the course of study. A heavy or a partial utilization was reported, in one extreme, by $89 \%$ of the mechanical engineers of an individual institu- tion of higher education and in the opposite extreme, by $66 \%$. In the case of economics/business, the corresponding figures ranged from $84 \%$ to $69 \%$, and in the case of social work, from $96 \%$ to $74 \%$.

We also examined whether or not the ranks of individual institutions of higher education varied according to the respective criteria employed ( $c f$. Table 4 and Graph 7). We thus also checked the configuration of the rankings.

In mechanical engineering primarily, differences in the career patterns of the graduates of all universities and of all Fachhochschulen emerged both two years after graduation and four to five years after graduation. Only one Technical University stood out positively, notably regarding reputation and to a lesser extent with regard to objective criteria, such as income. With regard to professional success, the graduates of another university seemed to be clearly less positive four or five years after graduation than they had been two years after graduation. In this case, a relatively high proportion of graduates was initially employed by the university. However, this employment was only short-term, and the graduates had a reduced opinion of this institution five years after graduation.

In economics/business, five institutions of higher education earned medium ratings with regard to the initial employment and careers of their graduates. One university, which had been classed as outstanding in previous surveys concerning the quality of its research and its reputation 


\section{Table 4. Professional success of graduate from 21 institutions of higher education two years after graduation, by institution of higher education (percentages, rank)}

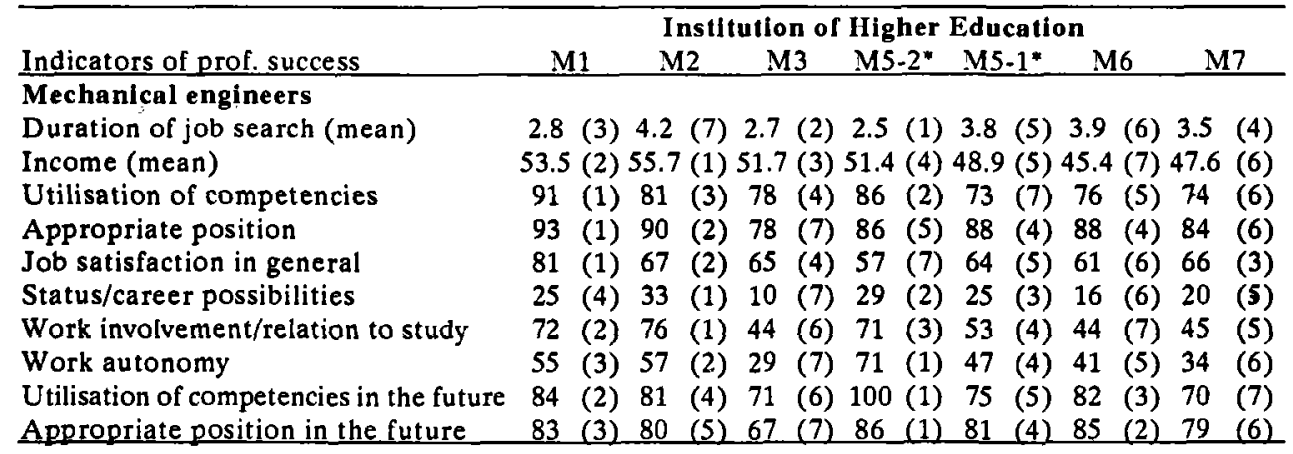

\begin{tabular}{lllllllll} 
Indicators of prof. success & W1 & W2 & W3 & W4-2* & W4-1* & W5 & W6 & W7 \\
\hline
\end{tabular}

Economics/business studies

Duration of job search (mean) 3.0 (1) 4.1 (3) 4.5 (7) 3.8 (2) 4.3 (5) 4.8 (8) 4.3 (6) 4.2 (4)

Income (mean)

Work involvement/relation to study 63 (5) 68 (1) 64 (2) 62 (6) 63 (4) 54 (7) 53 (8) 63 (3)

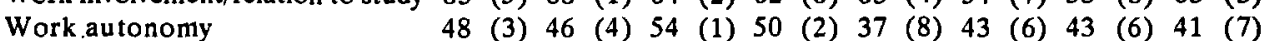

Utilisation of competencies in the future 80 (6) 85 (1) 81 (5) 77 (7) 81 (4) 82 (3) 76 (8) 85 (2) $\begin{array}{llllllllllll}\text { Appropriate position in the future } 79 & \text { (6) } 86 & \text { (3) } 77 & \text { (7) } 88 & \text { (1) } 86 & \text { (2) } 82 & \text { (5) } & 67 & \text { (8) } 84 & \text { (4) }\end{array}$

Institution of IIigher Education

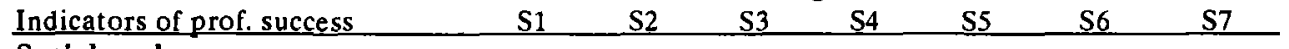

\section{Social work}

Duration of job search (mean)

$\begin{array}{cccccccccccccc}8.4 & (6) & 6.1 & (4) & 6.4 & (5) & 8.8 & (7) & 5.5 & (3) & 4.4 & (1) & 5.2 & (2) \\ 32.1 & (3) & 28.1 & (7) & 30.8 & (4) & 32.6 & (1) & 30.5 & (5) & 32.6 & (2) & 29.9 & (6) \\ 88 & (4) & 79 & (6) & 81 & (5) & 78 & (7) & 98 & (1) & 95 & (2) & 93 & (3) \\ 70 & (5) & 50 & (7) & 83 & (1) & 68 & (6) & 82 & (2) & 77 & (4) & 80 & (3) \\ 64 & (1) & 37 & (7) & 56 & (3) & 45 & (5) & 52 & (4) & 61 & (2) & 45 & (6) \\ 5 & (4) & 0 & (7) & 15 & (1) & 2 & (6) & 7 & (2) & 5 & (3) & 2 & (5) \\ 61 & (1) & 55 & (3) & 57 & (2) & 46 & (6) & 53 & (4) & 43 & (7) & 49 & (5) \\ 59 & (4) & 75 & (1) & 63 & (2) & 50 & (6) & 51 & (5) & 60 & (3) & 45 & (7) \\ 70 & (6) & 74 & (3) & 62 & (7) & 72 & (5) & 78 & (2) & 82 & (1) & 72 & (4)\end{array}$

Income (mean)

Utilisation of competencies

Appropriate position

Job satisfaction in general

Status/career possibilities

Work involvement/relation to study

Work autonomy

Utilisation of competencies in the future

70 (6) 74

$62(7) \div 72$

(3) 59 (2) 64

(1) $45 \quad(5)$

" 2 = second degree course at a Gesamthochschule; 1 = first degree course at a Gesamthochschule

For an explanation of the indicators see table 3.

Source: Kassel graduate survey; second survey 1985-87 
Graph 7. Ranking of institutions of higher education according to 10 indicators of graduates' professional success two years after graduation
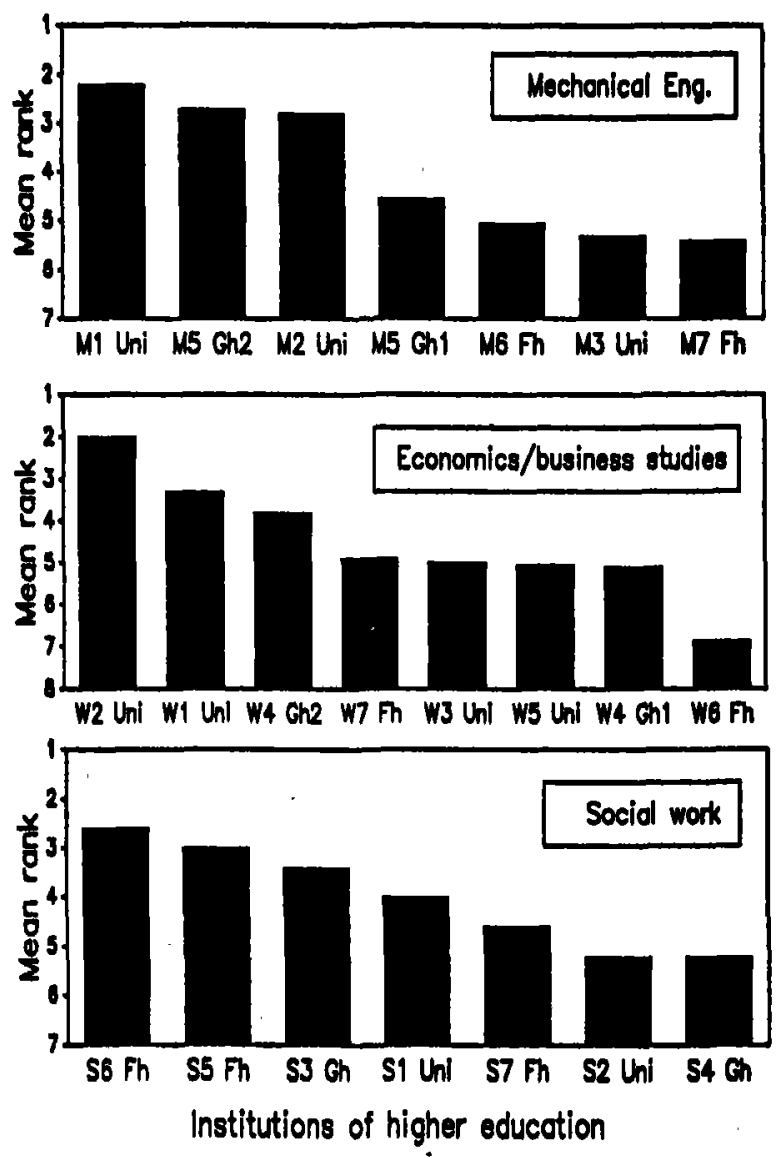
among employing organizations, came off very well, while one Fachhochschule came off badly in the survey. Four to five years later, we note three groups of institutions. On the one hand, graduates of a second university also fared well. On the other hand, the number of institutions the graduates of which came off badly had increased to three.

Surprisingly, the social work departments formed a hierarchy according to the initial careers of their graduates. The graduates of the two denominational institutions came out best. Four to five years after graduation, the differences between institutions according to the careers of their graduates had become smaller, with the careers of one denominational institution having, in the meantime, hit bottom.

The statistical links between institutions and graduate careers were analyzed. One can surmise, however, that the links established are not due to the quality of the respective institutions of higher education. Rather, they are the results of the different intakes of students and the respective regional labour market conditions.

Table 5 illustrates the results of covariance analyses in which the impacts of the socio-biographical backgrounds of students are examined. The data include such items as gender, marks on the school-leaving examination, and professional orientation. In engineering and economics/business, a very small net impact could be correlated with given institutions of higher education; however, no impact could be observed in the case of graduates in the fields of social work.

With regard to the regional labour market, we noted that the variance in the incomes of graduates two years after graduation was strongest according to the wealth or poverty of the region in which the institution of higher education attended is situated. If graduates moved from lesser known universities situated in relatively poor regions to jobs in relatively wealthy regions, they earned on average as much as graduates from the well-known universities of these relatively rich regions.

\section{Impact of Study Programmes and Conditions of Study on Subsequent Careers}

In addition to measuring the overall impact of the higher education institution, we tried to identify the single elements of the study programmes and other conditions most relevant to the careers and the assignments of graduates. In this analysis, several variables, including the study provisions and conditions of the fields of study, the study behaviour and orientations of students as well as the results of study (in terms of examination marks, self-assessment of proficiencies, etc.) were taken into account. Individual background was also considered. A multiple regression analysis was undertaken separately for the three fields of study according to the type of higher education institution, whereby eight variables apiece for occupational success, two years after graduation, and four to five years after graduation served as dependent variables. 
Table 5. The impact of individual background and the institution of higher education on the professional success four to five years after graduation (proportions of explained variance)

\begin{tabular}{|c|c|c|c|c|}
\hline $\begin{array}{l}\text { Indicators } \\
\text { of prof. success }\end{array}$ & $\begin{array}{l}\text { Institution } \\
\text { attended }\end{array}$ & $\begin{array}{l}\text { Personal } \\
\text { background }\end{array}$ & $\begin{array}{l}\text { Institution } \\
\text { and personal } \\
\text { background }\end{array}$ & $\begin{array}{l}\text { Net effect } \\
\text { of Institution } \\
\text { attended }\end{array}$ \\
\hline Mechanical engineers & & & & \\
\hline Position & 2.5 & $11.4 *$ & 13.2 " & 1.8 \\
\hline Income & 3.5 & $11.1^{*}$ & $15.2^{*}$ & 4.1 \\
\hline Utilization of competencies & $8.4^{*}$ & 5.8 & $10.7^{*}$ & $5.0^{*}$ \\
\hline Appropriate position & 1.3 & 3.6 & 4.5 & 1.0 \\
\hline Job satisfaction in general & 1.0 & 4.2 & 5.6 & 1.4 \\
\hline Status/career possibilities & 1.3 & 4.9 & $6.2^{*}$ & 1.3 \\
\hline Work involvement/relation to study & $6.2^{*}$ & $10.3^{*}$ & $14.2^{*}$ & 3.9 \\
\hline Work autonomy & $5.4^{*}$ & $12.6^{*}$ & $15.8^{*}$ & 3.1 \\
\hline Average & 3.7 & 8.0 & 10.7 & 2.7 \\
\hline \multicolumn{5}{|l|}{ Economics/business studies } \\
\hline Position & .8 & $7.3^{*}$ & $8.2^{*}$ & .8 \\
\hline Income & 1.7 & $10.8^{*}$ & $12.1^{*}$ & 1.4 \\
\hline Utilization of competencies & $2.0^{*}$ & $6.6^{*}$ & $8.0^{*}$ & 1.4 \\
\hline Appropriate position & 1.9 & $7.2^{*}$ & $8.5^{*}$ & 1.3 \\
\hline Job satisfaction in general & 1.5 & $7.6^{*}$ & $8.8^{*}$ & 1.2 \\
\hline Status/career possibilities & 1.7 & $11.6^{*}$ & $12.2^{*}$ & .6 \\
\hline Work involvement/relation to study & $2.2^{*}$ & $11.3^{*}$ & $12.5^{*}$ & 1,2 \\
\hline Work autonomy & .9 & $10.6^{*}$ & $11.4^{*}$ & .7 \\
\hline Average & 1.6 & 9.1 & 10.2 & 1.1 \\
\hline \multicolumn{5}{|l|}{ Șocial work } \\
\hline Position & 4.3 & 7.0 & 12.3 & 5.3 \\
\hline Income & 2.5 & $11.9^{*}$ & $14.8^{*}$ & 2.9 \\
\hline Utilization of competencies & 4.7 & 6.2 & 10.4 & 4.3 \\
\hline Appropriate position & $8.4^{*}$ & 4.1 & $12.5^{*}$ & $8.4^{*}$ \\
\hline Job satisfaction in general & 2.8 & 5.5 & 7.8 & 2.3 \\
\hline Status/career possibilities & 2.2 & . 7.9 & 9.4 & 1.5 \\
\hline Work involvement/relation to study & 1.3 & 5.7 & 7.2 & 1.5 \\
\hline Work autonomy & 2.1 & 5.6 & 7.5 & 1.9 \\
\hline Average & 3.5 & 6.7 & 10.2 & 3.5 \\
\hline
\end{tabular}

* significant $(\mathrm{p}<0.05)$

${ }^{1}$ Proportion of explained variance by institution attended with the statistical control of the per sonal background of the graduates (gender, achievement at school, job experience before start of study, social origin and work values) 
In the first step of the analysis, the impacts of the respective four areas (i.e., all variables regarding study provisions and conditions, and all those regarding study behaviour and orientation, etc.) were measured. As Table 5 shows, all the study variables had a moderate impact on the careers and assignment of graduates. Altogether, however, career and assignment can be explained only $10 \%$, at the most, by the variables related to study. The variables of course programmes and study conditions explained $7 \%$ of the variance two years after graduation and $6 \%$, four to five years after graduation for mechanical engineering, $4 \%$ at both intervals for economics/business, and finally $7 \%$ and $6 \%$, respectively, for social work.

By taking into consideration variables regarding the backgrounds of students as well, one can note that $12 \%$ of the career and professional assignment categories can be fully explained by the backgrounds and study variables of students. About half can be attributed to students' background and half to the various variables linked to study.

In turning to the individual variables of course programmes and study conditions as a second step in the analysis, we found that only a few links are noteworthy so far as a discernable impact on career and work assignment are concerned.

- In the case of engineering graduates from universities, the following bore some weight: "integration into research", "institutional support in job search", "orientation help through ex- aminations", and "sufficient institutional resources";

- Engineering graduates from Fachhochschulen: placed "emphasis on methods";

- Economics/business graduates from universities cited "transparency of achievement standards", "integration into research", and "research orientation", but stated that "emphasis on theories" had a negative impact;

- Economics/business graduates from Fachhochschulen cited "transparency of achievement standards" and "emphasis on application";

- Social work graduates from universities cited "positive social climate";

- Social work graduates from Fachhochschulen cited "emphasis on methods", "student-orientated teaching staff", and "institutional resources".

These findings demonstrate that we cannot identify any elements of a study programme and study conditions which have consistent impacts on the subsequent graduate careers and work assignments across fields of study and types of higher education institutions. Rather, different factors seem to play moderate roles regarding each field and type of higher education institution.

\section{DISCUSSION OF THE RESULTS}

The Kassel Graduate Survey challenged various widespread views and perceptions regarding the relationships between higher education and employment in Germany. 
- Employment problems are less serious in general and less diverse according to field of study than generally assumed.

- Employment opportunities for Fachhochschule graduates are less favourable than claimed in public debates.

- Women's career disadvantages vary more substantially according to field of study than the general debate on women's employment suggests.

- The vertical diversification of higher education according to the careers of graduates is less pronounced than was expected in recent years.

- Horizontal differentiation is achieved primarily through the options of students with regard to specialization and only additionally through different institutional profiles.

- No dominant elements of study provision and study conditions can be observed which might explain study outcomes, careers, and job assignments.

This study enabled us to examine career success with the aid of a broad range of measures, rather than with only a few of them, such as employment status and income. We found that the more measures relative to career success we take into account, the less career successes appear to vary according to the higher education institutions which graduates attended. This finding permitted us to conclude that single measures might create artificial differences in assessing the impacts of universities on careers.
Our findings are disappointing for persons who believe that only a few outstanding factors determine the quality of higher education and that improvements would require only a few marked changes. Rather, a broad range of factors explains only a small part of the quality of higher education programmes and institutions. Also, infrastructural differences between departments or between institutions of higher education seem to play marginal roles. Finally, we had the impression that neither typical measures of educational quality nor those of research reputation best explain the outcomes, but rather factors which lie somewhere between teaching and research, such as work in student assistant positions, contacts between professors and students regarding academic matters, early explanation of the rationales of the given disciplines and course programmes, etc. This observation might confirm the view that universities in Germany are most successful when they emphasize the unity of research and teaching, indeed, the ideal which they in principle profess.

We found that students' ways of handling universities play an important role, but clearly not to the extent that the characteristics of universities can be said to be negligible.

We believe that the design of this research allows us to check many relationships between the quality of provisions and conditions at institutions of higher education, the competences the students acquire, and their careers - relationships which have been objects of specialization in most other projects. Altogether, we came to the conclusion that differen. 
ces in quality among higher education institutions determine the careers of graduates to a lesser extent and that the academic reputation of the given higher education institution is less important for the careers of graduates in the Federal Republic of Germany than many scholars at universities would like to believe. We also. note that many factors contribute in small ways to the success of graduates rather than a few factors having a strong influence. Further, we pointed out that the quality of higher education cannot be viewed only hierarchically but must also be considered in terms of links between content of learning and work assignments. Finally, we believe that more attention should be paid to the factors which bridge the teaching and the research functions of higher education. 


\title{
CAREER PATTERNS OF FINNISH ACADEMICS AND INTELLECTUALS: A LONGITUDINAL STUDY OF THE 1965 STUDENT GENERATION
}

\author{
Yrjö-Paavo HÄYRYNEN with Liisa HÄYRYNEN
}

This article is concerned with the career patterns of Finnish intellectuals and professionals. It aims to illuminate the trajectories of individuals who studied in universities in the 1960's and later found various types of positions in Finnish society. It illustrates certain aspects of this career differentiation and the role of the university in this process. The group being studied represents the professional and managerial core of society. Many of

\section{INTRODUCTION}

The notion of career traditionally refers to a person's passage'through different jobs and statuses' (cf., Spilerman, 1977, and see also Super and Bachrach, 1977). Van Maanen suggests that a career can be either brilliant or disappointing, a success or a failure: "In the world of work, therefore, prostitutes, plumbers, doctors, factory workers, managers, housewives, bartenders, waitresses, lawyers, criminals, and cops all have careers" (1977, p. 1). But is this way of explaining what a career is actually true? Do we use the concept of career in the same sense for doctors and plumbers, lawyers and criminals, for male politicians and female design artists? This conception seems to overlook the basic social differentiation which underlies different job titles. In question is the opposition between those with power and those the individuals concerned hold visible positions in the public life of the nation. They do not, however, form any unitary class. The educated population is divided into various sections and levels which display quite different models of career trajectories and different forms of social influence. This diversity makes both the study of the impact of university education and the system of careers an extremely complex research theme.

with insignificant or subordinated positions.

The basic factors of all career differentiation are linked, it seems, to gender, to social class, and to the degree of wealth or influence which different positions in the social structure permit their occupants. These factors determine the strategies and skills which people use when trying to reach different career goals.

A gender-related division of labour and a hierarchy of social status even exist inside the academic sector. A fine line also exists between those academic people who influence society with their thoughts, for example, through their publication productivity, and those who are chiefly concerned with their professional work and its methods (intellectuals versus professionals). That different aspects of university education motivate, in quite separàte form, 
these different subgroups of academic intelligentsia is very probable.

According to the French sociologist, Pierre Bourdieu, modern society is actually composed of several different types of hierarchies. One cannot be content, therefore, with the unrivalled notion of career as related to labour market mobility. In fact, each social group or field specifies its own type of social capital: scholarly, intellectual, or moneyed, which is valuable to this group and which its members utilize (Bourdieu, 1984; Bourdieu, 1990). A primary division runs between the economic and the cultural poles of society. The former is visible in the system of status; the hierarchy of the latter is externalized in the degrees of education and cultivated behaviour which people in different intellectual positions demonstrate. Since these two poles are intertwined, one cannot strictly separate the operation of power from the scheme of idea production. Bourdieu's recent analysis of academic fields illustrates, in detail, this tension between institutionalized power and intellectual spirit in the university world (1988).

Bourdieu uses the notion of modal trajectory to refer to the normal lifecourses of people with certain social backgrounds. A modal trajectory is related to the "given volume of initial social capital", which determines the most common route of the members of this group: "a band of more or less equally probable trajectories leading to more or less equivalent social positions" (Bourdieu, 1984, p. 110; see also Harker, et al.; 1990, p. 20). In a similar way, it seems justified to speak of the modal admission pattern of a group, which would indicate the most common way of entering a certain social field or achieving a certain cultural/social position (i.e., the characteristic route of becoming a medical doctor, university professor, or intellectual in a given society). In fact, this study applies the notion of modal trajectory chiefly in this latter sense of the term. One should note, however, that deviations from the modal educational or professional trajectory exist as well: people may move from the modal trajectory of their group into another type of trajectory (Bourdieu, 1984, pp. 109111). This freedom of choice is attributable to the fact that careers are patterned by two different factors: the existing social and cultural hierarchies and the spontaneous activities of people, which sometimes produce new models of social transition. In addition to acquired personal skills, the social trajectories of people are dependent on the outcomes of social competition in which different social groups defend or increase their initial social capital (Harker, et al., op. cit.). .

\section{CATEGORIES OF THE ACADEMIC-PROFESSIONAL FIELD}

We now turn to a discussion of our empirical data. This study was originally based on a 1965 survey made of approximately 6,000 applicants to Helsinki University which investigated their educational plans, occupational preferences and values, and ratings of their own abilities ( $c f$, Y.-P. Häyrynen, 1970). A sampling of university entrants was designed in 
the early 1980's. The subjects, who were located in 1982-1983, consisted of three main samplings: persons who were identified on the basis of their current élite status (one hundred were located in this way); those who had regular academic careers (those admitted to the university in 1965 and who were studied again in 1969), and the 1965 rejects, those who were not admitted to the university in 1965 and who often represented more or less problematic career development. In addition, certain persons were selected for an extra survey on the basis of their professions. A total of 795 returned viable responses during the autumn of 1982 or the winter of $1983 .{ }^{1}$

These groups cover most of the key areas in the Finnish academic professional field, although not in statistically correct proportions. The research material also includes a substantial number of replies from persons in so-called creative occupations (e.g., science, journalism, art and design, television), and in the administrative élite: 193 of the whole sample were classifiable, on the basis of their public output or social position, as "influentials" or the "élite" ( $c f$. Y.-P. Häyrynen, 1985). Eva EtzioniHalevy (1985) speaks of intellectuals as a group "who have influence but not power" and accordingly calls them the "knowledge élite". She excludes administrators, whose main task is not to create knowledge but to exercise political control. In this study, we made a similar demarcation between the cultural and the administrative élites, even though these groups seem to overlap more in Finland than they do, for instance, in Australia.

Thus, our empirical study stressed the difference between 1) the intellectual and managerial groups of the $n a-$ tional élite and 2) the élite and the sub-élite, as it was characterized earlier. In addition we separated 3) a semi-academic group, those without full university degrees (chiefly nurses, commercial engineers, or elementary school teachers). In many analyses, a finer classification was applied in which the central mode of influence (artistic, scientific, or administrative) was considered. The sub-élite was similarly divided into three sections, the scientific-medical, the social-pedagogical, and the juridical-organizational subgroups. These made a total of seven basic groups (see Table 1). In most analyses, the men and women in each segment are treated separately, thus

\footnotetext{
${ }^{1}$ In all, $67 \%$ of the 1,368 subjects who could be located returned the questionnaire. The proportion of those who did not respond was largest among women in the social and humanistic sectors who had not generally completed their degrees. The numbers which are presented in later statistical analyses vary, depending on whether or not those who responded to the supplementary survey of physicians and theologians are included. In the trajectory description we have used, the standard sample totals 714 . The scientific-medical sub-élite may be oversampled with physicians; the pedagogical and social intelligentsia similarly may be slightly oversampled with theologians (both were sought through professional directories, and they had a larger than average proportion of return). The semi-academic subgroup represents people with institute-level educations who had once applied for university admission but were not admitted. Still one notes that this study does not aim so much at general statistical representativeness as at revealing the basic dimensions of intergroup differences and the relationships between different elements of a trajectory.
} 
increasing the number of subgroups to fourteen. ${ }^{2}$

\section{INVESTMENTS AND GAINS IN TRAJECTORY}

Is it possible to find many modal trajectories leading from the university to these different fractions of the academic-professional field? As graduates of upper secondary school, the subjects of our longitudinal study had a more favourable social background than the general population. Most of them were placed in employment in which autonomous work is the rule rather than the exception. Yet there were differences in the social backgrounds of the persons concerned and in the relative proportion of men and women in different "basic groups". The proportion of subjects with a high degree of inherited cultural capital - estimated on the basis of the educational level of their parents and the number of academic relatives as listed in the 1965 questionnaire - varies noticeably among the different "basic groups". It is highest for the subgroups of female artistic intellectuals and the male academic élite (Table 1). Another key factor is the success of university applicants in the uniform national matriculation examination (student examination or Abitura). Although this indicator of scholastic capital correlated slightly with the degree of cultural capital, it also had (according to subsequently performed loglinear analyses) an independent influence on the later academic career. In a parallel way, there was a separate correspondence, even within the élite, between the initial cultural capital of subjects and their later literary output. In general, better initial resources piloted subjects toward more prestigious positions or greater autonomy of work. The modal trajectory directing male students toward the academic élite (i.e., university posts and research careers) was composed of the following key elements:

- a high volume of initial capital (40\% of the entrants into the male academic élite came from academically educated urban families in which many relatives were also highly educated; $80 \%$ were sons of upper-middle class fathers);

- a prominent result in the general matriculation examination (58\% had an overall mark of laudatur);

\footnotetext{
${ }^{2}$ We also computed, for each subgroup, the relative proportions of free-lancers or persons with private businesses, and managers or persons playing an important role in institutional decisionmaking (rectors, deans, executives, and heads of governmental departments). These categories are loosely related to Erik $O$. Wright's theory of "mixed class positions" of educated intelligentsia. What we added to this scheme is the sphere of public influence, observable in literary production and other public output. Table 1 quotes the proportions of free-lancers and persons with private businesses, symbolizing the degree of autonomy in respective subgroups, and the proportion of those persons in each subgroup who had published at least 10 papers before 1983 (one of the indicators of "public influence"). In further analyses, we shall specify the international activities of different segments of the intelligentsia: their studies abroad, etc., as a new type of "symbolic capital".
} 
Table 1. Trajectories of seven 'basic groups' 1965-1983 (standard sample by gender, $\mathrm{n}=174$ )

1. ScC: Scholastic Capital; school success in 1965; 2. CultC: Inherited Cultural Capital; 3. AcC: Academic Capital or highest degree earned in 1983; 4. LIT: proportion of intensive writers in each subgroup; 5. Entrepreneurs (LIB), 6. Attained social status. ${ }^{1}$

\begin{tabular}{|c|c|c|c|c|c|c|c|}
\hline & ( & $\begin{array}{c}\text { 1. } \mathrm{ScC} \\
\text { lauda- } \\
\text { turs } \\
1965 \\
\%\end{array}$ & $\begin{array}{c}\text { 2. CultC } \\
\text { parents } \\
\text { uni/col } \\
1965 \\
\%\end{array}$ & $\begin{array}{c}\text { 3. AcC } \\
\text { degree in } \\
1983 \\
\text { average }\end{array}$ & $\begin{array}{c}\text { 4. LIT } \\
\text { (publ } \\
10+\text { ) } \\
1983 \\
\%\end{array}$ & $\begin{array}{l}\text { 5. LIB } \\
\text { (lib. } \\
\text { prof) } \\
1983 \\
\%\end{array}$ & $\begin{array}{l}\text { 6. STATUS } \\
\text { (prestige } \\
\text { index) } \\
1983 \\
\text { average }\end{array}$ \\
\hline $\begin{array}{l}\text { 'ELITE' } \\
\text { 1. ARTISTIC/M } \\
\text { ARTISTIC/F }\end{array}$ & $\frac{(193):}{\left(\frac{31)}{14)}\right.}$ & $\begin{array}{l}29 \\
36\end{array}$ & $\begin{array}{l}29 \\
50\end{array}$ & $\begin{array}{l}\text { Lower } \\
\text { Lower }\end{array}$ & $\begin{array}{l}65 \\
26\end{array}$ & $\begin{array}{l}26 \\
57\end{array}$ & $\begin{array}{l}\text { MID } \\
\text { MID }\end{array}$ \\
\hline $\begin{array}{l}\text { 2. ACADEMIC/M } \\
\text { ACADEMIC/F }\end{array}$ & $\frac{(67)}{(18)}$ & $\begin{array}{l}58 \\
59\end{array}$ & $\begin{array}{l}40 \\
22\end{array}$ & $\begin{array}{l}\text { Doctoral } \\
\text { Doctoral }\end{array}$ & $\begin{array}{l}81 \\
72\end{array}$ & $\begin{array}{l}25 \\
11\end{array}$ & $\begin{array}{l}\text { UPPER } \\
\text { UPPER }\end{array}$ \\
\hline $\begin{array}{l}\text { 3. POL. ADM/M } \\
\text { POL. ADM/F }\end{array}$ & $\begin{array}{l}(58) \\
(5)\end{array}$ & $\begin{array}{l}26 \\
20\end{array}$ & $\begin{array}{r}21 \\
0\end{array}$ & $\begin{array}{l}\text { Univ.Grad. } \\
\text { Univ.Grad. }\end{array}$ & $\begin{array}{l}57 \\
40\end{array}$ & $\begin{array}{l}3 \\
0\end{array}$ & $\begin{array}{l}\text { UPPER } \\
\text { UPPER }\end{array}$ \\
\hline $\begin{array}{l}\text { SUB-ELITE } \\
\text { 4. SCI-MED/M } \\
\text { SCI-MED/F }\end{array}$ & $\begin{array}{l}(401): \\
\left(\frac{61)}{311}\right)\end{array}$ & $\begin{array}{l}39 \\
45\end{array}$ & $\begin{array}{l}23 \\
13\end{array}$ & $\begin{array}{l}\text { Univ.Grad. } \\
\text { Univ.Grad. }\end{array}$ & $\begin{array}{r}10 \\
6\end{array}$ & $\begin{array}{l}11 \\
16\end{array}$ & $\begin{array}{l}\text { UPPER } \\
\text { MID + }\end{array}$ \\
\hline $\begin{array}{l}\text { 5. SOC.PED/M } \\
\text { SOC.PED/F }\end{array}$ & $\left(\frac{77}{(106)}\right)$ & $\begin{array}{l}16 \\
17\end{array}$ & $\begin{array}{r}16 \\
9\end{array}$ & $\begin{array}{l}\text { Univ.Grad. } \\
\text { Univ.Grad. }\end{array}$ & $\begin{array}{r}18 \\
9\end{array}$ & $\begin{array}{l}2 \\
0\end{array}$ & $\begin{array}{l}\text { MID } \\
\text { LOWER }\end{array}$ \\
\hline $\begin{array}{l}\text { 6. JUR. ORG./M } \\
\text { JUR. ORG/F }\end{array}$ & $\frac{(20)}{(36)}$ & $\begin{array}{l}10 \\
14\end{array}$ & $\begin{array}{r}17 \\
5\end{array}$ & $\begin{array}{l}\text { Univ.Grad. } \\
\text { Univ.Grad. }\end{array}$ & $\begin{array}{r}16 \\
8\end{array}$ & $\begin{array}{r}14 \\
8\end{array}$ & $\begin{array}{l}\text { MID + } \\
\text { MID }\end{array}$ \\
\hline $\begin{array}{l}\text { 7. SEMI-ACAD. } \\
\text { SEMI-ACAD./M } \\
\text { SEMI-ACAD./F }\end{array}$ & $\frac{(112)}{\left(\frac{58)}{64)}\right.}$ & $\begin{array}{l}03 \\
06\end{array}$ & $\begin{array}{r}20 \\
3\end{array}$ & $\begin{array}{l}\text { Lower } \\
\text { Lower }\end{array}$ & $\begin{array}{l}4 \\
0\end{array}$ & $\begin{array}{l}7 \\
3\end{array}$ & $\begin{array}{l}\text { LOWER } \\
\text { LOWER }\end{array}$ \\
\hline
\end{tabular}

${ }^{1}$ 1. 'Scholastic Capital': \% of highest overall marks in the Matriculation Examination 1962. 2. Inherited Cultural Capital: Father's and mother's educational level: $\%$ of the university/college levels, added with relatives in the academic level. 3. 'Academic Capital': Highest degree earned in 1983: doctoral (incl. 'Licentiate of Philosophy') degree, university graduation; lower degrees (institutes, art colleges). 4. 'Intensive Writers': Percentage of those having published at least 10 papers/articles in 1983 (professional, scientific, political, art critic but not specifically esthetic products). 5. LIB: Percentage of free-lancers/entrepreneurs in each subgroup. 6. Social status: prestige of the present job (mean of the subgroup on the 9-point scale by Rauhala); UPPER: professors, judges, executives, heads of department; MID: upper secondary school teachers, psychologists, research assistants; LOWER (lower middle): nurses, social workers, commercial travellers, secretaries etc. 
- earning a postgraduate degree (many were still preparing their doctoral dissertations in 1983);

- a high prestige rate in their current jobs, one-fourth being freelancers or owners of private businesses or consulting firms; a similarly high rate of literary productivity, indicating their spheres of public influence as well (see Table 1).

Table 2 illuminates the subjective side of these social trajectories: the motivational factors which promoted attainment of various career goals ( $P h D$ motivation and the proportion of creative orientation), and experiences that were related to the attained position: the degree of fulfillment of abilities in work and major life-orientation. These subjective factors actually indicate how the initial cultural or scholastic capital and the current work situation are mediated into experiences and into the constituents of personal habitus. For example, the academic élite trajectory portrayed above was linked in 1965 to a moderate creative orientation, to a high motivation expressed as a student for earning a $\mathrm{PhD}$, to an appreciation of the family as the source of present life enjoyment, and to a high proportion of those who use most of their abilities in their current work. The fact that $82 \%$ of the persons in this category would select the same course programme again is worth mentioning. In Bourdieu's conception, these people had successfully transformed their initial cultural and scholarly capital into "academic capital", enabling them to gain independent and prestigious positions in the scientific realm.
The much smaller group of women scholars had a similarly high proportion of overall marks of laudatur but humbler social origins (Table 1). Yet one-third had, already in 1965, considered presenting a PhD thesis later on - this ambition being more related to their excellent success at school than to the influence of their home (Table 2). Frequently a university teacher was the person who actually gave these female students the final impetus to select a career in academic research.

The interesting point is that women with a high level of inherited cultural capital did not generally display strong academic interests. They sometimes interrupted their univer: sity studies and transferred to art institutes, later being found among the artistic intellectuals (Table 1). Socially inherited cultural capital had encouraged their orientation towards creative work (the high proportion with an Investigative-Artistic orientation, as shown in Table 2) but a distaste for an academic career. In fact, - many creative female students were frustrated by the contents of university teaching, and many concentrated more on private creative hobbies in their later careers than on active productivity. In this group, $5.7 \%$ worked in the liberal professions or in their own enterprises (as authors, free-lance editors, designers, or performing artists). In this sample, the female artistic group had the highest rates of studying abroad, autonomy of work, and proportions of estheticvisual output. They seem to have used their initially high social resources to implement a large amount of their 
Table 2. Subjective side of trajectory, the seven 'basic groups' by gender

1. CREA: Percentage of subjects with inteHectual-artistic orientation (IA +) in 1965. 2. High 'Ph.D.-motivation' in 1965 (\%). 3. LIFE-ORIENTATION: 'Affective life-orientation' in 1982/83. 4. FULFILMENT OF TALENT: Percentage of high ability-users in each subgroup in $1982 / 83$. $^{1}$

\begin{tabular}{|c|c|c|c|c|c|}
\hline & & $\begin{array}{l}1 . \\
\text { CREA } \\
\text { IA + } \\
1965 \\
\%\end{array}$ & $\begin{array}{l}\text { 2. PhD- } \\
\text { Motiv. } \\
1965 \\
\%\end{array}$ & $\begin{array}{l}\text { 3. LIFE- } \\
\text { ORIENTATION } \\
1983\end{array}$ & $\begin{array}{c}4 . \\
\text { FULHMEN } \\
\text { OF TALENT } \\
1983 \\
\%\end{array}$ \\
\hline $\begin{array}{l}\text { 'ELITE' } \\
\text { 1. ARTISTIC/M } \\
\text { ARTISTIC/F }\end{array}$ & $\begin{array}{l}(193): \\
\left(\frac{31)}{(14)}\right.\end{array}$ & $\begin{array}{l}29 \\
36\end{array}$ & $\begin{array}{r}13 \\
0\end{array}$ & $\begin{array}{l}\text { Inventive/Fam } \\
\text { Fam/Invent. }\end{array}$ & $\begin{array}{l}58 \\
64\end{array}$ \\
\hline $\begin{array}{l}\text { 2. ACADEMIC/M } \\
\text { ACADEMIC/F }\end{array}$ & $\stackrel{(67)}{(18)}$ & $\begin{array}{l}24 \\
11\end{array}$ & $\begin{array}{l}58 \\
33\end{array}$ & $\begin{array}{l}\text { Fam } \\
\text { Fam }\end{array}$ & $\begin{array}{l}57 \\
56\end{array}$ \\
\hline $\begin{array}{l}\text { 3. POL. ADM/M } \\
\text { POL. ADM/F }\end{array}$ & $\begin{array}{l}(58) \\
(5)\end{array}$ & $\begin{array}{l}9 \\
0\end{array}$ & $\begin{array}{l}17 \\
20\end{array}$ & $\begin{array}{c}\text { Fam/Work } \\
\text { Fam }\end{array}$ & $\begin{array}{l}50 \\
60\end{array}$ \\
\hline $\begin{array}{l}\text { SUB-ELITE } \\
\text { 4. SCI-MED/M } \\
\text { SCI-MED/F }\end{array}$ & $\begin{array}{l}(401): \\
\left(\frac{61)}{31)}\right.\end{array}$ & $\begin{array}{l}10 \\
19\end{array}$ & $\begin{array}{l}39 \\
23\end{array}$ & $\begin{array}{c}\text { Fam } \\
\text { Fam/Cult-Soc }\end{array}$ & $\begin{array}{l}39 \\
48\end{array}$ \\
\hline $\begin{array}{l}\text { 5. SOC.PED/M } \\
\text { SOC.PED/F }\end{array}$ & $\left(\frac{77}{(106)}\right)$ & $\begin{array}{r}10 \\
7\end{array}$ & $\begin{array}{l}13 \\
10\end{array}$ & $\begin{array}{l}\text { Cult-Soc/Fam } \\
\text { Fam/Cult-Soc }\end{array}$ & $\begin{array}{l}28 \\
36\end{array}$ \\
\hline $\begin{array}{l}\text { 6. JUR. ORG./M } \\
\text { JUR. ORG/F }\end{array}$ & $\frac{(20)}{(36)}$ & $\begin{array}{l}7 \\
8\end{array}$ & $\begin{array}{r}17 \\
3\end{array}$ & $\begin{array}{c}\text { Work } \\
\text { Cult-Soc/Work }\end{array}$ & $\begin{array}{l}46 \\
30\end{array}$ \\
\hline $\begin{array}{l}\text { 7. SEMI-ACAD. } \\
\text { SEMI-ACAD./M } \\
\text { SEMI-ACAD./F }\end{array}$ & $\begin{array}{l}(112) \\
\left(\frac{58)}{64)}\right.\end{array}$ & $\begin{array}{l}4 \\
2\end{array}$ & $\begin{array}{l}2 \\
0\end{array}$ & $\begin{array}{c}\text { Leisure } \\
\text { Cultural-Soc }\end{array}$ & $\begin{array}{l}44 \\
24\end{array}$ \\
\hline $\begin{array}{l}\text { Total } \\
\text { ('Standard Sample') }\end{array}$ & (714) & 10 & 19 & Family & 42 \\
\hline
\end{tabular}

\footnotetext{
1. CREA: Percentage of applicants with high preference both for investigative and artistic jobs in 1965 (the 'Interaction-type', indicating creative interest). 2. PhD-motivation: High interest and personal probability of earning a Ph.D.; self-rating in 1965. 3. Life orientation 1982/83: 'The realm giving most enjoyment of all': work, family, cultural-social entertainment with friends, leisure \& hobbies, or inventive projects (the scale by Mikk Titma). 4. Percentage of High Ability-users ('My job gives me the chance of using all my abilities'; self-rating in 1982/83.)
} 
creative capacity in various personal projects.

A third type of élite trajectory leads from among a cluster of lower-middle class male students to administrative top-careers. The subgroup of the administrative and political élite has a greater male dominance than any other subgroup (only five women were classified as being part of the administrative élite), but it does not differ much from the general academic population in social background. The 1970's witnessed the rapid expansion of the public sector in Finland. The academically-trained who were admitted to the planning and organizing establishment often received their degrees in Political Science or Law from Helsinki University. The high percentage of "intensive writers" in this subgroup is explicable both on the basis of their expert positions in social planning and their strategies for influencing public opinion. The motivational factor which initially propelled the bulk of this subgroup towards the State élite was a high level of aspiration.

In general, in all segments of the sub-élite, gender-related differences play a more important role than in the knowledge élite. While women and men in the artistic and academic élite display an almost equal degree of work autonomy, they have a lesser degree of work autonomy and usually a more problematic career model than their male counterparts (Table 1) in the sub-elite and the semiacademic group. We can also observe that the trajectory of women in the field of social and pedagogical work is similar to the semi-academic trajectory. University education did not ap- parently guarantee these women the kind of status and independence in their work which is usually linked with university graduation; only 36 percent estimated that they are using all their abilities in their work. Similarly, men in the socialpedagogical and women in the organizational and the semi-academic subgroups reported limitations on the uses of their abilities in their present work. One reason may be the lack of initial cultural capital, which would have supported the value of their academic qualification and guided them towards more independent positions. This fact was already apparent in the low degree of creative orientation and $\mathrm{PhD}$ motivation of these subgroups in 1965 (Table 2). These factors evoked very little response in them with regard to the intellectual appeal of university teaching; thus, many later complained of the irrelevance of their university studies ( $c f$., Figure 6, p. 74).

A university degree symbolized social promotion for many of our subjects, as compared with the status of their own families. As a group, they gained more formal education than their parents possessed. In particular, persons in the administrative élite or medical profession illustrate this case. For some other groups, education usually secured them a position which resembled the educational status of their families (e.g., males entering the university as a profession). Still others compensated for their lower academic qualifications by gaining intellectual capital (e.g., the female artistic intellectuals). For women with lower middle- 
Figure 1. Change of self-rated abilities during the social trajectory. Sample of university entrants 1965-1969-1982/83 Women $(n=107)$

As Applicants (1965)

In University (1969)

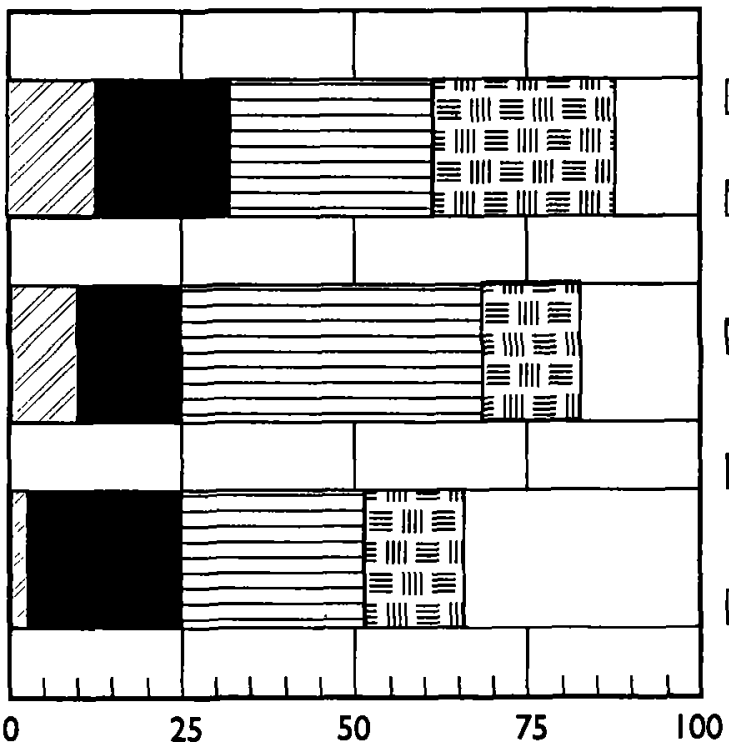

$\square$ EMPATHY

FIIIIIII LEADERSHIP

$\rightleftharpoons$ ACCURACY

"Peak abilities", \%

Figure 2. Change of self-rated abilities during the social trajectory Sample

of university entrants Men $(n=176)$

As Applicants (1965)

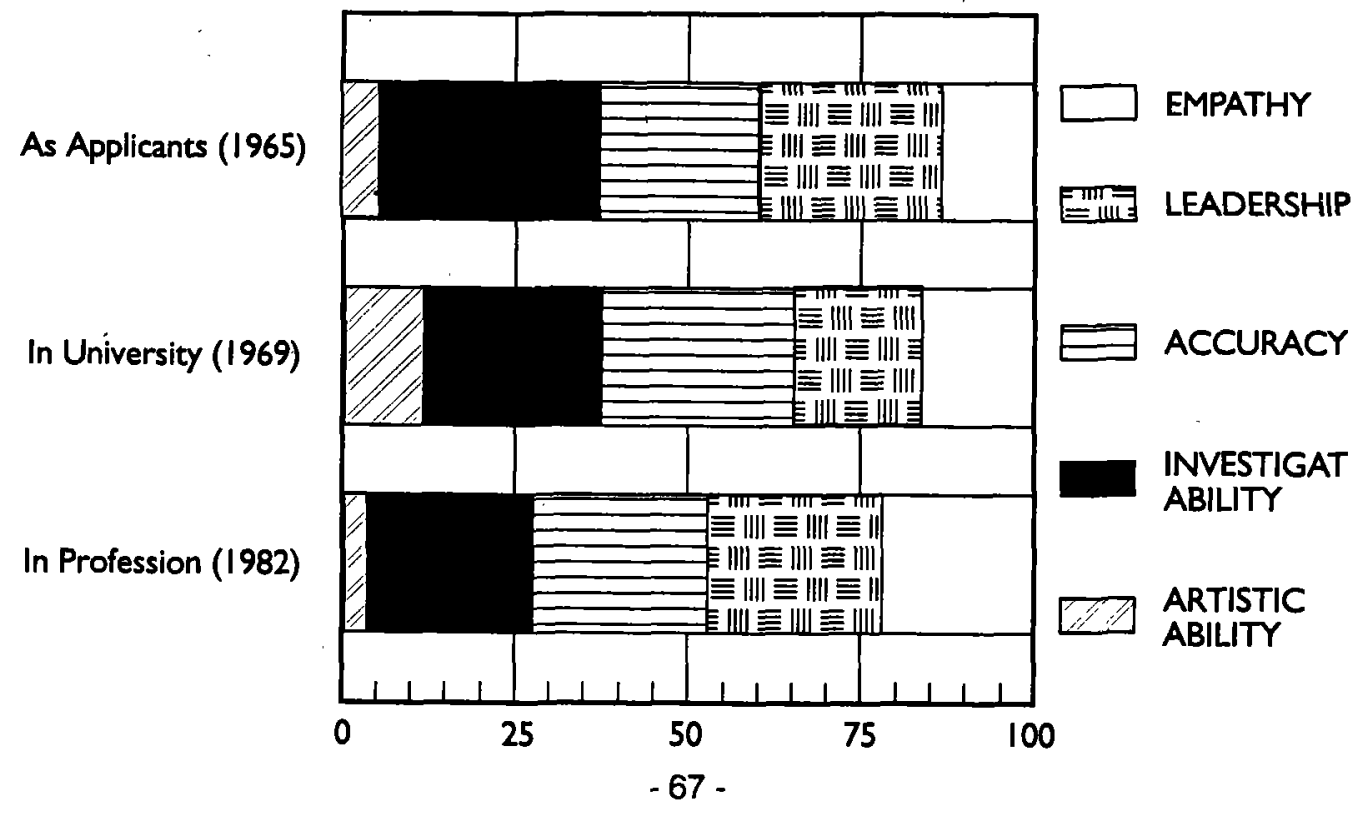

EMPATHY

ARTISTIC ABILITY

INVESTIGAT ABILITY

In Profession (1983) 
class origins, a research specialist's or a physician's career were often channels for social promotion. In general, autonomous work appears to be, for the female knowledge élite, a more appreciable goal than status, which is why so many prefer independent free-lance jobs to decisionmaking or management. It is, however, the lack of autonomy, rather than lowly status, which disappoints many women who are placed in the large sector of caring occupations or clerical jobs.

\section{TRAJECTORIES OF ABILITY FORMATION}

In Bourdieu's theory, the conceptions which people have of their own abilities reflect the "strategies of habitus" which they have learned to use in different life-tasks. Thus, changes in situational demands are mirrored in the transformation of habitus during the life-course. We shall examine below how the conception of one's own abilities is altered in the different phases of trajectory. In the 1965 study, a set of self-ratings concerned the subjects' evaluation of their own aptitudes. These were repeated in 1969 for those who studied at Helsinki University, and again in 1982-1983. The university entrant sample gave us the chance to compare the development of selfconceptions at three different points of trajectory: university entrance, fourth university year, and in midcareer. In order to condense the description we calculated five scores of self-assessed aptitude for each subject: 1) Investigative Ability(the rating of one's scientific and theoretical ability); 2) Artistic Ability (ratings of imaginative and artistic talent); 3 ) Enterprising Ability (self-assessed "enterprising spirit" and leadership quality); 4) Accuracy and Compliance ("accuracy" and "ability to follow instructions"); and 5) Empathy and Social Skills ("ability to understand people" and "oral performance skills"). These correspond to the vocational personality types suggested by John Holland (1966); his "realistic type" was not included in this classification. Each subject was classified according to his or her peak ability in 1965, 1969, and 1983. Thus it was possible to analyze the shifts of proportions during the 18year period.

Figure 1 indicates that the compliance, enterprising, and investigative peaks reached their highest proportions in the self-ratings of women university entrants. The university period caused a decline in the self-assessed investigative and enterprising capacities. This trend was more clearly visible in the 1969 self-ratings of female students. However, this decrease in investigative and enterprising capacity was usually offset in the later professional career (Figures 1 and 2). In these academic women, the fact of having undertaken challenging occupational tasks had obviously increased their self-confidence and social readiness. The proportion of social and enterprising ability had grown particularly after the university period. But we can also observe the reduction in aesthetic ability in this sample, which may be explained by the lack of cultural elements in average professional work. We should emphasize that for subjects who performed creative work in 
1982-1983, the picture of ability development was in many respects different. In the subgroup of the artistic élite doing autonomous, intellectually rewarding types of work, the proportions of both artistic and investigative skills had grown in 19821983 , as compared to the situation in
1965. Our data seem to indicate that one's ability development after completion of university studies is mainly linked to the content of work. Thus a conclusion that might be reached is that the intellectual impact of university studies can only be preserved if one's occupational duties support it.

Figure 3. Major content of present work in various subgroups, by gender

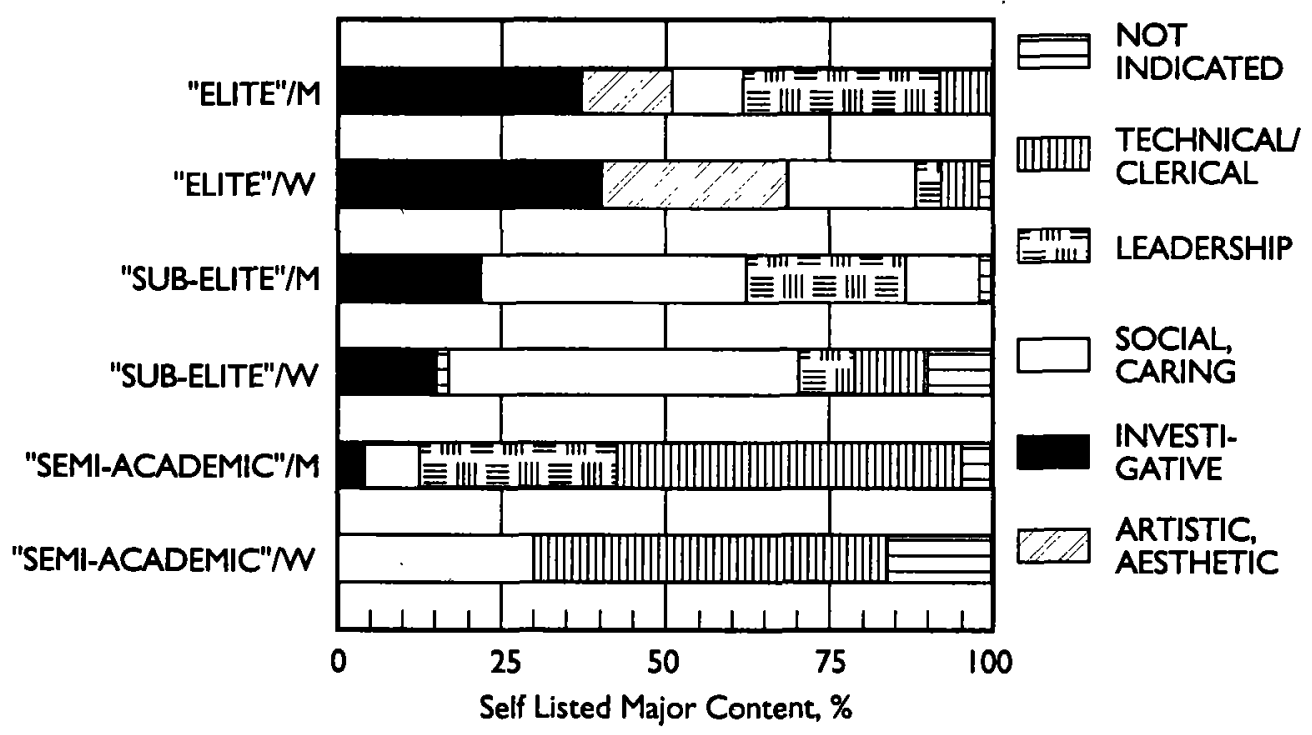

Figure 3 illustrates the large variation in the contents of work among different key-groups of our sample. Even in the same professional sector, the proportion of social service and contact duties was higher for women than for men. In contrast, men in all subgroups occupy the bulk of leadership positions. In the semi-academic intelligentsia, the proportion of secretarial jobs increases among women while that of caring duties decreases slightly. The theoretical and aesthetic functions of work seem to be concentrated in the élite part of the professional field. At the same time, creative and investigative work strengthens the intellectual aspects of their self-concept. Universities train their students chiefly for the investigative or rational aspects of activity. This training is effective if the 
work is based on a rational theory of problem solving, which happens to be the case in the academic and medical professions and for those in higher decision-making posts. However, the large area of social services and teaching work has only few investigative elements; it even seems to lack a comprehensive theoretical basis. The difficulty is not in the representativeness of social duties in the sub-élite, which has more face-toface communication with the general public than the isolated élite. The problem is rather in the lower degree of independence and in the less developed theoretical basis of these caring duties. ${ }^{3}$

\section{MODELS OF CAREER TRANSITION}

The 1982-1983 follow-up applied two life-historical methods which allowed the depiction of the yearly development of the professional situation and the annual time structure of the past life-course. One was an annual table (1965-1982) in which one column represented changes in education and the professional career and the other, occurrences in family and private life; the other was the life-line method (see Inga Elgquist-Saltzman, et. al., 1986). Here the respondent indicated in the line segments corresponding to ages 18-38 the main activities for each year (whether the time was used for study- ing, full-time or part-time work, family duties, seeking a job, etc.).

In the examination of the annual table records, we proportioned the yearly situation of the individual to previous occurrences: did the position remain the same, progress, or regress? It was possible to distinguish years clouded by employment problems or productivity crises, periods of stagnation, and those depicting steady or noticeable rises. The steady rises represent promotions in a job or the making permanent of a previously temporary work relationship, while sharp rises or "leaps" could include election to Parliament, gaining a $\mathrm{PhD}$, publication of one's first work, or promotion to a leadership position or to a position of international importance. In reality, career development can entail both modifications of status and the level of intellectual productivity, the two representing very different features of progression. Nevertheless, we compressed these two aspects in this description since our main concern was the general typology of transition. A problematic career was usually visible as a failure in getting the sought-after position, as interrupted free-lance activity, or as an insecure employment situation.

In general, $40 \%$ of the respondents experienced an advance in their workcareer in the early 1970's. Thereafter, the evenly advancing career model

${ }^{3}$ This conclusion differs in part from that which John Brennan and Maurice Kogan presented at the 6th CHER Conference. They mention state social services and teaching as a sector in which "university knowledge" would resemble, to a moderate degree, the actual content of jobs. This is certainly the case as concerns the practical side of teacher training. What is stressed here is the theoretical lag of this professional training as compared, e.g., to the scientific basis of medical teaching. 
among men increased until the middle of the decade. From then on, a new type of career model in men began to appear, with an increasing number of breakthroughs or significant rises. Women displayed a relatively greater degree of remaining at the same level or of problematic development. The feverish growth in public services began to fade in the mid-1970's, a situation which was related to the economic crisis in the same period. This slow-down appeared in men as a decelerated rate of promotion; in women, it could even lead to career breaks. Many respondents noted this deceleration in their comments. At the end of the long growth period (1960-1976), they found themselves in a new mental situation, which was also manifested in the observable rise in security values in 1982-1983.

Both individual factors, such as gender or the field of study, and the social development during the period influenced the mode of career transition. These factors could be analyzed better when we inspected the different types of transition that these basic groups displayed. To do this, we analyzed the successions of the threeyear periods which were coded from the annual table. All possible successions were prearranged by means of a sequential analysis programme which revealed certain indicative concentrations (e.g., "steady state" 1965-1971, "considerable rise" 1972-1975, "steady rise" 1976-1979, "problems or fragmentation" 1980-1982). The dispersion of various types of succession could be reduced by combining the rare types with adjoining major types. The con- secutive models of career development formed a typology depicting major combinations of career phases between 1965 and 1983:

1. Problematic type: stagnation or regression in several periods.

2. Early rise: followed by an evening out (a common model for salaried professions, such as physicians, upper secondary school teachers, etc.).

3. Late rise: uncertain phase followed by late steady rise.

4. Problems followed by a significant rise: "From difficulties to success".

5. Sharp rise or breakthroughs in more than one period: "The continuous success model".

6. Slight rise, but in several periods.

Figure 4 (p. 72) illustrates the distribution of these career patterns among the different basic groups. The sharp rise is common among males in the field of science or administration, whilst female respondents more frequently display the model of gradual advancement. Excluding the élite quarter, the model of problematic or stagnated development is more evident in women. Among women, only the élite displayed a higher proportion of rising career advancement. More than half the women scholars demonstrated at least a "steady rise" throughout the 1970's, and in the artistic élite, the women were more likely to show a rising career model than the men. Thus, it seems that a postgraduate degree or a free-lance career offers women the chance of avoiding the 
Figure 4. Modes of career development 1965 (1970)-1982 among the élite, sub-élite and semi-academics, by gender (M.W)

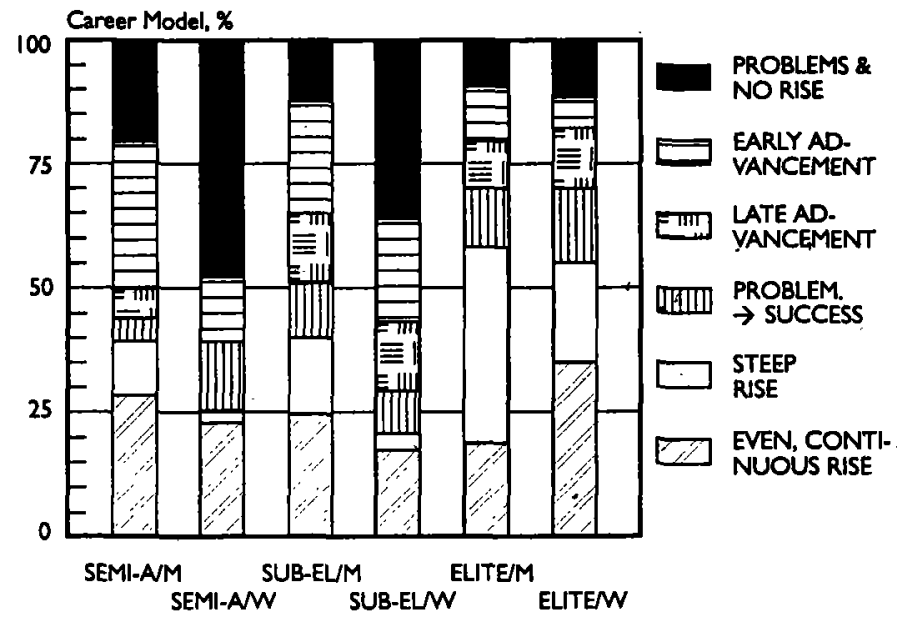

simple service tàsks whìch are common in the jobs of the sub-élite and the semi-professional fraction.

The results of the life-line analysis supported the picture of gender-related career models presented above (Figure 5). Instead of growth or decline, the typology of life-line data depicted the alternation of family and profession during the work career and the transition from education to work. Most typical of this academic population was the direct transition from full-time university training to full-time professional work. This type comprised a clearly greater proportion of men than women, and the model was especially typical of men who entered such classical professions as medicine, law, or theology. The women's life-structure showed two different models of fragmented or interrupted occupational transition. One which was linked to the family and to child-rearing was often intertwined with periods of part-time study. The second was coloured by a labour market situation peculiar to women: women were often placed in jobs where temporal work-relationships interfered with their career routes.

\section{THE PERSONAL VALUE OF UNIVERSITY STUDIES}

We have not yet discussed the explicit impact of university studies on the social life-trajectory. What do people in different parts of the educated intelligentsia believe they have gained from their university education? For many students, admission to their desired field of study, not the content of the curriculum itself, largely resolved their subsequent trajectories. Another factor was the formal competencies gained through university graduations. As noted in Figure 
Yrjö-Paavo HÄYRYNEN with Liisa HÄYRYNEN

Figure 5. Models of life-transition on the basis of the time-line (Age 18-38). ACS Total sample $n=792$
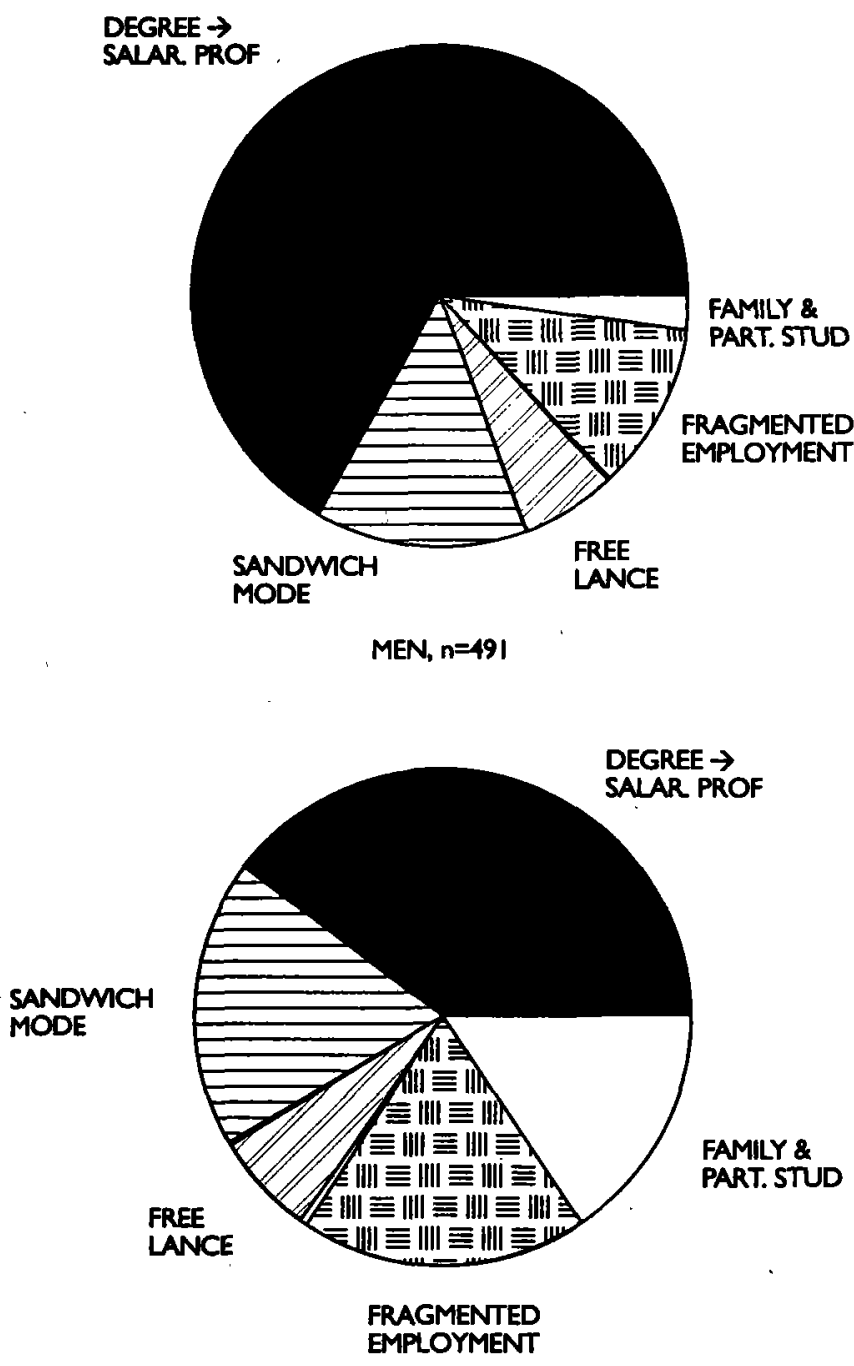

WOMEN, $\mathrm{N}=301$ 
6 , the bulk of our subjects felt that their university degrees formed the basis for their later professional lives, which in fact was true even when the curriculum had several weaknesses.

Figure 6. Evaluation of the value of one's studies 10-13 years later. Classification of open responses 1982-83 'élite' vs 'sub-élite' (men and women)

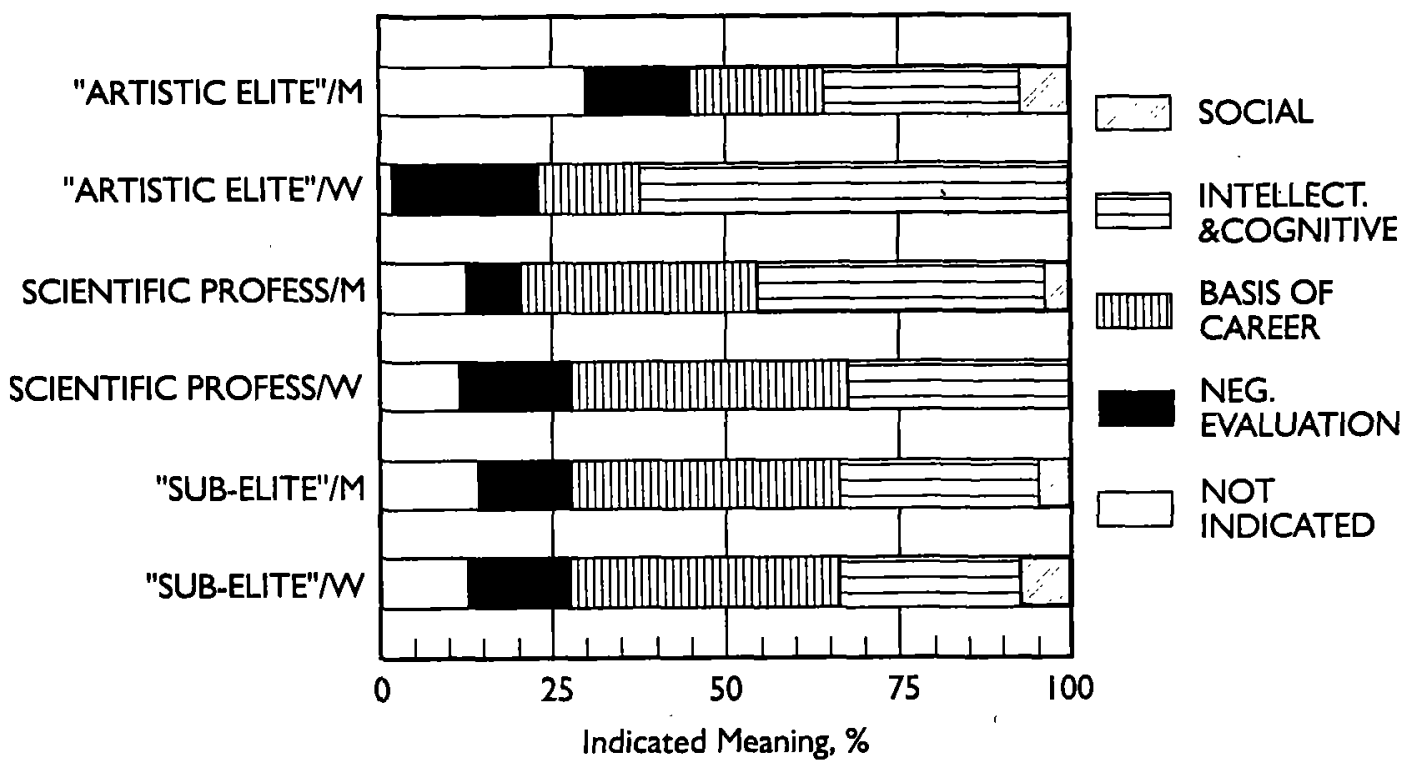

We should also note that one's personal impressions of university study are always coloured by one's inclination to compare oneself simultaneously with different reference groups: the status of one's own family, the most successful part of the academic intelligentsia, and the general standard of one's own subgroup, be these others upper secondary school teachers, university professors, or intellectuals. The patterns of rise or stagnation during the life-course have their own impact on these personal impressions (cf.,
Bourdieu, 1984). For example, students who failed the entrance examination often seemed to compare themselves later with those who were successful, even though they might nevertheless have better social positions than their parents had. This characteristic depends on how fervently they thought of themselves as future members of the academic élite and how deep the consequent frustration was. Many respondents commented in the 1982-1983 survey on the admission procedure in which they had participated eighteen years 
earlier, e.g., questioning its criteria. This reaction indicates that the admissions procedure was a key personal event for many, sufficiently serious to be processed several years later (on the impact of university admission on the later time structure of students see Y.-P. Häyrynen, 1986).

We shall end this discussion of university impact with some final words about the subjects of study. What did respondents regard as the most significant aspect of attending a university? The 1982-1983 follow-up included an open-ended question: "How would you evaluate the value of your studies - the most important thing or personal experience?" In the qualitative analysis, five classes of responses were established (Figure $6)$. The first class comprised responses expressing a negative attitude towards the university: "no value at all", "not relevant in this job." Often the negative judgments were associated with complaints about the abstractness of "university knowledge" which could not be used in practical social or organizational work.

However, the bulk related the significance of their university studies to attaining professional competence (Figure 6). The achieved expertise symbolizes, for them, the gained professional capital: "without this degree I would not be what I am" (lawyer); "a strong ground for mastering professional problems, such as cultivating a big farm" (MSc in agriculture). A third group was composed of descriptions of the cognitive capital absorbed from the university: "an analyzing mind, not relying on memory" (lawyer); "physical and mathematic thinking" (re- search scientists); "a theoretical way of reasoning" (PhD in medicine). A fourth major type of answer stressed the impact of the university in developing one's general world-outlook: "a widening of perspective"; "a good general education", etc. This group included a variety of responses, widely termed as the acquisition of intellectual capital group. The last group of descriptions was related to the impact on personal development: maturation or the gaining of independence and initiative during one's student years. This quite narrow group indicates the developmental impact of studies (it was chiefly stressed by persons with organizational, religious, or social service duties).

Thus, the accumulation of professional capital explained the largest proportion of the personal value of one's university studies. This explanation underlines the central role of the university in training the technical and professional intelligentsia. The proportion of answers stressing acquisition of cognitive or intellectual capital was highest in the elite fraction. The impact of university teaching on personal cultivation was most often mentioned by the mem. bers of the artistic élite, while 40 percent of the PhD's in our sample stressed the cognitive value of studies as the most important benefit of university education. Either these members of the academic profession have indeed been influenced by the intellectual virtues of university teaching, or they may wish to underline the value of the theoretical thinking on which their present social positions rely. As for the negative 
comments, the culturally productive respondents often complained about a lack of creativity in their university studies, while the members of the social intelligentsia and the semiacademic group were likely to underline the occupational irrelevance of their university education.

\section{CONCLUDING REMARKS}

In general, the impact of the university seems to be mediated through a complex system of life outcomes and original experiences. It is the whole social trajectory, including the early family influences, the process of school-to-university transition and the later place in the academic professional field, which defines the final outcome of university education.

Our findings showed that the groups favoured by the university of the 1960's were men, especially those with high cultural capital, and students displaying a good linguistic and conceptual capacity in upper secondary school: both women and men. However, a high degree of inherited cultural capital, connected to a strong personal orientation toward creativity, could generate a distaste for the academic profession, as was the case with some female subjects in our study. Our respondents judged the university's ability, in 1969 , to increase creative capacity to be very low. In its typical form, the Finnish university does not seem to teach "distinctions" nor does it seem to transmit cultural capital to students who cannot obtain it from some other source. But what the university apparently can do is to offer rational, cognitive explanations for different states of the world - still the only in- stitution in society capable of doing so, states Josef Langer (1989). With regard to this task, the Finnish university of the 1960's had the most secure basis; it mediated professional and cognitive knowledge to those who appreciated and needed this kind of knowledge. The problem was that systematic cognitive explanations were only employed in a limited sector of professional work, in medical, juridical, research occupations, and even in theology, in which the relationship between university education and professional cognitive competence seems to be most secure.

A gap exists between the everyday duties and the university knowledge provided in the sphere of the caring occupations which represents the female sector of the sub-élite. Women who work with other people - let us recall that their proportion of contact tasks is in most occupations higher than that of men - consider their duties to be challenging. But they often complain about the lack of autonomy in their work, The cognitive and social impact of university education could be amplified enormously if the degree of autonomy were larger in these academic jobs.

Current higher education policy appears to emphasize the professional function of the university at the cost of its intellectual or cultural function. This is related in part to the doctrine of budgeting and management, which stresses the estimation of visible and short-term results. It seems that this type of ideology easily and implicitly favours the meritocratic notion of career as well. However, the cultural effects of 
university education should similarly be taken into account when estimating the impact of the university. But doing so would require a study of the longlasting effects, for which the trajectory model outlined in this paper is one methodological alternative.

The meritocratic model of career characterized by the unidimensional criteria for occupational success, such as status, income, or organizational authority - belongs to the epoch of "simple modernism"; die einfache Modernisierung in the terms used by the German sociologist, Ulrich Beck. In a post-industrial, increasingly international, culturally diverse society it probably cannot remain the dominant paradigm. In the new situation, the potentials of many presently marginalized groups women, the sub-élite, intellectuals may play the main role; they represent those reserves of communicative and inventive talent which are unused in the meritocratic model ( $c f .$, Y.-P. Häyrynen, 1991).

\section{REFERENCES}

BOURDIEU, Pierre, Distinction: A social Critique of the Judgement of Taste, Original in French, 1979, (London, Melbourne, and, Henley: Routledge and Kegan Paul, 1984).

BOURDIEU, Pierre, The Logic of Practice (Le Sens pratique, 1980), Translated by Richard Nice, (Cambridge: Polity Press, 1990).

BOURDIEU, Pierre, Homo Academicus, Original in French, 1984, Translated by Peter Collier (Cambridge: Polity Press, 1988).

ELGQUIST-SALTZMAN, Inga, Annika FORSSLUND, Keiko SAMPEI, and Margareta SJÖSTRÖM, "The Life-History Approach - A Tool in Establishing North-South Education Research
Co-operation", Arbetsrapporter från Pedagogiska Institutionen Umeå Universilet, 32 (1986).

EIZIONI-HALEVY, Eva, The Knowledge Elite and the Fallure of Prophecy, Controversies in Sociology 18 (New York: George Allen and Unwin, 1985).

HARKER, Richard, Cheleen MAHAR, and Chris WALKER, An Introduction to the Work of Plerre Bourdieu: The Practice of Theory (London: MacMillan, 1990).

HÄYRYNEN, Liisa, Women in the Changing Medical Profession in Finland - A Longitudinal Study of 34 Female Physicians, Paper read in the International Congress on History of Science, 31 July-8 August, 1985, Berkeley, California, USA.

HÄYRYNEN, Y.P., "The Flow of New Students to Different University Fields: Educational Choice, Career Motivation, and the Discriminating Effects of University Admission", Annals of the Finnish Academy of Sciences and Letters, B 168 (1970)

HÄYRYNEN, Y. P. "Academic Careers Study 1965-1983: Account of Life-Course", Reports from the Institute for Educational Research, University of Jyväskylä, 364 (1985).

HÄYRYNEN, Y. P., "The Finnish University from 1965 to 1985: Expansion as Reflected in the Subsequent Life Patterns of University Entrants", European Journal of Education 21 (1986): 25-41.

HÄYRYNEN, Y.P., "Les Déterminants sociaux des valeurs et des intérêts des jeunes au cours de la période post-industrielle, Translated by Serge Blanchard, L'Orientation Scolnire et Professionelle 20 (1991): 357-376.

IIOLLAND, J. L., The Psychology or Occupational Choice (Waltham, Massachusetts: Blaisdell, 1966).

LANGER, Josef, Bewusstseinsentwicklung der Studenten und die gesellschaftlichen Funktionen der Universität (Frankfurt-am-Main: Verlag Peter Lang, 1989).

MAANEN, John Van, Organizational Careers: Some New Perspectives (London, New York, Sidney, and Toronto: John Wiley and Sons, 1977).

SPILERMAN, S., "Carers, Labor Market Structure, and Socioeconomic Achievement", American Journal of Sociology 83 (1977).

SUPER, D. W. and Paul B. BACHRACH, Scientific Careers and Vocational Development Theory (New York: Teachers College, Columbia University, 1977). 


\section{ACADEMIC DRIFT AND BLURRING OF BOUNDARIES IN SYSTEMS OF HIGHER EDUCATION}

\section{Claudius GELLERT}

A tendency towards academic drift and the blurring of boundaries exists in most differentiated higher education institutions as faculty members, particularly in non-university sector institutions, seek to emulate the research paradigm of universities. As non-university sector institutions perform essential educa-

\section{DEFINITIONS}

In the following, we shall deal with some implications of two related phenomena which in recent years have been of major concern for analysts and policy-makers in higher education. The first of these, academic drift, refers to the discernible tendency of tertiary institutions lower down in the hierarchy of prestige, i.e., of their faculty, to attempt to become like universities. This tendency signifies, above all, a predominance of the research paradigm in institutions of higher learning. Although we are dealing with places of higher education, advanced learning, postgraduate training, and so forth, the emphasis, at least in terms of aspirations, goals, and intended purposes, in most such organizations is typically not on teaching and learning, but on research and scholarship. This em- tional and training roles in meeting the labour requirements of complex developed societies, their specific characteristics and functions 'must be protected. The best way to guarantee protection is to maintain the separate administrative identities of non-university sector institutions and to encourage an ethos favouring such separation.

phasis, in other words, results in constant self-imposed pressure by those in positions of authority to excel through publication and other research activities, often at the expense of the teaching function.

By blurring of boundaries we then understand the corresponding assimilation of institutions, their becoming alike. This process usually occurs through the functional upgrading of lower-level institutions, but sometimes also (at least simultaneously) through attempts by prestigious subsectors of a national system to copy some of the more successful features of the other(s).

\section{EXPANSION AND DIFFERENTIA- TION $^{1}$}

Most European countries, like other advanced western societies, have seen an unprecedented expansion of their institutions of higher education

\footnotetext{
${ }^{1}$ Here, the terms differentiation and diversification are used as synonyms.
} 
over the last quarter of a century, and contrary to many predictions, this process of growth has not yet stopped. In fact, it has gained renewed momentum in several systems. We do not need to consider the reasons behind this development. One aspect, in any case, soon becomes clear, viz. that the traditional homogeneity of higher education structures is going to be replaced by diversified institutional settings. This process of differentiation, which is still continuing, was possibly the most fundamental change in higher education since the introduction of the research function through the German university model. In some countries, first-tier colleges were added to conventional universities, offering their students short-cycle degrees. ${ }^{2}$

The majority of states, however, opted for a different alternative, which was to make additions to the traditional university sector. Such non-university sectors (NUS's) emerged and established themselves as separate segments within higher education systems. In most national systems, they were particularly characterized by three aims and purposes: their institutions were supposed to be practically and vocationally oriented, thus fulfilling the needs of the economy better than the universities were doing; they were meant to offer educational opportunities to formerly disadvantaged social strata, thus improving egalitarianism and democracy within society; and finally, they were expected to be less expensive than traditional universities, thus supporting national governments in their desire to expand their systems of advanced learning. By the end of the 1960's, most European countries had established such NUS's, like the Fachhochschulen in Germany, (until recently) the Polytechnics in the United Kingdom, the IUT's in France, the $H B O$-sector in the Netherlands, and the Regional Colleges in Norway. In most countries they display similar features, which can be summarized as follows:

- shorter duration of course programmes than at universities;

- practical orientation of curricula;

- responsiveness to industry and business;

- limited ranges of subjects, mostly in engineering, business studies, and social work;

- little or only applied research;

- heavy teaching loads for faculty.

By now, these non-university sectors are generally accepted as playing a major role within national systems of higher education.

\footnotetext{
${ }^{2}$ Dorotea FURTH, Short-Cycle IIigher Education: A Search for Identity (Paris, 1973). Italy and $S$ pain are presently experimenting with short-cycle provisions within the university sectors.

${ }^{3}$ This aspect, like some of the others listed below, has not been characteristic of the United Kingdom.

${ }^{4}$ Organization for Economic Co-operation and Development, Alternatives to Universities (Paris: OECD, 1991).
} 


\section{COMPREHENSIVE UNIVERSITIES}

A variation in this process of diversification, although it remained an exception and was not maintained in the long run, should at least be mentioned: the comprehensive universities (Gesamthochschulen) in Germany. They attempted, to some extent, what Italy and Spain are presently aiming at, namely to introduce short professionally qualifying training schemes into established university frameworks. (In France, where short-cycle degree programmes were introduced in the early 1970's, they soon became the first step within larger programmes. These programmes still exist, of course, but they do not confer full professional qualification.) In the Gesamthochschulen, two kinds of degrees could be earned, side by side. The long and normal academic degree, and a shorter, more practically oriented degree, like that earned in a Fachhochschule. And school leavers with varying qualifications were entitled to matriculate in either programme. Another point was important: two kinds of professors coexisted under one roof: the normal, often full university professors, geared to fundamental research, who were highly respected; and the Fachhochschul-professors, with their specific attributes: practical work experience, little or no research, heavy teaching load, hold only lower- and middle-level positions (C2-C3). Naturally, the Fachhochschul-professors felt like second-class faculty, and the pressure in favour of institutional assimilation within the respective tertiary organization became strong.

Therefore, this institutional experiment, which in 1976 (in the Federal Republic of Germany) ${ }^{5}$ was still considered to be the model of future developments, failed for two reasons. The students overwhelmingly opted for the long academic degrees, and there were constant conflicts between the different categories of professors (over salary, prestige, influence, etc.). ${ }^{6}$

\section{ACADEMIC DRIFT AND THE FACHHOCHSCHULEN}

How, then, are the Fachhochschulen managing to cope with their distinct functional definitions and organizational patterns? The success of this reform model, insofar as it can be called successful, is due to a number of features (which distinguish Fachhochschulen not only from the traditional universities, but also from the Gesamthochschulen. The most important ones, in short, are the following:

- they possess a clear curricular and qualification profile;

- they are, all in all, successful in placing their graduates in employment;

\footnotetext{
${ }^{5}$ Hochschulrahmengesestz, Federal Framework Law for Higher Education.

${ }^{6}$ For a complete account of the development of the comprehensive universities in Germany, see R. PRITCHARD, The End of Elitism? The Democratization of the West German University System (New York: Berg, 1990).
} 
both of the above aspects result in high student demand. ${ }^{7}$

But at the same time, the Fachhochschulen are suffering from fairly low prestige, which prevents them from being satisfied with their relative success and merits. In comparison with the university sector, they are characterized by unfavourable working conditions for professors, such as heavy teaching loads, little or no fundamental research, little outside funding, no Mittelbau $^{8}$, no graduate students, lower salaries, scarce travel funds, and only very limited infrastructures (laboratories, equipment, etc.).

It is therefore not surprising that there have been tendencies recently within the Fachhochschul-sector to upgrade its own functions. This effort comprises improvements in the institutional representation in the Rectors' Association and in the German Research Foundation ( $D F G$ ), the idea to extend the range of disciplines offered ${ }^{9}$, the wish to have their graduates accepted for doctoral programmes at universities or, even, to have their own $\mathrm{PhD}$ programmes, or the desire for full professorships (which, so far, only universities possess). These points are all part of a lively but sometimes suppressed debate. Neither the universities nor the Fachhochschulen want to deal with these issues too openly, albeit for different reasons. While the former are not interested in upgrading their potential competitors, the latter are anxious to avoid raising suspicions that they wish to discard their original functions.

\section{SYSTEM INTEGRATION}

Similar developments and tendencies as the ones briefly referred to above can be observed in many higher education systems. Three of the more pronounced examples, which have manifested themselves in the last few years, are mentioned to illuminate the possible institutional consequences involved.

The most prominent model in recent years was, no doubt, the British one. Here, as was referred to above, the binary line between the universities and the main non-university sector, the polytechnics, has collapsed, and the latter have been renamed universities. The following organizational and functional implications seem to have been important in this development:

- little functional distinction was made between the two major higher education sectors, at the beginning, in the 19,60's;

- almost like the universities, the polytechnics had a very broad disciplinary range;

- they, furthermore, also offered graduate programmes, and their

\footnotetext{
${ }^{7}$ Organization for Economic Co-operation and Development, Alternatlves to Universitles in Higher Education: Country Study Federal Republic of Germany (Paris: OECD, 1989).

${ }^{8}$ Teaching assistants, research associates.

${ }^{9}$ Propagated, for instance, by the Wissenschaftsrat in Empfehlungen zur Entwlcklung der Fachhochschulen in den 90er Jahren (Cologne: Wissenschaftsrat, 1991).
} 
undergraduate study periods and qualifications did not substantially differ from those of the universities;

- they were, more than NUS's in other countries, strongly oriented to the traditional research paradigm (including research training);

- all of the above was reinforced by a liberal legal and political framework which allowed for processes of administrative and institutional assimilation;

- the above led to a blurring and ultimately the disappearance of institutional boundaries;

- the overall result is a new hierarchical ordering within the integrated system, with most of the previous universities and some of the former polytechnics in the top group. ${ }^{10}$

A similar development has occurred in Australia, however with a major difference. The impetus of the NUS integration into the university system did not primarily stem from the college sector, but from the government. Through the amalgamation of sectors, the government was hoping to develop a new kind of steering mechanism, because the whole process has been bound up with a strong push towards accountability. ${ }^{11}$ The main policy aim was to achieve system differentiation through research evaluation. Thus the government has in any case succeeded, at least for the time being, in stopping all major processes of academic drift by launching a preemptive strike against differentiation. Whether this system, as the British one, for that matter, can avoid the worldwide predominant movement towards diversification (which, after all, is a response to technological, economic, and other labour market needs), remains to be seen.

Finally, in Greece, Italy, and Spain, we can also observe overall system reactions to pressures of academic drift and blurring of boundaries. These are, however, occurring in two fundamentally different forms. While Greece is roughly following a combined Australian and British example by implementing a government prescribed upgrading of non-university sectors, Italy and Spain are hoping to avoid the politically ambiguous measure of institutional differentiation by creating short-cycle courses within the university system. ${ }^{12}$ While with regard to Greece we may pose the same question as with respect to Australia (i.e., whether or not a quasi-homogeneous

${ }^{10}$ Maurice KOGAN, "The End of the Dual System? The Blurring of Boundaries in the British Tertiary Education System", in C. GELLERt, ed., Higher Education in Europe (London: Kingsley, 1993), pp. 47-58.

11 Ingrid MOSES, "Against the Stream: Australia's Policy of Tertiary Integration", in C. GELLERT, ed., lligher Education in Europe (London: Kingsley, 1993), pp. 218-233.

12 Roberto MOSCATI, "Intended and Real Changes in Italy's Higher Education System: The Case of Engineering and Economics", in C. GELLERT, ed., Innovation and Adaptation in IIigher Education (London: Kingsley, 1993). 
higher education system can adequately react to the functional requirements of highly complex industrialized societies), Italy and Spain will be interesting experiments of a different kind. For if we take the German comprehensive universities as the most prominent example, it seems that functional differentiation under one institutional roof is very hard to maintain.

\section{OPEN QUESTIONS AND CONCLUSIONS}

We are thus left with a number of open and difficult questions. First of all, is there, in international comparison, a discernable general trend? What is more paradigmatic: the developments in the United Kingdom, Australia, and Greece, the reforms in Italy and Spain, or the massive models of the USA and Japan and the mainstream developments in continental Europe (like in the Netherlands, in Norway, in Germany, in France, and now, just emerging, in Austria)? The quantitative dimensions speak in favour of diversification. But historically speaking, some of the most important and paradigmatic innovations (like the research and personality functions) have initially been minority positions. The examples of the United Kingdom and Australia are in any case irritating. Is there perhaps an unavoidable tendency in academic institutions to attempt to copy the research paradigm of universities? Can academic drift and the blurring of boundaries be at all avoided? Do we wish to avoid them? And if so, under what conditions? A few tentative answers are offered in the lines that follow.

First, it is unlikely that an overall and unilinear trend exists. Distinctive national traditions and mentalities play a major role. They determine to a large extent the value frame of reference for higher education policies. National character has particular consequences in two interrelated areas being responsible for the degree of acceptance of individual and social differences and therefore also of institutional differentiation, and, vice versa, for the degree of state/government orientation, respectively. The USA and Germany are perhaps good examples of two rather opposed variations of national character and the consequences for the respective higher education systems.

Second, the main motive or reason for differentiation in higher education is the emergence of new functions (tasks) which are expected by society (i.e., by individual consumers/students, by industry, by the employment system in general, and by the state). The development which followed the Second World War has shown that functional differentiation can best be achieved with institutional differentiation. Other models have either failed (e.g. the Gesamthochschulen), or have not gained distinctiveness within systems (like short-cycle provisions in France), or will still have to prove their

\footnotetext{
${ }^{13}$ See, for instance, C. GELLERT, Wettbewerb und Leistungsorientierung Im amerikanischen Universitätssystem (Frankfurt: Lang, 1993).
} 
viability (like the Spanish and Italian reform experiments). The latter examples (Spain and Italy) are probably the least likely to succeed, as was pointed out above. ${ }^{14}$

Third, it is possible to argue that functional differentiation can occur within a unified system like in the United Kingdom, that there can be a constantly restructured hierarchy, based on differentiated access to research funds, etc. This policy ideal probably also holds sway in Australia. But it remains to be seen whether or not the expectations that one subsector (in the United Kingdom, mainly the former polytechnics) will continue to provide practical professional training and that in reality a functional differentiation can be preserved. One can probably expect that the pressure of faculty to receive equal treatment in terms of research funding, equipment etc., (at least in some selected areas) will increase. And then an internal blurring of boun- daries (within the newly unified system) will be the result.

Fourth, if, however, it should emerge that only a functionally and institutionally differentiated system is able in the long-run to provide the manifold qualifications required in modern societies, then at least the following preconditions must be given. In addition to the general public acceptance of differences in quality and prestige, there must also exist a high degree of legitimacy of functional differentiation within and outside academic institutions themselves. This consensus, moreover, has to be stabilized by political and administrative measures, i.e., by some form of government legislation. In some systems, however, particularly in most Anglo-American models, a relatively strong internalized set of values seems to prevail within the academic community itself which is able to bring about, informally, the same organizational features.

${ }^{14} \mathrm{Cf}$. also Andrea Orsi BATTAGLINI and C. GELLERT, "International Developments of the University within the Research System", In C. GELLERT, ed., The Future of European Higher Education: Funclional Changes and Analytic Dimensions (Frankfurt: Lang, 1993). 


\section{THE EXPANSION OF EDUCATION IN EASTERN EUROPE: A REGIONAL VIEW}

\section{Tamas KOZMA}

might adopt a massification scenario even in the face of financial restrictions. The higher education of Subregion B (territories with non-state education) might follow an élitist scenario in the course of higher education development according to which the autonomy of institutions and the privatization of systems would become major political issues.

\section{INTRODUCTION}

The expansion of education was one of the leading subjects in the relevant literature in the 1970's and the early 1980's. Authors and researchers have reacted strongly to expansionist policy decisions which have been justified more on political than on social or even educational grounds. Those were the times that Cerych and Sabatier (1986) called the period of "great expectations and mixed performances". In his classic study, Martin Trow (1974) developed a pattern according to which one could measure the level of massification of higher education. The "retrenchment" (Frackmann, 1988; Acherman, 1988) which has followed the expansionist decade has been described as a period of consolidation (Neave, 1985).

So many overviews and comparative analyses of European higher education systems, however, seem to omit the eastern part of the continent

(Eurich, 1981; Teichler, 1988; Gellert, 1992). The picture given is therefore incomplete and fractionated, in part because the authors might not have been able to obtain relevant data. There was (and still is) a need for a common frame of reference within which eastern and western policies can be analysed.

Such a frame of reference could be the regional analysis of supply of and demand for higher education throughout the continent. Kim and Brandell (1990) have correctly identified demography as an important element of regional analysis. If ordered according to geographical clusters, the data on changing demands for higher education display a continuum which can be used as an element of East-West comparison. The second element of comparison might be those policy decisions which reacted to the growing demand in question. Teichler's comparison (1988) is a good introduction which could be followed by 
an analysis of eastern European policy decisions. The following pages are an attempt to initiate such EastWest comparisons.

The expansionist policies with regard to higher education gave rise to special college and university organizations and required spatial analyses and regional planning (Bahrenberg, 1974). The use of human and social geography as a tool for these analyses is apparent in the literature on higher education published during the decade of expansion (Höfle, 1984). However, none of this literature dealt with eastern Europe. One of the aims of this paper is to demonstrate the possibilities of such an analysis using data from eastern and central Europe.

The expansion of higher education systems in eastern Europe is not separable from general European expansionist trends. It resembles the pattern of western European expansion as well as its dilemmas. Although the eastern part of Europe has a different type of history from the rest of the continent, it can only be properly interpreted in European terms.

This article has three sections:

- a short analysis of the nature of educational expansion which has, as mentioned, essential similarities both in eastern and western Europe;

- a presentation of the unique features of the expansion of higher education in eastern Europe, taking into account variations both in its history and its subregions;
- policy scenarios on the basis of which alternative higher education developments might be suggested for governments which compete for European harmonization and consider that expansion is the only possible policy for the future development of their higher education systems.

\section{THE PROBLEM}

The expansion of higher education is part of the wider process of educational expansion. Evident as this fact is, studies of all the stages of education seem to miss it. One cannot understand the scenario of higher education expansion without knowing more about the growing demand for education, one which exceeds formal needs in terms of educational stages and views education as a consumer good. As such, education consists of at least three stages or types, all of which are undergoing increasing social prestige and political importance. One cannot understand the expansion of higher education without being aware of the causes of educational expansion at elementary and later at secondary levels.

In his time series, J. Craig (19891990) collected statistics on several European education systems. A comparison of the data indicates a special European pattern: the steady growth of enrollment in each and every education system. Using a cartographical technique for data representation, Craig portrayed special tendencies throughout the continent in a way which separated centres of educational expansion from peripheral areas, the systems of 
which expanded at a later date. (The same method of analysis has been applied to various studies of innovation and social change. See, for example, Morokvasic, "Migration in Europe", 1984, and Cooke, Morgan, and Jackson, "New Technology and Regional Development in Austerity: Britain, the Case of the Semiconductor Industry", 1984.)

Figure 1 represents graphically the growing supply and demand characteristics of certain European education systems. It shows (a) that at a certain point, these systems enrolled different percentages of an age cohort from the given society; and therefore (b) that a state of mass education was reached at different points in time. Yet, a closer look at the various curves indicates background similarities. All the curves have the same shape (S-curve with a period of stagnation interrupted by the first point of inflexion, followed by a period of rapid growth, completed by a second point of inflexion and a new period of stagnation). The $S$-curve is always the representation of a special pattern of dissemination according to which the initial phase is slow but is followed by a rapid change dissemination and stagnation at a higher level. The changing social behaviour of schooling can always be described according to this pattern. (Figure 2 is a representation of the growing demand for and the expansion of secondary education in one eastern European country: Hungary, between 1955 and 1980.)

The unusual character of educational expansion comes from the fact that the top level of supply and demand at one stage is the initial level of growing supply and demand at a coming stage. For example, reaching the top level of elementary schooling in a given society is the precondition for the growing demand for secondary schooling, albeit during a period of stagnation. The S-curve, therefore, can be used not only to represent the expansion of elementary or secondary education but also to portray the sequences by which each stage of schooling prepares for the next stage. Mass elementary education is a precondition for the expansion of the demand for secondary education, and universal secondary education creates a growing interest in higher education. Educational expansion at every level follows a similar pattern. It can, therefore, be portrayed by S-curves. One can conclude that the European country education systems are following similar lines of expansion.

The unexpected similarities in the patterns of educational expansion can be explained in a number of ways. However, it is particularly important to understand the reasons for shifts from periods of stagnation to periods of rapid growth. The statistics can be interpreted so as to yield information about the changing patterns of behaviour of various actors in the educational systems (politicians, teachers, students, parents, employers, etc.).

Given below, in particular, are explanations concentrating on the reactions of parents and students:

- Educational expansion was an element in the period of national economic reconstruction which followed the Second World War. 
Figure 1. The development of secondary schooling 1930-1970

COUNTRIES

U.S.A.

Sweden

Great Britain

Japan

Norway

France

Denmark

German, Federal Republic of

Italy

Austria

German

Democratic

Republic

Czechoslovakia
STUDENTS IN SECONDARY EDUCATION

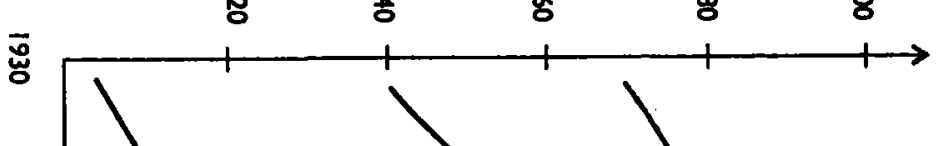

8

$8 \quad \overline{8}$

:

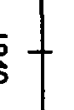

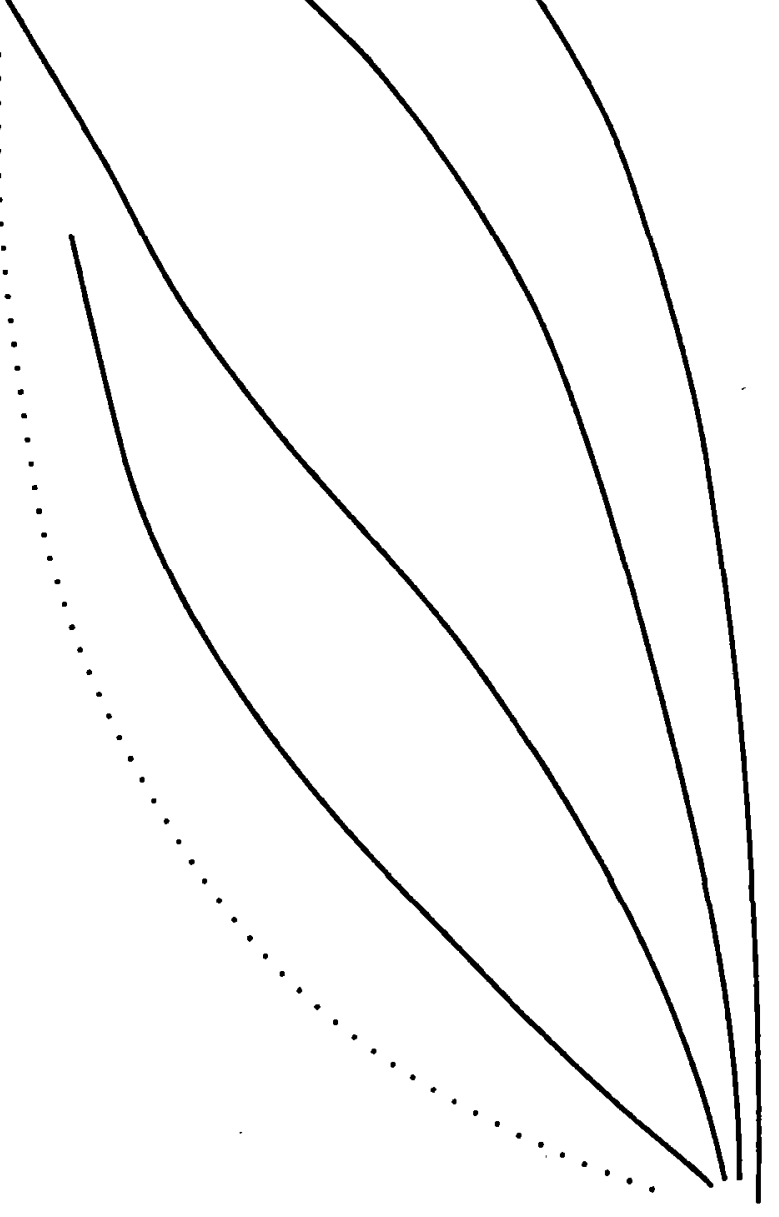

Spain

Poland 
Figure 2. The number of secondary school students according to age

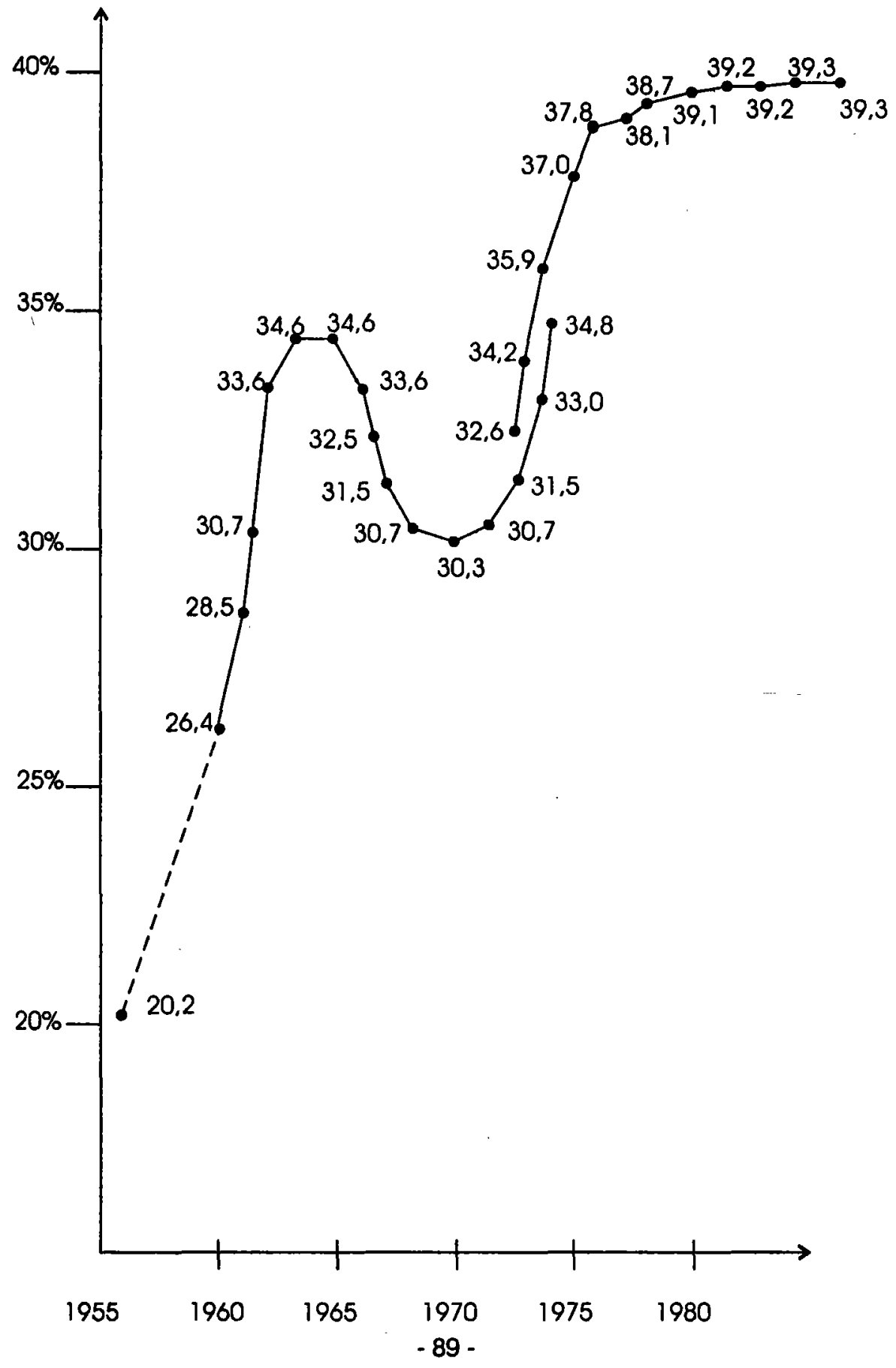


A rapid expansion of production was followed by a rapid period of consumption, which included a growing demand for education.

- Educational expansion after the Second World War created an element of democratization in each education system, especially in the 1950's and 1960's. This growing supply initiated a growing demand on the part of parents and students. Some countries also experienced a growing birthrate after the war.

- At the end of the 1950's and the beginning of the 1960's, educational expansion became a policy reaction to growing youth unemployment, the latter being the result of structural changes in the European economies as they moved into a new phase of technological change.

- Educational expansion was also the result of the appearance of new minority groups in the national political arenas and educational systems; in the 1960 's, new groups of women entered the systems, contributing to educational booms.

- Educational expansion as a phenomenon occurs independently of social, political, and educational systems. The growing demand for schooling is a cultural pattern which is inherited over generations. If the parents obtained elementary education, they required at least the same level of education, or higher levels, for their children. A certain shift in the demand for education occurs from generation to generation, growing ac- cording to the expanding number of graduates of successive levels of schooling.

- Educational expansion is the outcome of the expansion of middle class societies throughout Europe. According to the value patterns of this class, education is a consumer good which is highly valued. The expansion of middle class society is therefore accom. panied by a growing demand for schooling which, in turn, may explain the changing behaviour of political decision-makers. The stagnation or retrenchment of the middle classes during the 1980's may also explain the end of expansionist education policies.

All of the explanations listed above have their pros and cons. Perhaps the most reliable answer to the question of educational expansion is that it is a complex social phenomenon. The various explanations have varying validity according to historical periods and different socio-economic and cultural-political settings. At least one (but usually more than one) social change effects educational systems which display basic similarities in their expansion throughout Europe.

\section{THE PHENOMENA}

The above section has presented arguments in favour of the similarities of educational expansion in Europe, irrespective of political system. Turning specifically to eastern Europe, the statistical evidence indicates that the demand for higher education has been growing in this subregion. It has occurred, however, during different periods than in the West and has 
therefore been the object of different types of political decisions.

Figure 3 presents comparative data on the expansion of higher education between 1950 and 1990 . Two sets of countries are represented: The Netherlands, Denmark, Italy, and the United Kingdom which are Member States of the European Communities and Poland, Czechoslovakia, Hungary, and Romania which were members of the Soviet bloc. The following conclusions can be drawn:

- At the end of the 1980's, the EC countries were far ahead of the former Soviet bloc countries in terms of their student ratios per 100,000 inhabitants. The ratios of students in the EC countries were 2 to 3 percent, while in the eastern part of Europe, 0.7 to 1.2 percent. The EC countries resemble one another more than they do any of the former Soviet bloc countries, and vice versa.

- In spite of these striking differences, basic similarities exist in the nature of higher education expansion in the two subregions which are particularly evident with regard to initial periods of expansion (the early 1950's) when all the European countries had more or less the same ratios of students.

- The differences between rates of higher education expansion began between 1955 and 1965 . That decade was a period of rapid growth everywhere (as represented by points of inflexion in the S-curve of every country). From that time on, EC country statistics indicate steady and rapid growth, while the Soviet bloc countries experienced a first and early "retrenchment", sometime between 1965 and 1970 (in Czechoslovakia and Hungary, in particular) and a second one between 1975 and 1985 (in Poland and Czechoslovakia, in particular). Instead of moving into a period of growth, eastern Europe remained in a period of stagnation. The country curves display similarities between the situations in the eastern European countries and those in the EC countries. They also suggest that eastern Europe is poised to enter a period of rapid expansion of higher education.

For purposes of further discussion, two subregions are postulated: $S u b$ region $A$ consisting of territories in which education has long been established and is controlled by the state (central government) and Subregion $B$ consisting of territories with nonstate education.

In the territories of Subregion A, elementary education was required and sanctioned by administrative means. These territories also have a tradition of secondary education going back over two centuries. During this period, middle classes were established and social demand for higher education grew apace. In these areas, higher education systems are facing growing numbers of applicants. The social and political élites incorporated education into their value systems making it a commodity competitive with others. Here both the social demands and the political powers of the middle classes 
A REGIONAL VIEW

Figure 3. The ratio of students per 100,000 inhabitants

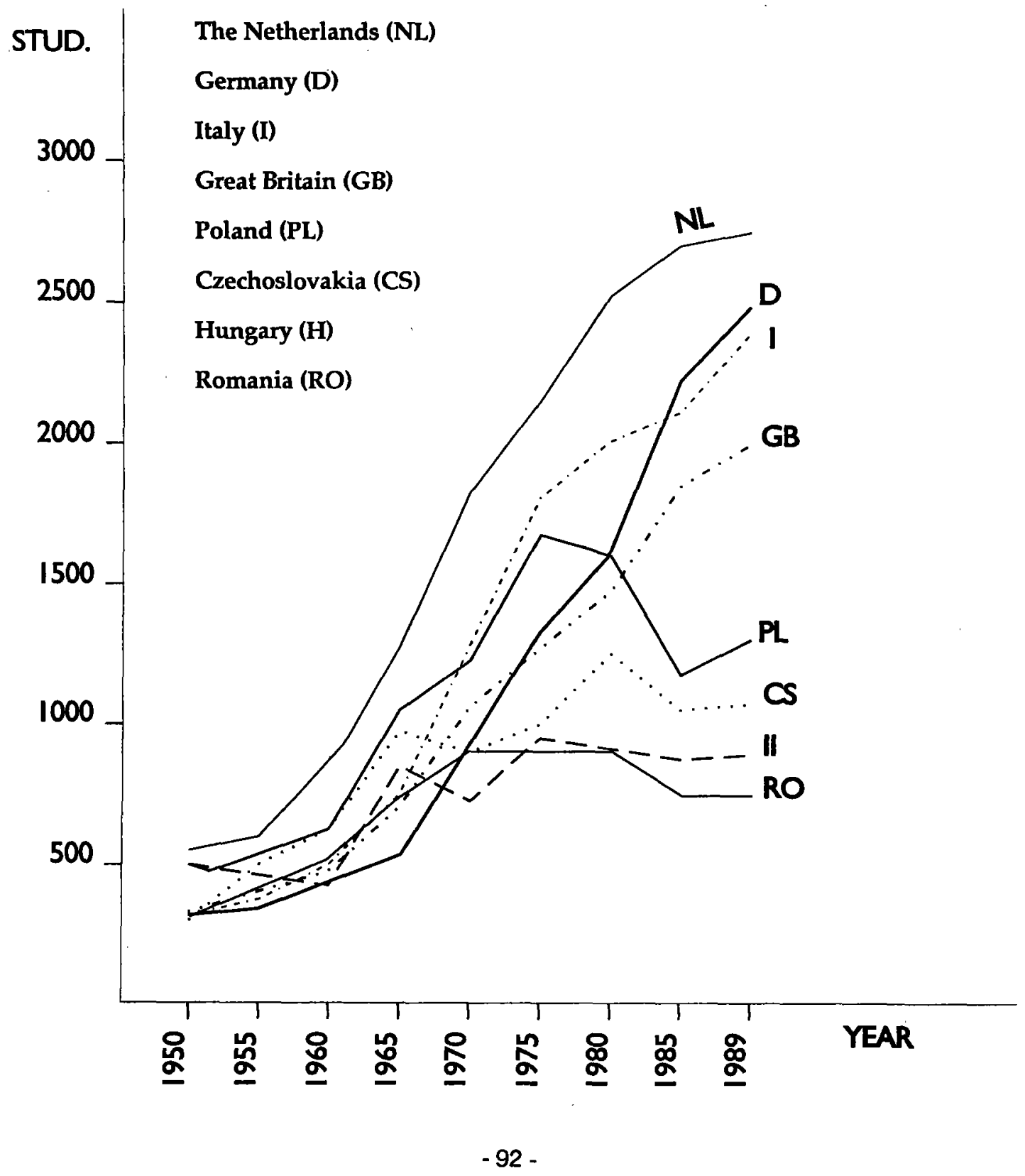


are strong enough to force the expansion of higher education even in the face of financial restrictions and welfare state retrenchment.

Subregion A, as applied to eastern Europe, consists of the Nordic areas (Finland and the Baltic republics), parts of present-day Poland, Bohemia, Slovakia, Hungary, Slovenia, Croatia, Vojvodina (Serbia), Transylvania (Romania), parts of Greece, the European part of Turkey, and includes Lebanon and Israel. It would be easier to speak of specific countries if the present borders had been stable for centuries, but they were not. Instead, various central governments influenced these territories, integrating them into larger European units (like Sweden, Prussia, and Austria). The eastern part of Europe still shows clear signs of that historical tradition as represented by new waves of conservatism or minority group movements.

As for the territories of Subregion $B$, they were organized and controlled administratively by new central governments only a century ago. The Balkans were completely separated from the Ottoman Empire only towards the end of the nineteenth century. Parts of Poland as well as the Baltic republics were under Russian control time and again from the seventeenth century up until very recently. Countries and states, like present-day Moldova and the Ukraine, Albania, present-day Bulgaria, and Bosnia-Hercegovina only came into being following decisive wars.

Educational developments began a century later in these territories. Their secondary schooling was still being reorganized in recent decades. Either their middle classes could not gain political power, or if they did, they did not include higher education among their social and political priorities. Here, general secondary schooling is still a priority for the respective administrations.

In Subregion B, higher education serves a role of enlightened flagship a place where intellectuals may gather, gain power, and make their own decisions. The autonomy of higher education is a political goal of intellectuals in these areas, and state control over higher education institutions is more a political than an administrative objective for policy makers.

\section{PERSPECTIVES}

Following the changes of 1989-1990, most of the new governments of the region made efforts to reformulate their policies with regard to higher education. Documents have been prepared with the stated aim of initiating long-term policies and the hidden objectives of influencing budget negotiations. Two powerful arguments refer to the increase in student numbers and to the promise and hope that the costs of higher education can be kept at a rather low level. The usual proposal is that a so-called European university should be relatively large in terms of size and be multifunctional with regard to its programmes (organization).

A proper means to achieve the latter end is the setting up of a universitas system.

The idea of universitas is known to the international community under 
the names of Gesamthochschule (Germany), polytechnics (UK), regional universities (Nordic countries), and community colleges (in its Canadian interpretation). In various discussions initiated both by governments and by institutional administrations, the universitas concept has been viewed as the prime vehicle for the promotion of institutional integration, serving the latter objective in three ways:

- entitling the university of a region (administrative district or geographical territory) to control higher education programmes by defining its own role so as to leave room for additional institutions;

- supporting university associations as well as assimilating colleges of the given region; and/or

- enabling universities to coordinate the research institutions of the Academies of Sciences of the given countries (and other research organizations) available in the region (district, territory).

The idea is known to specialists in elementary and secondary education who witnessed or were affected by the great wave of institutional integration which came at the turn of the 1950's and 1960's in most European countries. This wave produced the Gesamthochschule in the Federal Republic of Germany and the comprehensive school in the United Kingdom, the nine-year basic and comprehensive education institutions in Scandinavia and, mutatis mutandis, the eight-year general schools in most eastern European states, not to omit the the ten-year polytechnic secondary education in the former Soviet Union (as well as in the former German Democratic Republic). The documents mentioned (with the idea of institutional integration) leave space for further policy interpretations.

A reconsideration of the needs of higher education in eastern Europe may give rise, theoretically, to two alternative policy scenarios for the development of higher education. The first scenario would keep the access rate at the same level while increasing (and decreasing) student numbers according to future demographic requirements. According to OECD statistics, such a scenario would mean the maintenance of higher education as an essentially élitist system. The political benefit of an élitist scenario is that it retains higher education as an attraction and hope for a middle class society. The economic benefit of the scenario is more apparent. It would provide for institutional maintenance, equipment, and facilities, at a time of economic crisis and reconstruction.

The alternative scenario, Scenario $B$, assumes a rapid increase of students both in terms of absolute numbers and of ratios. Since higher education expansion is unavoidable in the European context, the sooner the better may be a good argument for it. Scenario B therefore represents an expansionist policy alternative for the development of higher education.

The problem with the present views of universitas is not their diversity but their inconsistencies. The 
documents available would apply both scenarios at the same time. The élitist scenario requires the maintenance of dual higher education sectors for a relatively long period, the concentration of efforts on flagship universities, the setting up of quality programmes right from the start, and the like. The expansionist scenario, on the other hand, would lead politicians into establishing new universities (without concentrating them); upgrading lower level institutions in remote regions; creating a training form of $3+2(4+2$ or $3+$ 3 ) according to which introductory courses might gradually become universal, both with regard to curricula and to attendance.

\section{RECOMMENDATIONS}

As the universitas concept may not be applicable in the same ways in each and every part of the subregion, a rapid increase in student numbers as an official policy may not be apparent everywhere in eastern Europe today.

i. As a general development policy, a differentiation by subregion (a northwesternsoutheastern axis) is recommended. Policies of expansion might be adapted and would be applicable only in subregions in which the ratio of secondary school graduates had passed a critical level.

ii. Most policy initiations follow projections of growth in social demand. Clear competition among the governments of the region with regard to catching $u p$ with western Europe is taking place. An aspect of this competition is the more rapid expansion of higher education in certain countries than in others. In the long run, however, the governments which will win this contest are those which do not change the current status of higher education in their countries. Such a policy gives governments a free hand in improving equipment, facilities, and programmes over the next few years.

iii. In those countries in which the rate of graduation from secondary education is at least 60 percent, an upgrading of higher education institutions is highly recommended. Appropriate upgrading would include the establishment of new universities (both in the form of universitas or in their traditional forms of organization) on the basis of already existing higher education institutions.

iv. The experience of secondary school development suggests that general introductory courses at the post-secondary level ( 2 - 3 years) should be established in the next few years all over eastern Europe. In the cases of governments which do not give in to social demands for higher education, unexpected forms of it will come into existence (private higher education sectors in Bulgaria and Romania; county, "district", or "urban" colleges in Hungary and in Slovakia; and church higher education sectors in Poland, Hungary, and Romania). 


\section{REFERENCES}

ACHERMAN, H. A., "Selective Retrenchment and Growth in The Netherlands", International Journal of Institutional Management in Higher Education 121 (1988): 41-48.

BAHRENBERG, G., Zur Frage Optimaler Standorte von Gesamthochschulen in Nordrhein. Westfalen (Bonn: Erdkunde, 1974).

CERYCH, L., and P. SABATIER, Great Expectations and Mixed Performance: IIigher Education Reforms in Europe (Paris: European Institute of Education and Social Policy, 1986).

COOKE, Ph., K. MORGAN, and D. JACKSON, "New Technology and Regional Development in Austerity: Britain, the Case of the Semiconductor Industry", Regional Studies 4 (1984): 277-278.

EURICH, N. P., Systems of Higher Education in 12 Countries: A Comparative View (London: Holt Saunders, 1981).

FRACKMANN, E., "Steering under Conditions of Retrenchment in Higher Education: The British Experience from a German Perspective", International Journal of Institutional Management in Higher Education 121 (1988): 27-40.

GELLERT, C., ed., Higher Education in Europe, Higher Education Policy Series 16 (London: Kingsley, 1992).
HÖFLE, K., Bildungsgeographie und Raumgliederung: Des Beispiel Tirol (Innsbruck: Institut für Geographie der Universität Innsbruck, 1984).

KIM, L., and L. BRANDELL, "Demographic Changes: A Challenge for Higher Education Planning in Sweden", II igher Education Management 2 (1990): 134-146.

MOROKVASIC, M., ed., "Migration in Europe", Current Sociology 2 (1984).

NEAVE, G., "Higher Education in a Period of Consolidation: 1975-1985", European Journal of Education 10 (1985): 2-3; 109-125.

TEICHLER, U., Changing Patterns of the Higher Education System: The Experience of Three Decades, Higher Education Policy, Series 5 (London: Kingsley, 1988).

TEICHLER, U., The Politics of IIIgher Education in a Comparative Perspective: France, Sweden, United Kingdom (Stockholm: University Press, 1988).

TROW, M., "Problems in the Transition from Elite to Mass Higher Education", in, Policies for Iligher Education (Paris: OECD, 1974). 


\title{
EDUCATIONAL POLICY AND ECONOMIC POLICY: THE CASE OF SOUTHERN ITALY
}

\author{
Roberto MOSCATI and Enrico PUGLIESE
}

\begin{abstract}
- The aim of this article is to describe the role of educational policies in state intervention in southern Italy. Its point of departure is recog. nition of the fact that education policies, particularly those concerned with higher education, have been given increasing importance in the plans for government intervention for development in this area. However, the increased emphasis on higher education, as well as on policies of technological development and innovation, has not resulted in improvements in the effectiveness of intervention. Rather, what has occurred has been the result of inadequate implementation techniques and
\end{abstract}

\section{INTRODUCTION}

When studying modernization processes in countries in which development has been delayed, the proliferation of analyses and research in the field has led to some significant modifications in the ways in which change is interpreted. A crucial modification has been the inversion of the relationship between economic and socio-cultural variables. According to the leading theories of the 1950's upon which the development policies for southern Italy were based, the evolution of life styles and cultural patterns depended on economic development (industrialization). Today the prevailing theory is that the terms of economic development depend on the social/cultural scene. of a general approach which has caused an overloading of the role and functions of higher education in a situation of general impoverishment and crisis in the basic educational structures (compulsory and secondary education). At the same time, the changing of the educational background of new and old professions due to the contemporary organization of labour seems to coincide, to some extent, with the emphasis on the upgrading of the general level of education, perceived as being needed for long-term modernization policies in developing areas (or countries).

On the other hand, a growing awareness has come into being that in economic terms, the increase of per capita product is "linked to the development of overall productivity and to the development of the ef ficiency of the labour force and not so much to the increase of capital used by each worker" Economic development therefore becomes more and more dependent, thanks to new technology, on "external factors" which derive from the overall level of school attendance and from shared capacities to learn and to communicate in the same language.

More than ever before, confirmation has been received from various segments of society of the importance of the widespread diffusion of medium/high levels of education. However, just as the latent functions of education are becoming increas- 
ingly relevant, the types of goals which formal education can and must set have to be reconsidered ${ }^{1}$. The authors of this article are of the opinion that the function of education in introducing emancipation into the Mezzogiorno (as southern Italy is commonly called) - as is probably the case for all developing areas - has been considered from a single angle, in terms of a linear, mechanistic, interpretation.

In fact, more attention should be devoted to the school system as a place of aggregation for peers, where young persons can discover a larger society as opposed to their restrictive family milieux. In the case of young people from lower class backgrounds, this discovery may have farreaching effects (Moscati, 1992).

If this consideration is taken a step further, the above-mentioned indications point to a transformation of the aims and the operation of education systems, especially at secondary and post- secondary levels.

According to an old distinction, education can be of two types: (i) liberal education which serves as a cultural base in generalized terms and its mass form which aims at developing a capacity to judge, imagine, learn how to learn, and to criticize; and (ii) vocational education linked to professionalism.

Currently, the dominant assumption seems to be that the former is more useful than the latter. However, a more in-depth consideration is re- quired when the process of discourse is moved to one of an analysis of the mechanisms underlying the surrounding reality (i.e., from the knowledge base to the process base). This step is justified in terms of the perceived need for everyone to have access to the information system, thus enabling everyone to take part in actions concerning themselves. Basically, the ensuing considerations are that first of all, the programmes and the institutions of the school must themselves be changed, and secondly, that the ruling classes in underdeveloped areas must be convinced that the aims of liberal education will be just as useful for economic development as the specific aims of vocational training. The same ruling classes must also be convinced that these educational aims will be of benefit, at least in the medium-long term, to the transformation of the current situation (instead of contributing to the perpetuation of the status quo, as the same ruling classes would perhaps prefer).

On the basis of these considerations, this article intends to analyse the ways in which educational policies have influenced the development of the Mezzogiorno, with particular reference both to the increasing awareness of the importance of the policies in question and of the need to adapt them to new requirements.

\footnotetext{
${ }^{1}$ For the theoretical concept of "latent function", see Merton, Chapter 3.
} 


\section{Roberto MOSCATI and Enrico PUGLIESE}

\section{GOVERNMENT POLICY IN AN AREA OF INTERNAL UNDER- DEVELOPMENT}

The Mezzogiorno accounts for one third of the overall population of Italy and for approximately one half of the total unemployment. In addition, the area is home to one-half of the families who live below the poverty line. It is an area in which the importance of agricultural work is far higher than for the nation as a whole and in which the rate of industrial employment is limited and decreasing.

The difference in salaries between southern Italy and the rest of the country is considerable, and the investment gap is particularly wide. The difference in rates of consumption, although significant, is not as marked, due to the fact that a substantial proportion of public spending is dedicated to the southern regions in the form of subsidies paid to families (social security benefits) and of other unproductive measures.

The area in question is very large but in no way uniform. In fact, it has many subdivisions, but it also has many common traits, the first of these being a labour market which has been historically and structurally characterized by high unemployment. Other such traits can be found in the political system, characterized here more than anywhere else in Italy, by electoral patronage and favouritism.

These traits have led to the tendency to refer to a situation of pronounced dualism between southern and central-northern Italy. At the same time, one must remember that southern Italy is a vast under- developed area within an economic, social, and institutional unitary sys$t e m$, a situation which has implications not only for the economy but also for education.

As a result of this unitary system, the Italian education system is highly centralized. As in the case of France, schools of each type and level have the same characteristics, the same general curricula, the same entrance procedures, and the same types of staff members. In terms of quality of education, the school system has various shortcomings and in some cases is affected by a deterioration of its territorial context. Nevertheless, these shortcomings seem to be due more to the rigid structure of the system (and to its limited adaptability) than to basic diversities for which the very nature of the Italian system does not leave room.

In the current scenario, the university system too adheres to a rigidly uniform state structure: autonomy is almost non- existent. Competitive examinations for university professors are organized nationally, and the curricula for various degrees are completely uniform. Teaching methods have, until now, followed an institutional rather than a contextual path. In some ways, this uniformity has served as a guarantee of the quality of university lecturing; however, it has its limits. As far as the labour market and contributions to the needs of development are concerned, graduates of Italian universities are far more suited to meet the generic and general needs for qualified staff on the national job market (which in fact is the job market in the northern regions) than they are to meet more 
specific regional needs. Proof of this reality can be found in the fact that one of the predominant features of migrants from the southern regions is their high level of education.

This element of centralization must be considered from an economic point of view as well. Essentially there is no political autonomy at the regional level with regard to economic development. Indeed the State, ever since the end of the Second World War, has tried through its so called intervento straordinario (special intervention) to bridge the gaps between southern and northern-central Italy. The goal is far from being achieved. Nevertheless, this plan has played a fundamental role in highlighting the current modernization processes.

\section{DEVELOPMENT POLICIES FOR THE SOUTH}

In the early 1950's, the Italian government created a special framework for the planning and allocation of subsidies to the Mezzogiorno, thus formalizing the involvement of state policies in the southern regions, which since the creation of the modern Italian State in 1861 had featured slower and more laboured rhythms and levels of development than the northern regions. The initial years of the Cassa per il Mezzogiono (Mezzogiorno Fund), which was assisted by the Ministerial Committee for the Mezzogiorno, as the body responsible for the drawing up of policies, were characterized by actions aimed at developing the basic agricultural infrastructure and prospectively, at attracting industry to the South. In a later phase, (beginning in the 1960's), this political course was modified in favour of mass industrialization, viewed as the sole means not only of promoting economic development in the area, but also of modernizing southern Italian culture. Because of its constant and pervasive attachment to old traditions, the cultural framework of the Mezzogiono was viewed as an obstacle to the modernization of customs and to the implantation of what is known as the industrial model of society.

To sum up very briefly, this policy was based on the implantation of base industries which, once consolidated, were expected to trigger the proliferation of the supporting industrial framework according to a natural cycle of continuous knock-on effects. In reality, this policy, from the start, was compromised by a series of national and international conditions, ranging from the possibility of moving what were principally state-owned companies to the South ${ }^{2}$, to the characterization of the national economy as determined by the international division of labour.

The result was that primarily large enterprises were established in the Mezzogiorno, mainly in the chemicals sector (refineries) and in the steel

\footnotetext{
${ }^{2}$ The reader is reminded that ever since the 1930's the Italian economy has experimented with a mixed system of large, jointly capitalized (public and private) enterprises. Although state control is dominant, the enterprises in question are expected to follow market rules.
} 
sector, enterprises which did not require a large labour force, despite the fact that in this area the labour available usually exceeded demand.

Needless to say, these enterprises failed to stimulate the creation of local industries. They had no more than a passing influence on the surrounding areas and were dubbed cathedrals in the desert. The policy of induced industrialization (aided particularly by tax relief and other incentives) failed to prove the soundness of the philosophy according to which economic development has a positive effect on the social and political situation (and above all on the cultural situation) of surrounding areas (Di Giorgi and Moscati, 1980).

More labour-intensive industrial plants, more consistent with the local economic environment, were also set up in the most developed regions of the Mezzogiorno, in particular in Campania. The industries involved included automobile assembly and metallurgy. But the size of the investments was not sufficient either to absorb the increasing labour supply, or to kick off a widespread process of industrialization. The general productive system was still very weak, and the level of industrialization, much below the national average.

In addition, by the late 1970's, state investment in the industrial sector had begun to decrease on the basis of a new market-oriented economic philosophy. Many scholars of the southern question and many policy makers adopted a new philosophy whereby only small firms, rooted in the local economic environment and managed by local entrepreneurs, would be able to create the conditions for industrial and general development in the South. Consequently, investment in large firms or in large industrial plants ceased. The general results of this more recent line of economic policy were probably worse than the results of the earlier initiatives. Unemployment in the South has increased steadily over the last fifteen years.

\section{EDUCATION AND EDUCATION POLICY}

In principle, the special intervention scheme for the Mezzogiomo did not neglect the promotion of education and of culture. In particular, a specific structure, known as Formez, was created in the early 1960's with the dual task of dealing with the updating of vocational training for management in small and mediumsized companies and with the spreading of modern culture by the establishment of a network of Cultural Services Centres based on the French Maisons de la culture ${ }^{3}$.

Whilst this initiative met with the resistance of local traditionalism and was seen as politically revolutionary by the central establishment (which rapidly diluted and ultimately abolished it), professional training encountered numerous difficulties, particularly in companies of limited size (which could not afford to train

\footnotetext{
${ }^{3}$ The Maisons de la culture were created by the late André Malraux, former Minister of Culture under President Charles de Gaulle in the 1960's
} 
their own staffs other than through on-the-job training). The situation was made worse by the shaky economic background which lacked both firm traditions and large company structures.

The training to be offered as part of the special intervention scheme was directed primarily at already employed persons. Basic professional training was to be provided by the state education system through special programmes which, at the beginning of the 1970's, were managed centrally by the Ministries of State Education and Labour and later on by the regions after the latter had begun to function.

In fact, as of its establishment, the special sector for state training in the Mezzogiorno clashed, on the one hand, with traditional skepticism as regarded the importance of education, and, on the other, with the resistance of all levels of state schools operating in the area to collaboration with other state institutions.

In order to understand the serious effects of the lack of co-operation between regular and special state intervention in the field of training, two aspects of education in the $\mathrm{Mez}$ zogiorno must be specified: (i) the extent of social expectations which were progressively channelled towards formal education, and (ii) the effective working conditions of the education system in the $\mathrm{Mez}$ zogiorno.

Normally, academic qualifications are viewed as a passport to nonmanual, socially (if not economically) prestigious employment. In a situation such as that of the Mezzogiorno, education was certainly considered to be one of the few courses of action, if not the only one, for those who did not enjoy high social standing. In the Mezzogiorno, in fact, education (and the official recognition of its results) often led to a transition from one organized form of social life to another, in which the parameters of assessment and social classification diverged from traditional patterns. Education was therefore seen to change, or attempt to change, traditional class relations. The most emblematic example of this new meaning attributed to education i.e., as a means to change not only lifestyles but also social status - has obviously been the increase in female demand for higher education followed by the subsequent entrance of women into the world of employment and their free adoption of emancipated family and social roles (Bonolis and Catanzaro, 1979; Moscati, 1992).

Faced with this burden of social backwardness, the striking features of the education system in the Mezzogiorno are its lack of effectiveness and efficiency. The numerous indicators of this lack of success can be summed up according to each level of education. In the first place, there is the serious problem of illiteracy which, according to the 1981 Census, reached 1,142,000 declared illiterates in the Mezzogiorno (out of an overall national figure of $1,608,000$ ), amounting to $6.3 \%$ of the total population. To this figure one must add 4,165,000 adults who have absoultely no academic qualifications (representing $22.9 \%$ of the population). Overall, then, the Mezzogiorno 
accounted for 5.3 million effective illiterates, that is $29.1 \%$ of the resident population over the age of 6 (whilst in northern and central Italy the same category represented $17.1 \%$ of the population) (CONFINDUSTRIA, 1990). With regard to compulsory (8 years of primary-junior school between the ages of 6 and 14), only 53\% of the pupils registered in the first year of primary school during the 1978-1979 academic year completed the eight years of compulsory schooling (whilst in the central-northern regions, $73 \%$ completed compulsory schooling within the prescribed 8 years). The phenomena of delays in the completion of compulsory schooling as well as of the high dropout rate give proof of the difficulty which substantial numbers of young people have in coming to terms with formal education. Frequently these persons are hampered by the attitudes of their poorly educated families or are forced by financial difficulties to accept precarious or illegal employment.

Significantly, the drop-out rate is considerably less widespread in the licei (high schools attended mainly by youngsters of relatively substantial cultural and social backgrounds, who are determined to go on to universities) than in the technical and vocational upper-secondary schools. With regard to the universities, the overall levels of effectiveness (the numbers of graduates as compared to the numbers of initially enrolled students) and of efficiency (the percentage of students who graduate on schedule) are lower in the South than in northern and central Italy, but there is also an internal productivity split accord- ing to faculties and the internal organization of various universities (the proportion of professors to students and study conditions in the different faculties and departments).

One can therefore see how at various levels of post-compulsory education different factors combine to cause the precarious functioning of the various institutions. On the one hand, the basic cultural level of the southern population which was low from the start and is changing very slowly affects the younger generations who have difficulty fitting into the educational system. On the other hand, the school system has not aimed at improving the quality of its services or of modernizing them. In a centralized public education system like that of Italy, the existence of such a situation indicates that the system has failed to take various realities into account and to implement a truly specific policy for basic structures even though called for by the social and cultural context.

For the reasons listed above,this distorted operation of the formal education system encountered a particularly buoyant demand at secondary level. The economic system did not develop enough to offer sufficient employment to absorb the output of the post-compulsory education institutions. Thus a surplus of high school graduates was created (one which can be assessed by comparing the rate of university entrance and the percentage of secondary school graduates among the numbers of young first-time job seekers). At the same time, the education system encouraged the continuation of studies by introducing an open door univer- 
sity admissions policy at the end of the 1960's and creating increasing numbers of study opportunities. The latter included postgraduate specialization courses, also supported by special government action, which was rarely linked to the actual demands of the labour market in the South. The migration of graduates from South to North, although occurring in what were thought to be temporary, difficult to evaluate phases, merged with the phenomenon of youth migration to the central/northern universities.

\section{THE TRANSFORMATION OF THE 1980's}

The flow of highly educated labour from the South to the North, a true brain drain, is the effect of a significant dualism which emerged in the last decades between the basic, crisis-ridden school system and the development of the higher education system. This contradiction follows from the pattern created by the unity and uniformity of the national education system, including the universities.

Despite a series of shortcomings, universities in the South have been able to keep up with the university system as a whole. Despite the generally backward economic situation, the strictly national character of the university system (that is to say, the basic homogeneity of curricula, the level of qualifications of the teaching staff, etc.) has encouraged processes of modernization in the universities of the South. This modernization has enlarged the national supply of highly educated labour the demand for which is localized in the northern regions.
Differences of course exist among universities within the South and also between those of the North and the South, but in the latter case, the differences are not as important as the differences in their respective economic and social settings would suggest.

Certain problems are more specific to southern universities, such as the problem of overcrowding and that of the lack of structures to cope with potential demand; however, such problems are much less felt in the universities than in the secondary schools. It is not by coincidence that many students from the South enroll in northern universities. A significant illustration of this phenomenon is the case of the Bocconi (a leading private university in Milan), in which the percentage of students from the South is expanding.

The expansion of the university system in the Mezzogiorno, the increasing number of high school and university graduates, and the very presence of universities as centres of research affect the modernization process and the professional structure of the labour force in the region. But this process of human capital enrichment has never been generalized. Therefore a dualism can be observed in the structure of the labour force with a still consistent number of workers, both employed and unemployed, having received very little formal schooling.

In order to understand the character of the modernization processes in the South, one needs to bear in mind the reality of the Mezzogiorno as an underdeveloped area within an ad- 
vanced society. Thus when innovations occur at the national level, they must per force concern the Mezzogiorno. Changes in the structure of the state apparatus as well as the implementation of new social policies have significant effects on the structure of the demand for labour in the private sector and even more in the state sector.

The reform of the national public health system can be cited. When this system was generalized, the result barring the infiltration of patronage and significant levels of inefficiency was an increase in the demand, over the last two decades, for persons trained in the new technical professions in the health field. In more general terms, phenomena such as the modernization of the banking and financial system and of the insurance sector have led to the expansion of occupational areas among those which are normally called the "new professions" (Aparo, 1985; Schenkel, 1986; Luciano, 1991). Changes in consumption patterns have also helped to create a stronger demand in the services sector for young (or relatively young) people with high levels of (university) education: architects, psychoanalysts, media workers, and persons in allied profes. sions.

But the limited character of the industrial development of the Mezzogiorno implies a weak demand for highly qualified manpower in the industrial sector and a limited development of activities related to industry, such as enterprise services capable of absorbing à highly qualified labour force.
Studies carried out in the 1980's on this question suggest that one should be cautious with regard to the drawing of conclusions and point out the dichotomy between isolated, feeble peaks of development (with the presence of highly qualified labour), and a general situation of stagnating employment with a huge problem of unemployment, mainly among youth (Boffo, Moscati, and Pugliese, 1985). In this context, those most at a disadvantage are the members of the less qualified sector of the labour force. These persons must also put up with the effects of the crowding out phenomenon in the labour market which is reaching serious proportions in the Mezzorgiorno. The number of young people with very high educational qualifications who are taking jobs requiring minimum qualifications is thus very high and is perhaps increasing.

With regard to unemployment, one must remember that in the short run youngsters with good qualifications (secondary school graduation or a university degree) are at a disadvantage. But in the long run, education proves to be helpful. Among adult groups, the unemployment rates of highly qualified workers are very low.

For the long term, therefore, a high level of qualification helps people to find employment, but the help proffered depends upon the degree of investment in human capital. This reality points to the recurring theme of internal migration of the highly qualified, who have three alternatives to unemployment: they may either migrate, content themselves with positions for which they are over- 
qualified, or attempt to find occupations locally which will permit them to make the most of their qualifications.

The low level of employment in the area of the new professions, the result of the low adaptability of the production system to the requirements of a process of social and economic development, offers few opportunities to the highly qualified.

The 1980's were years of change, but above all of stagnation in the system of production. Whilst the first aspect was considered systematically and often in laudatory terms, the second was frequently ignored (with obvious exceptions) by the experts.

The existence of a new development path based on services corresponds to a post-industrial development stage. This path has been neglected in the Mezzogiorno because of the insufficient level of industrialization in the region.

In other words, and this is the principal stumbling block for economic development, the Mezzogiorno is undergoing premature deindustrialization which is having an extremely negative impact on the occupational prospects of the workforce at all levels of education. The very narrowness of the industrial production system has created a situation whereby these professions fail to fit into the secondary sector. Activities such as enterprise services are feeling the pinch of the situation which is caused by the stagnation affecting the industrial firms themselves.

Therefore, the new professions are concentrated in the tertiary sector and are more closely linked to inter- mediary than to primary production processes.

\section{CONTRIBUTIONS OF THE SPE- CIAL INTERVENTION SCHEME TO THE FIELD OF EDUCATION}

The transformation of production processes and the re-structuring of certain crucial economic sectors in the 1980's led to a reduction in the special intervention schemes operating in the Mezzogiorno, or at least to their transformation following accusations that they were inefficient and a waste of public money. The new philosophy which became prevalent favoured the strengthening of the regular policies and the use of the special schemes for precisely identified strategic issues and projects.

With regard to training, two priority courses of action emerged: on the one hand, the strengthening of the efficiency of public administration, with a view to delegating larger tasks and responsibilities to regional and local bodies; and on the other hand, the organization of new companies, and in particular, the introduction of new technology, were expected to be more successful if preceded by the creation (or the strengthening) of entrepreneurial and managerial skills.

With regard to public administration, consideration was given to the fact that, in view of ever closer European integration, the relative importance of a region should not depend so much on the influence of its economy on the European Communities as a whole or on the initiatives of large companies or of its banking system, but rather on factors 
which are not strictly economic, such as the efficiency of the administration and of the decision-making processes of the political/institutional structures. From this point of view, the regional and local administrations tend to be supplied with highly qualified staff who are able to programme, plan, and implement administrative actions and evaluate their results. The special project known by the acronym of (RIPAM) consists of rapid training schemes geared to provide new, highly professional staff, and requalification and refresher programmes for staff already in service.

In addition, pilot projects exist at a provincial level to improve existing organizational models via group consultancy work carried out by special task forces which are able to provide various technical and organizational support services. In addition to these pilot projects, other training programmes have been introduced at the postgraduate level. Known in Italy as Masters, they originated from private enterprises and ad hoc corporate consortia. In its turn, the special intervention scheme in the South created its own Master courses in public administration with the task of training managers for local authorities through two- and threeyear courses.

In order to train personnel to a level at which they can evaluate and support the contributions provided by the new production technology, the philosophy of the government is to increase the extent of managerial training. This aspect, which is also part of a new company attitude, underlines the need to stimulate the spreading of organizational culture. Although the latter is considered of great importance for public administration in the Mezzogiorno, it is also crucial for small and mediumsized firms in the ever expanding context in which they must compete, even though they operate in an area, which traditionally offered few opportunities. This scheme, which for some time now has been aimed at management training, is now being pursued with entrepreneurs as the primary target in order to support the capacities of the latter to cope with the growing international market through the creation of technical and organizational assistance programmes.

As can be observed in both cases, we are talking about training schemes which aim to meet a hypothetical high demand for the training of managers both for public administration and for private entrepreneurship in view of the changes which will be introduced by technological innovation and market expansion resulting from European integration.

In addition to this type of training strategy, the special intervention scheme has created a second strategy geared to the low demand for training. It is aimed at compensating for the shortcomings of the public education system at various levels. This action includes a number of schemes, such as school guidance (continuous tutorship and counseling), remedial courses for drop-outs from compulsory schooling, the creation of vocational post-secondary training programmes (short cycles), and assistance to the regions for professional training schemes and special courses 
for drop-outs in coordination with working activities.

Although most of these schemes have a potentially wide appeal, they still remain primarily on the drawing board due to the difficulty, one which is almost endemic, in creating a true link between every type and level of regular schooling and special, supplementary education schemes. The latter require co-operation among the Ministry of Public Education, the regions, and the universities. In reality, such co-operation will probably not be feasible until the true autonomy of single universities and single secondary schools is acknowledged, and professional training is dealt with at a regional level according to programmes drawn up in agreement with the business world and according to the real needs of local economies.

\section{CONCLUSION}

In the web of traditional and modern forms of identity and of links, both personal and impersonal, formal and informal, which today make up the fabric onto which the processes of transformation and change are woven, the general cultural level plays a central role, which is, however, difficult to gauge. Therefore the degree to which education is generalized is a decisive factor. In the attempt to combine traditional forms of interpersonal solidarity with confidence in formal and impersonal institutions, the crucial factor becomes the common level of knowledge acquired through uniform mechanisms and collective institutional processes: that is, through school (Mutti, 1991). To extend this logic to its full implications, we can argue that in the Mezzogiorno the rules governing civil society determine community relations and, at the same time, the success or failure of the hidden rules of favouritism (and of Mafia clans) (Paci, 1992).

The evolution of educational policies in the area under examination does not seem to have taken sufficient account of these functions of civic culture, and consequently, of education, aiming instead at bearing out the myth of prestigious qualifications even when they do not correspond to existing labour demands. On the other hand, the very same theories of economic development seem to favour the expansion of medium-high levels of education rather than more advanced forms of education which per force are linked to the new professions and to the application of technological innovations (which are not appropriate for developing areas). From this point of view, the most recent interpretations of the modernization process consider that the education policies resulting from both ordinary schemes and the special state schemes are inappropriate for the special conditions of the Mezzogiorno. In conclusion, the traditional strategy which influences the human factor, beginning with the top levels of the managerial classes (which should lead the processes of change), does not seem to follow the most recent theoretical interpretations of development. The latter imply that, although the direct effects of education might be less decisive, they would, for this very reason, aim to be more effective than previous policies 
of economic and socio-political development.

The alternative for a state policy for such a large developing area as the Italian Mezzogiorno would bear on the priority to be given either to high level up-to-date vocational training or to the spread of basic (and subsequently, secondary) education, in order to start a new trend of induced economic development, or to set the preconditions for its autonomous take off.

The problem is one of whether or not to emphasize visible, politically appealing economic development projects entailing a direct rate of return for the ruling class or, instead, to give priority to the creation of cultural and social preconditions for subsequent economic development (with no short-term political payoff).

As could be expected, government policy in Italy followed the former path. Currently, however, the new element which has to be taken into consideration is related to the recent theory of modernization which no longer supports such policy. However, so far as the Mezzogiorno is concerned, both the theory and the results of previous policies suggest a shift to the latter path. What is im- plied is a global change of perspective, one worth verifying in other developing areas.

\section{REFERENCES}

APARO, A., "Innovazione tecnologica e nuove professioni negli anni 1980", Economia e Lavoro 2 (1985).

BOFFO, S., R. MOSCATI, and E. PUGLIESE, Nuove professionalità nel Mezzogiorno (Roma: Cies - unpublished research paper, 1985).

BONOLIS, M. and R. CATANZARO, "Influenze della famiglia e dell'istruzione sul comportamento nel mercato del lavoro", Inchiesta 40 (1979): $35-43$.

CONFINDUSTRIA, scuola e formanione, (Roma: Sipi, 1990).

DI GIORGI, U., and R. MOSCATI, "The Role of the State in the Uneven Spatial Development of Italy: the Case of the Mezzogiorno", The Review of Radical Political Economics 123 (Autumn 1980): 50-63.

LUCIANO, A., Innovazioni in un'economia as. sistita: nuove professioni nel Mezzogiorno (Università di Torino, W.P.S., 1991).

MERTON, R. K., Soclal Theory and Social Structure (New York: The Free Press, 1968).

MOSCATI, R., "Il sistema formativo nel Mezzogiorno: funzioni manifeste e funzioni latenti in contraddizione", Polis 2 (August 1992): 343-371.

MUTTI, A., "Sociologia dello sviluppo e questione meridionale oggi", Rassegna Italiana di Sociologia 2 (1991): 155-180.

PACI, M., "Sviluppo del Mezzogiono e capitale umano", Economia e Lavoro 4 (1992): 3-13.

-SCHENKEL, M., Strutture professionali e occupazione: un confronto internazionale, unpublished paper, 1986. 


\section{THE LOST PROFESSION}

\section{Ronald BARNETT and Robin MIDDLEHURST}

In the United Kingdom, the higher education community is being deprived of components of its professionalism just when it is clarifying to itself the nature of that professionalism. Historically, academics were not required to define their obligations to society. Now, they must function in an age of accountability in which public services are being asked to demonstrate their wider value. Behind this shift stands a changing relationship between

\section{INTRODUCTION}

Both individually and collectively, academics are being challenged to take on new commitments and to reshape the balance of their professional activities. This challenge is a feature of academic life across the western world. Reassessments of the balance between teaching and research, increasing use of evaluation procedures, and more explicit interlinkages between universities and the world of work are three symptoms of more general transitions.

We can readily identify a number of specific demands to which academics are generally being asked to respond. They are being asked:

- to become more productive in their research (to improve the research ratings of their institutions);

- to attract income (as institutions seek to diversify their sources of income); higher education and the state in which the state has moved to assess the quality of what was on offer and is now playing a direct part in influencing the shape of graduate formation. Currently, academic life is becoming so subject to external control that the autonomy required as a necessary component of professionalism is being lost. In Halsey's terminology, academics are changing from being a status group to being a proleta riat but without ever having properly been a profession.

- to become more effective as teachers (as non-completion rates and degree performance become visible as performance indicators);

- to raise the quality of their teaching (as institutions are more subject to inspection);

- to be responsive to the perceptions of their students (as institutions become more responsive to the student market);

- to take into account the views of employers in curriculum delivery (as higher education becomes more responsive to the labour market);

- to be willing to work in teams with regard to course design and delivery;

- to be more conscious of the financial base of their teaching operations;

- to be more entrepreneurial in research, consultancy, and teaching; 
- to be more professional in the administration of all of their research and teaching activities.

One consequence of all these changes taken together is that the nature of academic professionalism is changing. Two obvious general changes are that academics are having to be more accountable to external constituencies for their actions and performance and that the profession is having to be much more sensitive to the different markets that may have a claim on its services. These changes engender others. The proportion of disinterested research will most likely fall, and that of short-term consultancies focussed on customer-driven projects will rise. Most likely also, programmes of study will take on the form of professional education in which both the substance (in the form of externally useful skills) and the delivery (in the form of problembased and experiential learning) will come to the fore.

A more fundamental aspect of these changes concerns the nature of academic professionalism itself. For changes of this range, significance (as it bears directly upon the character of the work of academics), and impact raise the question of what is academic professionalism. In what ways might academics be said to constitute a profession and in what central senses is that professionalism changing? Only by becoming clearer about these fundamental questions will we be in a position to understand and form coherent views about the immediate future of academic life as it seems to be evolving.

The question, What is academic professionalism? admits of no straightforward answer, for the very changes that prompt it are producing new definitions of academic professionalism. In turn, those new definitions of professionalism are linked to emerging new patterns of professional activity, for example - the focus of this paper - in the field of curriculum specification and delivery. The pedagogical relationship is changing and, with it, the sense of professional responsibilities owed to the student. That, at least, is the position taken in this article.

This article will examine the evolving relationships between higher education and state and chart the associated changing definitions of academic professionalism. Following Becher and Kogan (1992), we shall distinguish between structural features of these changes and ideological or valueoriented aspects. A central question underlies our discussion: in what ways can the academic role - particularly in relation to teaching - be considered to be professional? Our argument is that, in relation to its teaching function, academics as a collectivity have lost their chance to legitimize any claim to professionalism. At the present moment, just when we see signs that the academic community is reaching for new internally-produced definitions of professionalism, wider structural aspects of the changing relationship between higher education and the state are working to deny that possibility. Far from becoming a new profession, 
we are witnessing signs of the making of a proletariat (Halsey, 1992).

Our argument has two parts, descriptive and explanatory on the one hand; and evaluative and recommendatory on the other. That is to say, we shall develop an analytical framework for comprehending the contemporary changes; and we shall go on both to form views about the character of those changes and to point up practical issues for the development of a professional ethic.

Our analysis is mainly situated in the context of the United Kingdom, especially its changing patterns of academic life since the Second World War. But we believe that the key components that we pick out and the specific forms to which their interrelationships have given rise can be adapted to any system of higher education in western society, especially those of western Europe. Certainly, some kind of transferability of our thesis should be possible since the dominant categories with which we work - higher education, the state, curriculum, research, and professionalism - do have cross-national connotations even if their actual interpretations are often quite varied.

\section{ACADEMIC PROFESSION?}

We talk comfortably about the legal profession, the medical profession and, over the last half-century or so, have extended the application of the term profession to a very wide range of occupational groupings, including librarianship, account ancy, and pharmacy. The number of such groupings which are commonly termed professions will vary, even across modern societies, but it might be of the order of a hundred. However, we are less comfortable about extending the term to a number of occupations, for example, politics, taxation, photography, plumbing, and the world of haute couture which are none the less deemed to be of value. Even engineering, social work, and school teaching, in the United Kingdom at least, occupy this twilight zone of being occupations with their own demands and standards, yet of not being ones which are always perceived as professions.

The explanation of these differences in description is complex and involves a sociological interweaving of fact and value, of social institutions, and of social values. On one hand, we would need to ask empirical questions with regard to issues of power, institutionalization, and access. Does this occupation have a professional body? Is entry to the profession only open to members of that body? Is entry restricted to those who have successfully undergone specified programmes of education and training? Do the practices of the profession require the deployment of a corpus of complex knowledge and understanding? Does the professional body have state-backed powers of licensing those deemed suitable to practise? (cf. Goodlad, 1984, chap. 1; Jarvis, 1983, chap. 2; Rueschemeyer, 1986, chap. 6). Questions such as these would deny the designation of profession to the occupations just mentioned. There is, then, some factual warrant for our customary use of language.

The ascription of profession, however, is also a social evaluation. It 
reflects the evaluations of society with regard to different occupations. To term an occupation a profession is both a claim of truth (that the occupation has certain fairly objective characteristics) and an evaluation as to its worthiness (Downie, 1990; Jarvis, 1983, chap. 9). It would not make logical sense for an occupation to be termed a profession which was generally held to be socially injurious. In sofar as there is general agreement that the first group of occupations do indeed count as professions, this designation comes partly in virtue of there being a significant constituency of opinion that would testify to their general worth. That accountancy, for example, might be deemed to be a profession is as much an expression of changing social values which now accord a high evaluation to the occupation as it is a description of the contemporary social arrangements which attach to $b e$ coming an accountant.

With these generalizations set out (admittedly in a fairly sketchy fashion), we are now in a position to ask in what sense The Academic Life (to employ Burton Clark's title) can be considered to be a profession. Or, more cautiously, we can now begin to have a sense of the considerations involved in coming to view the work of academics in the language of professionalism.

Harold Perkin was in no doubt. For him, the work of academics constituted The Key Profession, and his book begins with the bold assertion that "University teaching is the key profession of the twentieth century" (Perkin, 1969). Burton Clark's opening is more cautious: "There can be no doubt that the academic profession is an odd profession" (Clark, 1987). These contrasting views, it is worth noting, spring from different assessments of the same feature of academic life. Both writers note the increasingly fissiparous nature of academic life, but for Perkin, it is this feature which provides the expertise upon which "the very survival of civilization, if not of the human race itself, has come to depend"; while for Clark, writing in an age perhaps less sanguine about the authority of expertise, at once points to the "opaqueness" which he views as characteristic of the style of the members of the academic profession. Clark goes on to state that "Variety is its name, for it is inevitably a conglomerate of interests in which purposes and tasks steadily divide along lines of subject, clientèle, and occupational linkage". The question which then arises is whether or not the academic profession is one profession or a "conglomerate" of different professions" As Clark implies, the answer is not simply a matter of internal differentiation, for some of the academic groupings are more or less loosely attached to or identify with mainstream professions in the wider society. The "territories" of some of the "academic tribes" extend beyond the boundaries of academe as such (cf., Becher, 1989).

In what follows, however, we want to sidestep many of the issues so far raised. Our concern is not to assess objectively the extent to which academic life counts as a profession, against any sociological calculus of. the meaning of profession. No such unassailable calculus is available. All 


\section{THE LOST PROFESSION}

occupations are more or less professions in the sense that against any well-developed list of criteria, even well-established contenders will perform unevenly. What, for instance, is the professional body for the clergy? We do not intend, therefore, to emerge with a definitive view as to whether or not academics constitute a profession.

We shall, however, pick up three issues: the dynamic of "professionalization" (Johnson, 1972), reflected in the changing character of professional life in academe; the wider societal evaluation of that life (the value component of professionalism); and the linkages of the academic profession with the wider society, especially through its shifting relationships with the state. Our argument will be that major changes are taking place in the academe-state relationships in terms both of structural arrangements and of the perceived value of the profession, and that these changes are affecting the character of academic life. These changes pose to the academic profession the challenge of working out its responses.

\section{A STATE PROFESSION?}

In many European countries, for well over one hundred years, the academic profession has been explicitly part of the state apparatus, with academic appointments being ratified by the state. The academestate relationship is therefore not new. What is new, however, is the way in which higher education has quite generally, over the past thirty or forty years, become gradually more absorbed into the ambit both of the state and of the wider society. Two dominant moves are evident.

On the one hand, the higher education (perhaps more than the research) function of the universities has been perceived as a means of improving a country's economic performance through the supply of advanced expertise to the labour market. In Marxist terms, knowledge has taken on the character of a force of production. One consequence of this new appreciation of the economic value of knowledge has been the state-sponsored exponential growth of higher education in advanced and even less advanced countries (Edwards, 1982). Another consequence has been the willingness of the state to invest in higher education so that the state could rely on a regular supply of highly skilled labour. In the process, higher education was able to rely on a regular source of income. Yet another consequence has been the development of a higher education system in which the universities and other post-compulsory institutions have become subject to some degree of state planning.

These developments in turn raise questions about the extent of institutional autonomy: to what degree are institutional charters which confer state-endowed autonomy fictions? (The new United Kingdom universities, in fact, do not have the royal charters previously identified with the title, university.) However, here the key point is that these changes in the character of institutional life - expansion, increased state funding, and decreased autonomy - are simply the by-products of the strategic role, in terms of knowledge, technology, and 
expertise, which well-formed graduates are felt to play in modern society.

On the other hand, precisely because of this new importance accorded to higher education, the state first developed and then considerably increased its apparatus for exercising surveillance and influence over the sector. This development has two aspects, technical and ideological.

At the technical level, the sheer expansion of the higher education system has presented the state with problems of finance and of quality maintenance. These problems are linked, falling unit costs (the state being unready to sponsor the system at the historic unit costs compatible with an élite system) giving rise to concerns about the quality of the operation of the system. Coupled to this concern is the new and understandable desire on the part of the state to closely monitor the operations of the higher education system as an increasing and not insignificant claimant on the public purse. All these motives and interests on the part of the state have given rise to the development of state-encouraged or even state-directed systems of performance monitoring and evaluation. Accountability, efficiency, and productivity are only a few of the terms in the resulting new vocabulary of higher education.

The ideological level of state influence is, as yet, less developed, but there are signs that this gap is being filled. Having to some extent erected an operational framework for monitoring and evaluating the performance of the system, the state is now in a position to turn to the substance of the inner processes and enter the secret garden of the values and processes constituting the central activities of academic life. Firstly, research experienced the attention of the state as state agencies developed research strategies, classifying research according to the immediacy of its applicability and identifying broad themes or topics for research bids. More recently, the state has shown an interest in the content of teaching, seeking to find ways to reposition programmes of study nearer to the world of work.

In both its forms - research and teaching - the interactions at work can be termed ideological since what is being attempted by the state is a shift in the interest structure of the academic corps. These are processes of displacement by which the academic corps is being asked to exchange its belief in the separateness of its cognitive interests from those of the wider society to a recognition of an identity between the two; that is, to move from dualism to monism ( $c f$., Minogue, 1973).

These two areas of state influence, technical and ideological, have very recently come together in what is a drive to separate research and teaching. On the technical side, funding for the two activities is being separated, and it is being made clear that some institutions of higher education should not expect to be funded to conduct research on any major scale. On the ideological side, the state is attempting to legitimate such moves through such arguments as claiming that the whole teaching staff does not need to be involved in 
research in order for higher education to be increasingly effective.

In this article, our main focus is on the teaching activities of academics.
Accordingly, we can generalize our introductory observations by means of the model depicted in Figure 1.

Figure 1. How the State Influcences Higher Education

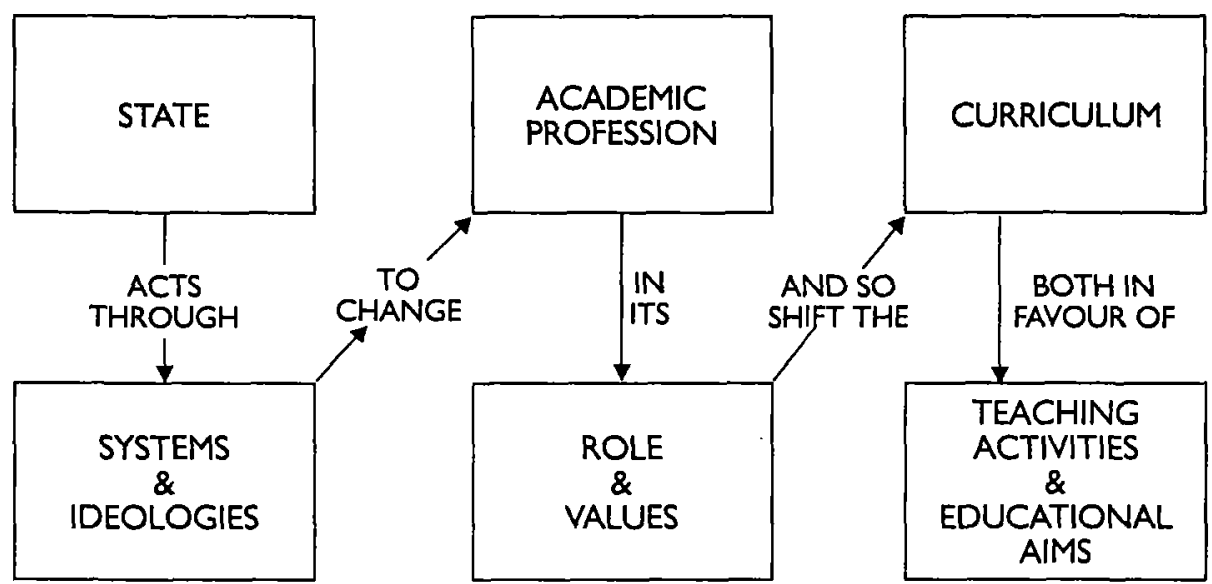

This model, which is deliberately schematic, will be developed as the discussion goes forward. The value of putting down such a bare schema is that it emphasizes key points. Firstly, external influences exert their influence on the curriculum through the academic corps. This influence, to be effective, must operate in the domains both of the activities or operations of academics and of the self-definition of those academics (cf., Becher and Kogan, 1992). For example, the government may wish to see a shift in the balance of activities between research and teaching and may restructure the funding arrangements accordingly. A real change in the pattern of activities may result.
But to be fully effective, a change in the self-definition of academics is called for: ultimately, they may have to realign their own sense of the nature of the academic life if that new pattern of academic activities is to have existential reality (Collier, 1993). In short, a shift of ideology at the level of the state has to be accompanied by a shift of ideology within the academic corps if the intended shift in the curriculum is to occur to any significant degree ( $c f$. , Tapper and Salter, 1992).

Secondly, systemic changes in the curriculum and in the student experience are likely to arise as a result of influences external to the 
academic corps. Inevitably, local and small-scale changes will occur in the teaching practices and values of academics, both because disciplines are differentially related to and permeable to the claims of the wider society, and because they tend to generate their own internal ways of going on (according, for instance, as to where they stand on the soft-hard and the pure-applied axes (Becher, 1989)). But system-wide change, we would suggest, is likely to be the result of global, externally generated influences which impact on academic life itself.

Here, it is worth pausing to reflect that our observations have begun to exploit a number of key concepts and conceptual frameworks which we shall build on as our discussion unfolds. Firstly, we are situating our analysis of contemporary movements in academic life in the context of changing relationships between the academic corps and the wider society. Secondly, we are distinguishing between the activities and the value structures of academics. Thirdly, the institutional dynamic at work is saturated by and is itself reflected in contending ideologies. Ideologies are not lightly surrendered: resistance will be offered (cf., Giroux, 1983). However, the strength of the resistance will be uneven, a function of the market position of different institutions (that is, their ability to command resources) in the wider society. Fourthly, the extent of change will have both external and internal determinants, in the (external) permeability and the (internal) epistemic and social conditions of the production and reproduction of knowledge.

\section{CHANGING FORMS OF ACADEMIC PROFESSIONALISM}

Our contention is that the nature of academic professionalism cannot be understood fully without attending to the wider institutional context within which the academic corps is situated. A consideration of the institutional context points us in the direction of addressing the relationship of higher education, as a social institution, with the wider society.

That higher education has had some kind of relationship with its wider society since its medieval origins and that this relationship has changed over time can hardly be in doubt. What is less clear, however, is the nature of the changing structure of this relationship. Our concern here is not to engage in an historical analysis, but to offer some insight into the possible forms of relationship available to the modern university.

We can distinguish four models of higher education-society relationship. The usual caveats apply; these are not intended to be discrete models. They do not tell an unequivocal story in temporal terms, nor need they apply to systems of higher education as a whole. Insofar as the four models have applicability, elements of more than one model might be found together in any one system at a given point in time. A system might take the form of the different models for different periods of time, and alternative models might apply to different sectors of a system at any moment. 


\section{Higher Education as Private Interest}

In this form of relationship (Figure 2 ), higher education is granted a large degree of autonomy by the state. In this circumstance, the forms and practices of higher education are largely a matter of the internal or private interests of the academic community. In turn, the interests of the academic community will lead it to make research the dominant activity and focus of its values. Although teaching has a minor role to play in the professionalism of academics, the teaching activity is viewed as being integrated with research. A strong teaching-research relationship is proclaimed and becomes an ideology of the academic profession.

Accordingly, in this form of the higher education-society relationship, the professionalism of the academic community is constituted by its internal norms, deriving both from its epistemic interests and demands and from the perceived high value of those norms and activities in the wider society. We might hypothesize that such a higher education-society relationship is characteristic of a small-scale higher education system which has a close relationship to élite culture generally (In the United Kingdom this model might have typified the situation in the first half of the twentieth century.)

\section{Higher Education as Public Interest}

In this form of the higher educationsociety relationship (Figure 3 ), the state takes on a coordinating and even a planning role and begins to develop its powers of surveillance over higher education. Surveillance may be exercised directly or through so-called buffer institutions. The planning role is made effective through linked resource allocation mechanisms. The surveillance role is made effective through various performance review systems.

One outcome of the new interest of the state in higher education is that teaching is no longer a private matter of the internal interests of academics but something which now attracts explicit attention. Offerings to students become systematized in courses or programmes carrying some degree of public shape rather than simply being loosely floating intentions in the minds of lecturers. Those programmes, too, become anchored to particular subjects or disciplines (even if multidisciplinary in form) thus making national and institutional planning more feasible.

The professional consequences of this shift are quite obvious. Firstly, there are the beginnings of an uncoupling of research and teaching. There will continue to be much intellectual and human traffic between the two activities, but it now becomes possible to conceptualize teaching as an activity forming a significant component of academic life in its own right.

Secondly, calls develop for academics to be accountable for their teaching activities, independently of their research activities. To begin with, moves of this kind may take apparently benign forms, with academics being asked to make explicit (whether in purpose-designed 
Figure 2. HE: Private Interest

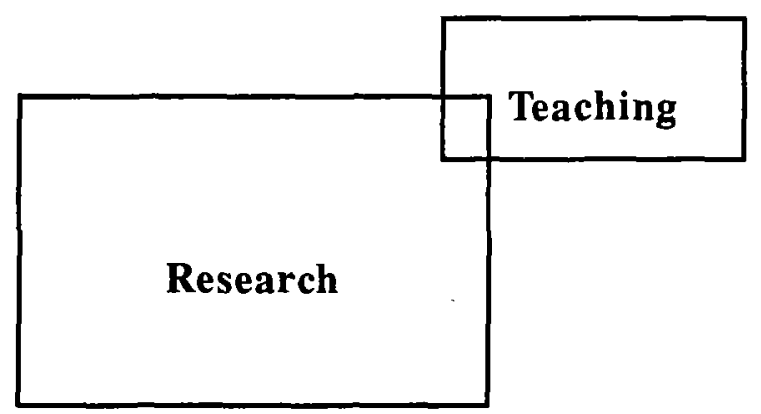

Figure 3. HE: Public Interest

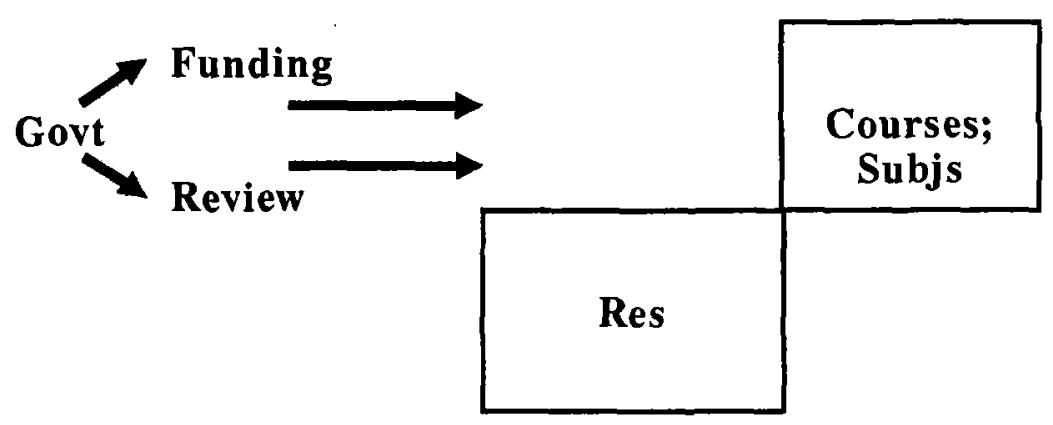


documentation or in programme documentation) their intentions with regard to the curriculum. Indeed, anguished debates may arise for the first time in academic settings about the meaning itself of curriculum, as efforts are made to respond to requests from external monitoring bodies.

Figure 4. HE: Public Direction

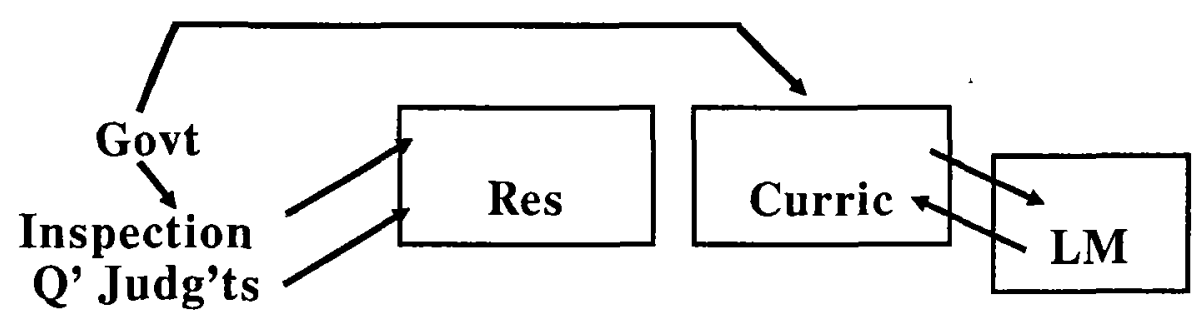

\section{Higher Education as Public Direction}

In this form of higher education (Figure 4), the state actively intervenes in the internal character of academic life, possibly through a number of strat egies.

Firstly, its systems of performance appraisal are developed from assessing institutional efficiency to forming judgments as to the effectiveness of institutions. Further levels of sophistication are, however, possible. State sponsored evaluations (conducted by agencies of or linked to the state) or state encouraged evaluations (conducted ostensibly by collectivities of the institutions themselves) may move from being paper exercises to being direct assessments of the performance of staff, whether through appraisal (with institutions acting as state surrogates) or through inspection in situ of the curricular offerings themselves. A further consequence of all these developments is likely to be a debate, often heated, about the appropriateness of performance indicators as a means of illuminating programme and staff performance.

Secondly, the character of research programmes may come under state influence as research is publicly classified under external criteria (strategic, applied), and the consequent effect on the flow of resources affects research capability in specific areas. Research needs are identified by the state and transmitted to the academic community. Certain areas of research (and not just in the military area but much more general1y) are directly funded by the state, and decisions may be taken - even ad hoc - as a result of lobbying by influential interests which affect the survival or otherwise of specific research units. 
Thirdly, the state may begin to attempt to reshape the character of the curriculum itself. Perhaps sensing that the academic community has not reacted sufficiently to external pleas to be more responsive to the claims of the wider society, the state may sponsor its own initiatives with regard to curriculum development and innovation on a piecemeal or even on a national basis. Schemes of this kind are therefore linked to certain agendas of the state; for example, developing civil and community virtues in a multi-ethnic society or enterprising and transferable capabilities amidst changing and more competitive world markets. One outcome of such developments is that they separate teaching even further from research and identify the curriculum as worthy of systematic attention in its own right.

The central effect of moving into this particular stage of the statehigher education relationship is profound. Academics are increasing. ly having to respond to agendas set by external agencies. This evolution in itself can be described as a process of deprofessionalization of the academic class.

All professional groupings, to secure their livings, must be attentive to the wider world: they cannot simply pursue their interests as defined by themselves. So the element of responsiveness is not significant here. The key is that, here, strategic agendas themselves are framed by the external interests. In such a situation, one element of what it is to be a professional, having the capacity to determine one's own goals, is to some degree at least, diminished. The academic life is reduced to one ap- proaching mere technique in fulfilling the ends set by others.

\section{Higher Education as Market Direction}

The last stage to be identified in the higher education-state relationship is that in which the market becomes a significant influence on the character of higher education (Figure 5).

According to this model, as indicated by the diagram, the state is no longer an overtly significant determinant of academic life, having been replaced to a large degree by the market. The shift from state to market is both an outcome of state policy and a concomitant of the move to a mass higher education system. In such a system, the research function becomes a relatively minor activity as the majority of resources in the system are oriented towards teaching. In such a system, too, with the combined pressures of sheer volume of throughput of students and declining unit costs, the management of the curriculum takes on a new significance at the institutional level (King, 1992). Accordingly, the curriculum becomes unitized and learner-based. The unitization of the curriculum offers managerial flexibility in controlling teaching resources and curricular offerings, while students are recognized as an underused teaching resource and are asked to bear increasing responsibility for their learning programmes.

Externally, the dominant relationships are with the market in various senses. Firstly, the students themselves carry and exercise increasing purchasing power. Secondly, the labour 
Figure 5. HE: Market Direction

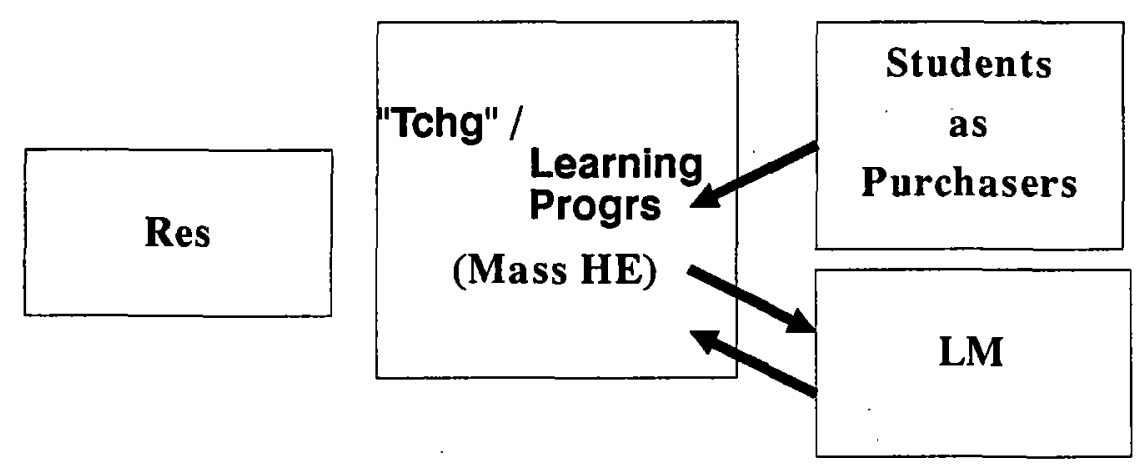

market comes more into the consciousness of curriculum providers, since a mass system is one in which the articulation between higher education and the economy is an essential, not contingent, aspect of its development. Thirdly, increasing numbers of students are themselves active in the labour market and are looking to higher education to assist their career development, whether through the imparting of new skills and understanding or through the credentialling service that it offers.

In this form of the higher education-society relationship, academic professionalism is triply challenged. Firstly, the capacity of academics to be involved in knowledge creation is limited because much of their time is now devoted to orchestrating learning programmes. Secondly, and linked to that first point, teaching, across the system as a whole, is cut adrift from its earlier tight relationship with research; and new defini- tions of research are developed stressing its societal, pedagogical, and action mission (Boyer, 1990).

Thirdly, the customers (students) and the consumers (the labour market) come to exert their claims on the curriculum, in its content, process, pedagogical relationships, and outcomes. Fourthly, the once esoteric knowledge base of academe is both challenged by new claimants for the title (knowing-how, knowingin-action) and by the increasing permeability of knowledge problems and issues (what counts as an issue is defined in part by external interests).

The general consequences of these changes are, firstly, that the role of the academic as teacher becomes problematic. Less a matter of imparting a canon or consensually defined corpus, his role is now cast to a significant degree as a facilitator of learning and a manager of the curriculum. Secondly, the curriculum and pedagogy come onto the agenda, 
both within higher education and as part of the wider debate about higher education.

In short, a new sense of academic professionalism is called for, built more around concepts of teaching, students, learning, student experience, and development than around research, knowledge, expertise in relation to a discipline, and the initiation into a particular epistemic tradition.

\section{CHANGING VALUES OF ACADEMIC PROFESSIONALISM}

Our fundamental point is that the idea of academic professionalism cannot be fully understood without an understanding of the changing character of higher education and the shifting relationships between higher education and the wider society. We have just examined the structural aspects of the changing higher education-society relationships; now we turn to the normative aspects.

Here, our main contention is that the changing relationships between higher education and society are generating changing sets of values within academe, which in turn are affecting the dominant ways in which the curriculum is understood. What we see is less a shift from one stage to another than the progressive addition of a series of layers of influence and interaction.

Four recent stages can be identified.

1. Higher education as a public service: In this stage of its development, higher education is regarded as a public service. The state sees itself as having claims on higher education both because of the demand on the public purse of the latter and of its emerging critical function in modern society. At this stage, however, the state is at a distance from the main activities of higher education. Its concerns are with the operation of the system, both as institutions and as a whole. The key concepts here, as shown above, are those of resources and efficiency. Accordingly, dominant concerns behind curriculum change -which transmit themselves into the definitions of academic professionalism - are those of changing staff/student ratios and of efficiency indicators such as unit costs. The key sense of professionalism imparted here is that of the academic as a manager of scarce resources.

2. Higher education as requiring accountability: Here, the state deepens its involvement in higher education, calling for evidence that the operations of the black $b o x$ are satisfactory. To administrative and operational con-. cerns is added an interest in the effectiveness of the operations, including teaching. Again, the definitions of academic professionalism are modified, as academics qua teachers are asked to give an account of their activities. The teaching activity is no longer taken for granted as being of value: value has to be demonstrated. In this situation, the higher education curriculum is itself exposed and brought under processes of state scrutiny. The key sense of professionalism 
imparted here is precisely that of the academic as teacher; in other words, as one with a professional responsibility for a curriculum.

3. Higher education as a system responsive to the labour market: In this strand of the changing state-higher education relationship, an economic ideology is pursued by the state and counters an ideology of higher education as liberal education (knowledge is its own end) which is still powerful in the academy. Dominant concerns of the state are reflected in changes in the internal culture within academe.

From an initiation into worthwhile forms of thought to the acquisition of marketable skills; from a sense of knowledge as process to a view of knowledge as product and outcomes; from an identification on the part of the student with the internal values of academe to an orientation towards the economy and enterprise; from propositional knowledge to actionoriented forms of knowing; from curricula designed and delivered solely by the academic world to curricula designed and delivered at least in partnership with the world of work if not entirely in that domain - these are only some of the changing value systems and consequent changes in the form of the student experience. The key sense of professionalism imparted by these changes is that of a producer of economic value.

4. The arrival of mass higher education: In the mass system of higher education, teaching skills be- come significant. Firstly, the student/staff ratios undergo further rapid change such that the logistics of handling large numbers of students per staff member come to the fore. Secondly, as we implied earlier, higher education takes on the form of a quasimarket, and students exert newly-acquired consumer power. Thirdly, a concomitant of a mass system is a growing heterogeneity of entrants. For all these reasons, the sheer act of curriculum delivery becomes more problematic. Student feedback and signs of its being taken seriously - is just one outcome of this marriage of a mass system with market responsiveness.

The demand for higher education not only grows quantitatively but also in complexity. One way of meeting that complexity of demand is to inject flexibility into curricular offerings through the provision of modular systems. Many lines can be offered to the customer. Those that fail to attract demand can easily be withdrawn. New ones can be added with relative ease ( $c f$. , Watson, 1989). Individual products can be consumed by students taking different programmes. As power shifts to the consumers to define their own learning experiences, the relative responsibilities between teacher and learners are formalized in learning contracts.

With a unitized curriculum, two important consequences flow. Firstly, as well as having - in the mass market - to compete externally for customers, academics 
must also compete in the internal market that develops within institutions. Students are no longer captured once enrolled; they can easily depart for modules on offer elsewhere in the institution. Secondly, no longer is the student seen as an inheritor of a specific tradition of epistemic understanding, entering a conversation going on across the generations (Oakeshott, 1979). Now, students are viewed as persons who are acquiring meta-disciplinary competences to aid their life chances. Transferable skills are substituted for a deep understanding of a disciplinary field. The intellectual project of students is radically recast.

The key sense of professionalism imparted by these changes is of entrepreneurialism and of the academic as a facilitator of metalearning experiences.

\section{ACADEMIC PROFESSION OR ACADEMIC PROLETARIAT?}

In his recent book, Decline of Donnish Dominion, A.H. Hasley introduces the concept of proletariat as a possible description of the academic class. Of any class, whether proletariat or not, the key question is that of the extent to which the class has control over its own forms of production and reproduction. There is also the further question of the extent to which the class recognizes itself as a class and has a sense of itself as a definite social collectivity with its own interests. But the first question is the more important, both in general terms and in the present context.
The story that we have sketched gives a significant measure of backing to the idea of the academic class as a proletariat. The essence of the story is captured in a three-stage sequence.

\section{Status Group}

In its first stage - that is, over its first seven hundred years, until the late Nineteenth Century, academics (as scholars) constituted a closely knit but small status group. Having social legitimacy, offering narrowly defined services for a narrowly defined clientèle, academics were able to secure their livings from supportive benefactors (the state and the church). With a definite market niche carrying high status, the academic guild was left largely to its own devices. Indeed, those devices were sanctified and given protection by the church and the state. Academic products were valued but were relatively marginal to the main framework of society as medieval military power gave way to mercantile and then to industrial trading power.

\section{Academic Class}

The second stage of the evolution of the dons has been relatively shortlived, lasting for about a century, from the end of the Nineteenth to the end of the Twentieth Centuries. This stage marked the high point of academic power. The period was characterized by the growth of formalized knowledge and its sequestering by the newly emerged academic class. As knowledge came to be viewed as the key to the success of modern society (bureaucratized, 
scientized, and professionalized as it was), the academics found themselves with new influence and, thereby, new powers. Not only were they left to their own devices to store and reproduce knowledge (as in the previous stage); they were now also left to their own devices to redefine and to reclassify knowledge. They had become a professional class, providing expert services to the state as their major client. If a profession is marked by its control over knowledge, then academics constituted the supreme profession, for it was their task to control the very definitions of knowledge in circulation in the wider society.

\section{Academic Proletariat}

The contemporary stage now shows signs that a once dominant class is becoming a proletariat. Less and less are the means of knowledge production in its own hands. The conditions of the relationships between itself and its new clients (the students and employers) are being defined for it rather than by it. With the loss of tenure and the growth of temporary appointments, it is even less able to determine its own reproduction. As internal evaluation, accountability systems, and customer responsiveness grows, more time is spent on administration and academic role fragments (McInnis, 1992). At the same time, academics are witnessing the continued slippage of their wider market position (a point well reflected in Hasley's data on comparative salaries).

More significantly still, the teaching function has been deskilled in three ways. Firstly, teaching is itself recast as a set of skills to be applied to students as learners. Secondly, now separated from a research context, learning is redefined as acquiring skills rather than as a deep understanding of a disciplinary field. The division of academic labour into academics as researchers and academics as teachers (whether within institutions or as a result of institutional differentiation) strengthens both developments. Thirdly, as higher education is enjoined to meet the requirements of the labour market, whether of a specific or of a general character, the pedagogical relationship changes. The new professionalism lies more in interpreting the signals of the labour market and delivering them in the curriculum than in enabling students to evaluate critically society's knowledge and understandings. Higher education, and with it professional competence, becomes more a matter of supplying externally identified techniques than in mounting a social and epistemological critique.

The notion of students as products rather than as co-participants in an open-ended and transformatory conversation severely reduces the scope of the teaching task. Vision, imagination, and wisdom are downplayed (cf., Midgley, 1989). The task is increasingly viewed as one of imparting specific and limited skills with an exchange value on the labour market. Far from being transformatory and emancipatory in intent, teaching becomes a matter of assimilation to the dominant interests of the age.

Beyond the degree of complexity of the task and market power, a further index of proletarianization lies 
in the degree of surveillance and control to which academics are now subjected. No longer trusted as professionals to exert their own forms of self-monitoring, they are subjected to proliferating forms of state-sponsored inspection and scrutiny. Even the curriculum is inspected and increasingly controlled (in the United Kingdom, through the Enterprise Initiative and in the work of the National Council for Vocational Qualifications).

\section{CONCLUSION}

The story charted in this article has been a bleak one. With the changing relationships between higher education and the state, on the one hand, and the market, on the other hand, rapid changes have taken place which have affected the professionalism of academics. The story, however, raises questions which lie in the academics' court as much as elsewhere.

If the professionalism of academics has come under attack, whether intended or not, and if that attack has succeeded, to what extent is this outcome the result of failure on the part of academics to explicitly define their professionalism ( $c f$., Lublin, 1990; Warren-Piper, 1992)? Admittedly, attempts were made to do so, but that definition came across as an apologia for the continuing control over the research function of the academy and a defence of the academics' own interests. There were, we would contend, shortcomings both in identifying a general social responsibility on the part of the academic community and a more specific set of professional respon- sibilities in relation to the teaching function.

Not having worked out a set of values around the teaching function, it is not surprising that the operations of the teaching function have been pushed rapidly and comparatively easily by external forces (Robbins, 1992). It would be exaggerated to say of the teaching function that there was no professionalism. In the United Kingdom, some institutions (notably Oxford and Cambridge through their tutorial systems; the Open University; the universities founded in the 1960's; and many, but not all, of the former polytechnics) and many individual academics took the teaching function seriously. Two things, however, were missing: firstly, a clear sense of the professional expertise appropriate to the teaching function. Knowledge and the ability to handle knowledge in skillful ways were necessary for research and scholarship, but the desiderata of high level professionalism in teaching and in promoting leárning were never spelled out (until very recently) by the academic profession (cf., Carr and Kemmis, 1986; Carr, 1989; Zuber-Skerritt, 1992). Secondly, the academic community - again, apart from the kinds of exceptions just noted - failed, as a collectivity, to develop a coherent view of the relationship between the teaching function and the wider society ( $c f$., Eraut, 1992). It was, therefore, comparatively easy for the state to engineer a switch towards a new vocationalism. The substitution of a narrow professionalism - the curriculum as training for a research career - by a narrow training in skills 
was a kind of rough justice. The idea of higher education as an education for life (rather than academe or work) had never been fully developed; and certainly not implemented.

In short, the ever-narrowing form of professionalism being enjoined on the academic community is the result in part - of the narrow definitions of professionalism which the academic community had framed for itself. It is not so much a matter of a lost professionalism as a matter of a certain kind of professionalism which was never developed.

\section{REFERENCES}

BECHER, T., Acadenic Tribes and Territories (Milton Keynes: Open University Press, 1989).

BECHER, T., and M. KOGAN, Process and Structure in Higher Educalion (London: Routledge, 1992).

BOYER, E.L., Scholarship Reconsidered: Priorities of the Professoriate (Princeton: Carnegie Foundation, 1990).

CARR, W., ed., Quality in Teaching: Arguments for a Reflective Profession (Lewes: Falmer, 1989).

CARR, W., and S. KEMMIS, eds., Becoming Critical: Education, Knowledge, and Action Research (Lewes: Falmer, 1986).

CLARK, B. R., The Academic Life (Princeton: Carnegie Foundation, 1987).

COLLIER, G., "Learning Moral Judgement in Higher Education", Studles in Higher Education 182 (1993).

DOWNIE, R. S., "Professions and Professionalism", Journal of Phllosophy of Educatlon 24 2 (1990): 147-160.

EDWARDS, E. G., HIgher Education for Everyone (Nottingham: Spokesman, 1982).

ERAUT, M., Developing the Professions: TrainIng, Quality, and Accountabllity, Professorial Lecture, University of Sussex, 1992.
GIROUX, $\mathrm{H}$. Theory and Resistance in Education: A Pedagogy for the Opposition (London: Heinemann, 1983).

GOODLAD, S., Education for the Professions (Guildford and NFER-Nelson, 1984).

HALSEY, A. H., Decline of Donnish Dominion (Oxford: Oxford University Press, 1992),

JARVIS, P., Professional Education (Beckenham: Croom Helm, 1983).

JOHNSON, T. J., Professions and Power (Basingstoke: Macmillan, 1972).

KING, R., "An Institutional View", Paper for the NATFHE Conference on Managing the University Curriculum in the Year 2000, mimeo, 1992.

LUBLIN, J., "Academia and Industrialization", in I. Moses ed., Higher Education in the Late Twentieth Century (Kensington, Australia: HERDSA, 1990).

McINNIS, C., "Changes in the Nature of Academic Work", Australian Universities' Review (1992)

MIDGLEY, M., Wisdom, Information, and Wonder (London: Routledge, 1989).

MINOGUE, K., The Concept of a University (London: Weidenfeld and Nicolson, 1973).

OAKESHOTT, M., in T. FULLER, ed., The Voice of Liberal Learning (London: Yale, 1979).

PERKIN, H., The Key Profession (London: Routledge and Kegan Paul, 1969).

ROBBINS, D., Business and Management Education and the Rise of Entrepreneurial Society in England, 1945-1992, mimeo, 1992

RUESCHEMEYER, D., Power and the Division of Labour (Cambridge: Polity Press, 1986).

TAPPER, T., and B. SALTER, Oxford, Cambridge, and the Changing Idea of the University (Buckingham: Open University Press, 1992).

WARREN-PIPER, D., "Are Professors Professional?", Higher Education Quarterly 462 (1992): 145-156.

WATSON, D., Mannglng the Modular Course (Milton Keynes: Open University Press, 1989).

ZUBER-SKERRITT, O., Prolesslonal Develop. ment In IIlgher Educatlon (London: Kogan Page, 1992). 


\title{
COMPARING QUALITY IN EUROPE
}

\author{
John BRENNAN, Leo C.J. GOEDEGEBUURE, Tarla SHAH, \\ Don F. WESTERHEIJDEN, and Peter J.M. WEUSTHOF
}

- As higher education begins to operate increasingly in a European framework, consequences for the assurance of quality in higher education are bound to become evident. A pilot study to develop a methodology for the comparison of quality across different higher education systems is described. The project involved comparison of ten study programmes in economics in Germany, the Netherlands, and the United Kingdom. A design derived from general considerations about the concept of quality and about the nature of

\section{QUALITY ASSURANCE IN THE EUROPEAN CONTEXT ${ }^{1}$}

In the 1990's, higher education institutions will be operating increasingly in a European framework, producing citizens living and working in an environment with few remaining national barriers. The growth of a European labour market for skilled manpower will extend the search by employers for new graduates across different national systems of higher education. Similarly, the aspirations of students to study abroad and the enhanced opportunities for them to do so will lead to much higher levels of student mobility across national boundaries. In addition to choosing between subjects and institutions,

\begin{abstract}
higher education and different systems incorporated two stages. First was the collection of information and the processing of this information into manageable data sets; second was the assessment of the information by way of peer review. The proceedings and principal findings of both stages followed the overview of the project design. The article concludes by highlighting some implications of this pilot project for the future of quality assurance in higher education on a European scale.
\end{abstract}

students will also be choosing between different systems of higher education. Such trends reinforce each other and raise questions as to the eventual emergence of a European higher education system.

National governments have a number of concerns in these matters. Economic competitiveness in the single market will be significantly influenced by the amount and quality of the skilled manpower available for national economies. The returns on investment in higher education will also be viewed in an international context. If it takes longer and is more expensive to produce a graduate engineer in one country than in another, are there any compensating advantages occurring from the addi-

\footnotetext{
${ }^{1}$ The authors of this article acknowledge the contributions of the other members of the project team: Edgar Frackmann, Richard Lewis, and Frans van Vught. They also wish to thank the participants in the peer review groups in the project.
} 
tional investment? And, if students prefer to study abroad, for whatever reason, one might predict that increasing numbers will not return home. Some countries, therefore, might be faced with a net outflow of skilled manpower - a phenomenon already perfectly common on a regional basis in many nation states.

Many higher education institutions are already developing substantial international activities: in research; student exchanges; joint study programmes, etc. For the individual higher education institution, Europe provides an extended arena in which it must compete for acceptance, prestige, students, staff, and funding as it must in its local, regional, and national arenas.

But the matter is not simply one of competition. The academic enterprise is intrinsically co-operative and collegial. The standards of work of the individual academic, department, or institution are referenced against the standards of work achieved elsewhere, both within countries and internationally. Thus, if institutions, departments, and individual academics wish to assure their standards - which includes seeking ways of improving them they will increasingly find a need for comparators from beyond their own countries.

All the interested parties - governments, institutions, students, and employers - are facing these issues within national higher education systems which are themselves expanding and diversifying. New kinds of institutions abound, with new and frequently changing names. New distinctive non-universitysect or sareemerging in some countries just as oldernonuniversitysect orsaredisappearing into enlarged unitary systems in others. The same can be said of qualifications and study programmes.

This rapidly changing European higher education scene provided the context for a project undertaken by the Center for Higher Education Policy Studies (CHEPS) in the Netherlands, the Council for National Academic Awards (CNAA) in the United Kingdom, and the HochschulInfomations-System in Germany. The impetus for the project, which came initially from the Dutch government, arose out of a concern about the quality of the graduates who were being produced by Dutch higher education in a European context. At the same time, in the United Kingdom, the CNAA was considering how far, in light of European developments, it could discharge its statutory obligations for the maintenance of standards if it continued to restrict its frame of reference to the United Kingdom.

Governments, employers, students, academic staff members, institutional managers, and others can and do make judgments about quality. What is at issue is how they do it and the evidence they use. Judgments about quality which transcend national boundaries are particularly difficult to make, yet, as we have tried. to show above, will become increasingly necessary. How then might quality be compared? 


\section{John BRENNAN, Leo C.J. GOEDEGEBUURE, Tarla SHAH, Don F. WESTERHEIJDEN, and Peter J. M. WEUSTHOF}

\section{METHODS OF QUALITY COM- PARISON}

\section{Preliminary Definitions: System and Process of Higher Education}

For the purpose of this study, higher education will be observed from a systems theoretical point of view, it providing generally applicable concepts that facilitate analysis. Systems consists of interrelated elements ${ }^{2}$, meaning that the state of any element (or actor) is influenced by the states of the other elements within the system. The relevance of these abstract statements for the purpose of observing quality in higher education is that the quality of a study programme is influenced not only by the characteristics of the study programme itself, but also by other elements of the higher education systems (the environment of the study programme). In the systems approach, it is usual to view the behaviour of elements as a process. Processes consist of input, throughput (the process in the strict sense), and output, plus the feedback of output via the environment of the actor to the input of a new round of the process. In Figure 1 an overview is given of how these concepts are applied in the practice of higher education.

\section{What is Meant by Quality?}

We shall not go into a discussion of what quality essentially is. A single, substantive definition of it is not possible - the one person who almost found one, the Phaedrus in Pirsig's novel, went crazy when he found it, so all we are left with is the famous quotation: "But when you try to say what the quality is, apart from the things that have it, it all goes poof! There's nothing to talk about".

More viable (and more mentally sane) is the notion that quality is fitness for purpose and that to say what quality is depends on the subject's view of the purpose of higher education. There are at least as many definitions of quality in higher education as there are categories of stakeholders (such as students, teaching staff, scientific communities, governments, and employers) multiplied by the number of purpose or dimensions these stakeholders distinguish. This fact, however, does not yet tell us what to look for when we are interested in observing the quality of higher education, but it does provide the necessary sensitivity to the fact that it can be viewed from different perspectives and that each perspective consists of multiple dimensions.

\section{Quality of What?}

In keeping with the two possible answers to the question (broadly stated) of what higher education produces, two objectives of the assessment of quality present themselves. On the one hand, one can concentrate on the quality of the output, the graduates. What is their quality on the labour market, or what is their gain in terms of personal qualities

${ }^{2}$ See also J. K. DE VREE, Foundations of Social and Political Process (Bilthoven, Netherlands: Prime Press, 1982).

${ }^{3}$ R. M. PIRSIG, Zen and the Art of Motorcycle Maintanence (1974), p. 163. 
Figure 1. System and Process of Higher Education

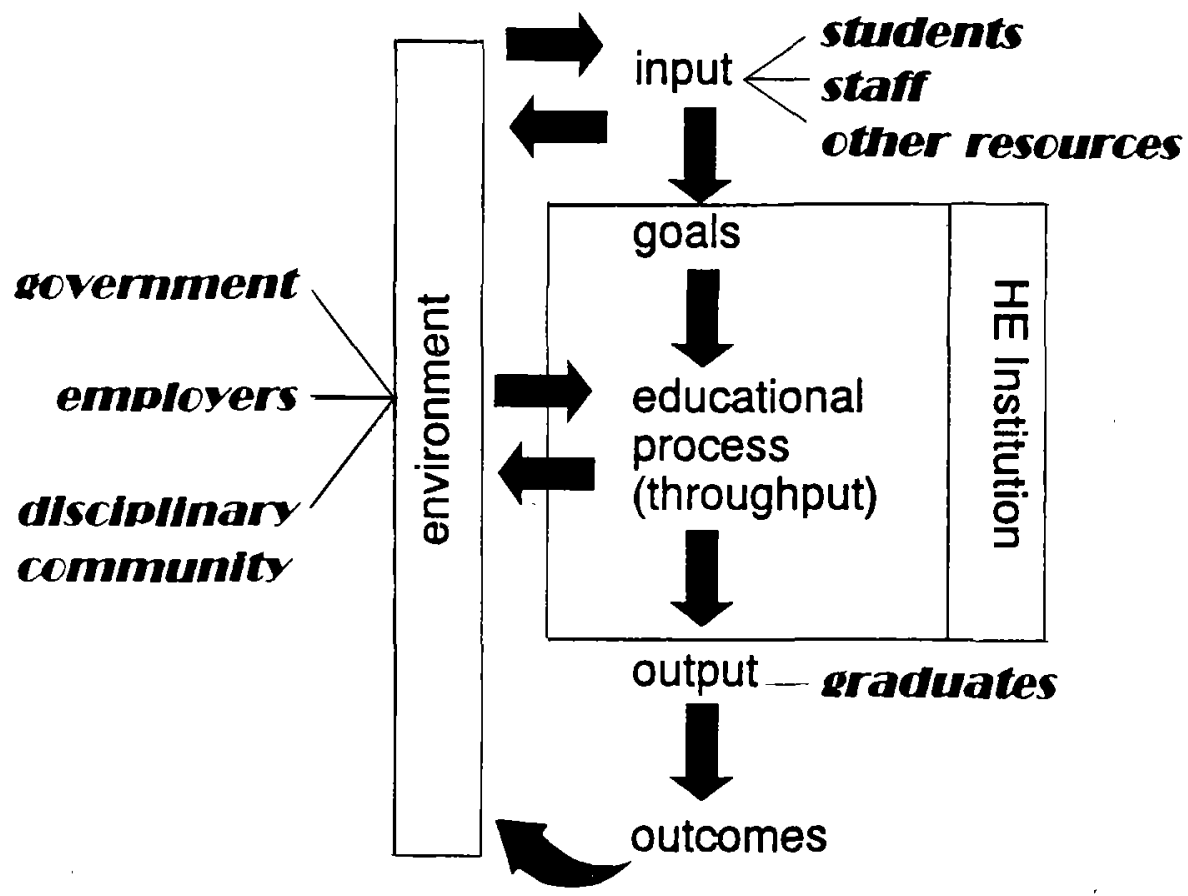

from experiencing higher education? On the other hand, one can argue that as higher education is the provision of education - a study programme to students, the quality of this process is what should be assessed.

Given the background of the project, what we were eventually interested in is the quality of graduates. But quality depends largely on the study programme (including the way it is delivered). Other factors may include the personality of the student, etc. As the study programme and its immediate context (forms of teaching, staffstudent ratio, physical environment, remedial teaching programmes, etc.) are the factors that can be manipulated by the actors enagaged in higher education, we focussed on the process.

This focus still does not indicate exactly what will be observed or how it will be observed. As the how to a large extent influences the what, we shall now turn to how we shall look at quality, and then go on to consider methods that can be used to gauge quality in higher education.

\section{Threshold Quality or Relative Quality}

The way accreditation agencies usually judge educational programmes involves the decision as to whether or not the programme satis- 


\section{John BRENNAN, Leo C.J. GOEDEGEBUURE, Tarla SHAH, Don F. WESTERHEIJDEN, and Peter J. M. WEUSTHOF}

fies a number of criteria. If these are met, the programme has passed the test. It is acknowledged as a genuine higher education level study programme. This way of looking at quality requires some (preferably explicit) set of criteria against which the programme is to be judged. Furthermore, the only interesting question is pass or fail? - not whether the programme passes by a narrow or by a wide margin, or whether it has improved since the previous accreditation.

Another way of looking at quality does not require the prior definition of a set of (absolute) criteria, but is concerned with relative quality. Relative quality is the concept that immediately comes to mind when either diachronous comparisons have to be made of a single study programme (such as whether or not it has improved since the previous accreditation) or when synchronous comparisons are made, that is, comparisons between different study programmes.

\section{Performance Indicators and Peer Review}

Two basic methods exist for assessing quality of education. One is based on performance indicators and other intersubjective data, the other on evaluations by colleagues, by experts - so-called peer review.
When speaking of performance indicators, one is tempted to think first of all of quantitative measures. Qualitative performance indicators also exist. However, an authoritative definition of performance indicators does not exist. Many aspects and categories of performance indicators can be distinguished ${ }^{4}$, but for the present purpose, as it is enough to differentiate between performance indicators and peer review, a relatively simple definition will suffice: performance indicators are empirical, quantitative, or qualitative data that point to the goal achievement of a system. ${ }^{5}$ The concept of indicators is used in this study in this broad sense - not in the narrow, reductionist sense of quantitative, preferably financial, data.

The traditional example of peer review is the referee system of scientific journals. An anonymous output of scientific activity (a manuscript) is judged by a few anonymous fellow scientists (peers) who are reputed to possess sufficient expertise with regard to the questions addressed in the article. The norms and criteria they use are in their judgment the canons of the methods and subject matters of good science that dominate in the particular discipline. These norms are not, as a rule, fully explicit. It is impossible to define $a$ priori the characteristics that make an article superb, whether it concerns

4 See M. CAVE, et al., The Use of Performance Indicators in Higher Education (London: Jessica Kingsley, 1988, pp. 17ff).

${ }^{5}$ See M. S. R. SEGERS, F. J. R. C. DOCHY, and W. H. F. W. WIJNEN, Een set van prestatie-indicatoren voor de bestuurlijke omgang tussen overheid en instellingen voor hoger onderwijs (Zoetermeer: Minsterie van Onderwijs en Wetenschappen, 1989), pp. 2-3. 
the craftsmanship and literary value expected of a historian, or the parsimoniousness and elegance of a mathematical treatise. ${ }^{6}$ Even less can such norms be turned into intersubjective data. Another example of peer review is provided by the study by the former Advisory Council for Research Policy (RAWB) on health science in the Netherlands: here, among other methods, scientists in the international field, part of a sampling, were asked in a questionnaire to judge different aspects of the research of their Dutch peers. Again, the norms the respondents used remained unknown. This virtually inevitable subjectivity forms the essence of peer review.

In the context of quality assessment in higher education, the concept of peer review is often used somewhat loosely. All methods which involve human judgment are then called peer review. The judgments may or may not be informed by more or less objective data bases (among them performance indicators); the judges may or may not be peers. What peers are is not clear. Peer review as it is known in science studies involves scientists from the discipline under consideration who have a high reputation in their field. Sometimes, however, the opinion is expressed that peers should not be too different in terms of reputation from the persons whose quality they are to assess. Thus the circle of peers available for any one institution becomes much smaller. It becomes very difficult to produce a discipline-wide, national assessment, given the existence within a discipline of research groups with highly different reputations. The definition of peers is sometimes broadened, on the other hand, to include not just scientists, but also representatives of audiences for the discipline under investigation, such as members of industry, employers, and professionals. The latter, broad, definition is the one often used in practice.

\section{International Comparison of Quality in Higher Education}

Defining quality in higher education is never an easy matter. The problems, indeed, are multiplied, as shown in the examples given below, when comparing quality internationally.

Although the several elements of the higher education systems are present in different countries, they have different characteristics. The input varies in that staff-student ratios vary widely. The relationships with the environment vary because government funding levels vary. Institutions vary, for example, in the sense that what in one country is the exclusive realm of university teaching, can be taught in another country by other kinds of institutions. The educational processes vary in that they take three years in one country and four or five in others. The goals of these processes vary from specialized training in one country to general education in another. Who then can expect the quality of these

\footnotetext{
${ }^{6}$ For the different criteria applied in different disciplines, see also T. BECHER, Academic Tribes and Terrltories (Milton Keynes: SRHE/Open University, 1989).
} 


\section{John BRENNAN, Leo C.J. GOEDEGEBUURE, Tarla SHAH, Don F. WESTERHEIJDEN, and Peter J. M. WEUSTHOF}

processes, or the quality of graduates, to be even approximately the same?

Categories of stakeholders, and the power balances among them, vary in different countries, with consequent variances in the socially accepted definition of quality of higher education. Moreover, different dimensions of quality may be emphasized by categories of stakeholders in each country. For example, differences in government policies among countries imply a different weighting of dimensions of quality (cheaply educated labour force as against broad individual development at top-level, no matter what the cost in time and money).

National traditions regarding the acceptability of methods of quality assessment vary. In one country, performance indicators are accepted and used on a regular basis, while in another country, they are treated with great suspicion. Peer review may not be accepted in another country because of its corruptibility by cartels of colleagues, while in a third country, it is the only legitimate method.

It is already far from easy to reach national agreement on the definitions of data to be used as performance indicators, or even simply as statistics. But internationally, the chances are slight at best that such definitions are the same even in only two countries. This problem is aggravated (or perhaps caused) by the fact that concepts or phenomena that on the surface seem to be the same in different countries, appear, on second look, to have different meanings, because of the differences in the context in which they are used, which is often a consequence of the different structures of the higher education systems. Thus data (whether quantitative or qualitative), even if present for all programmes within a national higher education system, will hardly ever be comparable internationally.

Some aspects of higher education in the different countries remain that are more or less the same. For instance, higher education always strives to pass on the best of the knowledge in a discipline to a new generation of students. Some commonality is an absolute requirement, without which the comparison of higher education internationally would become impossible. But given this common core, the challenge is to find a way of mapping the different qualities of different national higher education systems, recognizing their unique strengths and weakenesses.

\section{DESIGN OF THE PILOT PROJECT}

\section{Delimitation of the Scope}

The previous section gave a short overview of the methodical difficulties in observing quality in higher education. To summarize in one sentence: the assessment of quality in higher education is a complex question, and international comparison of it is even more complex, but not impossible. To keep the project manageable, a rigorous delimitation of scope was necessary.

Keeping in mind that education is always education in something, we did not try to establish the quality of higher education, but the quality of study programmes in a certain dis- 
cipline. An appropriate discipline for a pilot project should have an internationally recognizable body of common knowledge: a number of subjects or methods, etc., that is, part of the knowledge every peer in the disciplinary community should possess. This requirement rules out some of the soft disciplines of the humanities and the social sciences. On the other hand, for a pilot study it is interesting to study a discipline in which some national differences may exist, not only in the environment of the educational programme (e.g., government policy, student age at entry, number of years of study), but also in the educational process itself. For while it may be interesting in its own right to observe the influence of environmental factors on an otherwise identical study programme, it is advisable for a pilot project to check every part of the analytical scheme. This requirement makes some of the hard disciplines, such as physics or chemistry, less attractive. In those sciences, supposedly, the disciplinary core is so large and the content of study programmes is so much controlled by the international disciplinary community that national differences are relatively unimportant. As a happy medium in between these two extremes, economics was chosen as the discipline for this pilot study. Economics has a common body of knowledge, consisting of, i.a., microeconomic theory (theory of individual choice, utility maximization principle), macro-economic approaches (neo-classical, Keynesian, and post-Keynesian economics), and a common language (economicmathematical modelling). However, this common body of knowledge leaves sufficient room for national differentiation, e.g., to the extent to which institutional economics, economics law, or econometrics are part of what is expected of graduates at national level.

Given the expected importance of national, system-wide characteristics and the complexity of any one higher education system, the number of countries to be involved in the project had to be kept limited. The participating countries in the project were the Federal Republic of Germany, the Netherlands, and the United Kingdom. In practice, the overview of Germany was limited to the Bundesländer that were part of the federal republic at the start of the project, in 1989. For the United Kingdom, attention was focussed on England.

Within these countries, different types of higher education and different levels of academic degrees exist. As regards degrees, the decision was made to concentrate on the first, most common degree, that is the Diplom (or equivalent) in Germany, the doctorandus in the Netherlands, and the Bachelor's in the United Kingdom. More or less arbitrarily, the decision was reached that from the Continental systems, only the university sector would be involved, leaving out the less academically and more professionally oriented Fachhochschulen and Hogescholen (HBO-institutions). On the British side, however, the polytechnics were included in the project, since 
both universities and polytechnics award Bachelor's degrees.

\section{Focus on Which System Level?}

Viewing higher education as a system leads to the question of which system level should be the focus for comparison. The original intention of the project was to focus on the national level: in what ways are the qualities of economics different from each other in the three countries? The basic idea behind such a focus was that systemwide characteristics are the boundary conditions for any higher education programme within that country. For example, the nominal number of years of study is often determined nationally, as is the certification of study programmes or the entry qualifications.

It was clear from the outset, however, that in addition to betweencountry variance, there is also withincountry variance. In every academic discipline, some sort of status-hierarchy exists of the individual peers. The result is a status-hierarchy of institutions (which partly leads its own life; if, for instance, a bigh-reputation professor moves from one institution to another, his doing so does not automatically result in a proportional reduction of status for the institution). In European higher education, this institutional hierarchy is often informal. No Carnegie-classifications or authoritative rankings exist on the eastern side of the Atlantic. Moreover, in many European countries, the basic quality of all institutions (within a given sector of higher education) is a premise of higher education policy, even if informal hierarchies do exist, as evidenced by the Oxbridge complex in the United Kingdom or by the rumour-like knowledge peers all have of their own disciplines. To take this within-country variance seriously, the level of the individual study programme should be the focus of comparison.

Recognition of the differences among individual study programmes does not imply neglect of the influence of higher level factors in determining the quality of higher education. Moreover, the relative importance of the different levels is not known beforehand. Therefore, a multi-level approach was chosen for this project, even though the emphasis was on study programmes (see Figure 2). Consequently, decisions also had to be made about the study programmes to be involved, since it would not have been feasible to cover all economics programmes in the three countries. The decision made was to identify some typical examples, with a certain range of quality within each country (as far as this could be assessed beforehand).

\section{Choice of a Method for the Pilot Project}

As indicated in the previous section, neither performance indicators nor peer review are perfect ways of assessing the quality of higher educa-

${ }^{7}$ A recent effort at ranking higher education institutions (per discipline) has been made by Libération (December, 1989). 
Figure 2. Scheme of the Multi-Level Approach of the Project

\begin{tabular}{|l|c|c|c|}
\hline & system & discipline & $\begin{array}{l}\text { study } \\
\text { programme }\end{array}$ \\
\hline context & & & \\
\hline input & & & \\
\hline process & & & Imost \\
\hline output & & & \\
\hline
\end{tabular}

tion. The performance indicator side of this question has been discussed rather extensively. Although critiques of peer review are less common, they also exist. ${ }^{8}$

In line with the methodological advice that, when several imperfect measurement strategies are available, it is good practice to triangulate the results of one method by those of another, the practice has developed of using performance indicators, not at face value, but following intelligent manipulation. ${ }^{9}$ This means that the data are put into the hands of a committee of peers, who can, on the basis of their expertise, evaluate the data and who can supplement them with their knowledge of the field. On the other hand, objective indicators put reins on the otherwise uncontrolled subjective judgments of peer reviewers.

The hope was that this method would give the best of both worlds; however, there was no way of knowing whether or not this result would be attained. (If there were a method that could be used as a criterium, it, rather than the less perfect approximations, would have been used!) The design of the project was based on the following logic: a trial peer review was preceded by the collection of indicator-type data (qualitative and quantitative inter-

${ }^{8}$ For an (incomplete) overview see, e.g., D.F. WESTERHEIJDEN, Promises, Problems, and Pitfalls of Peer Review, Paper for the 3rd International Seminar on Assessing Quality in Higher Education, Bath, 16-19 July, 1991.

${ }^{9}$ See also the data on the emerging patterns in British and Dutch quality assessment systems in higher education, as evidenced in, e.g., L. C. J. GOEDEGEBUURE, P. A. M. MAASSEN, and D. F. WESTERHEIJDEN, eds., Peer Review and Performance Indicators (Utrecht: Lemma, 1990). 
subjective data). Therefore, the project consisted of two stages: in Stage 1, material was gathered about higher education in economics in the three countries, in Stage 2, a peer assessment of the quality of the economics programmes was implemented.

\section{STAGE 1: COLLECTION OF WRITTEN DATA}

The objective of the first stage of the project was to gather relevant information for the peers on which they could base their judgments regarding ten programmes that were expected to give a typical view of higher education in economics in each of the three countries.

\section{Method of Data Collection}

Before beginning data-collection, a checklist was developed. The structure of this checklist was based on the system/process view of higher education as shown in Figure 2 (input, process, and output) and the different system levels (system, discipline, and study programme). On the basis of this checklist, which contained a large number of features, data were collected as to the different higher education systems in the countries mentioned. We shall not mention all the features here but shall give some indications.

The input dimensions we were interested in at the system level were general selection procedures, the average student-staff ratio in a country, and some general characteristics of students at entry. The process dimensions in which we were interested were completion and transfer rates and length of study programmes. The output dimensions at this level were characteristics of graduates such as average salary, the sectors in which graduates are employed, and the number of unemployed graduates. As context at the system level, we gathered information about the structure of the three higher education systems and qualification structures. The information about the characteristics of the three national systems was intended to provide the context comparison of quality by clarifying what should be compared with what in different systems.

The second level at which we looked for data was the disciplinelevel. At this level we described elements common to all study programmes in economics in the higher education system of a country, such as the sectors of higher education in which economics programmes existed, the main specialisms within the discipline, the job prospects, broadly speaking, of graduates in this field (did they differ from the national average?).

At the lowest and most important level, that of the study programme, we collected information on three or four more or less typical study programmes per country. The information at this level consisted of, among other things, a description of the course structure, detailed descriptions of course units organized into core subjects and specializations, and entry level and exit level examination questions in core subjects and in some important optional subjects. 


\section{A Preliminary Assessment of the Data Collection Process}

We knew beforehand that the Netherlands and the United Kingdom differed from Germany with respect to the tradition of quality assessment. Both the Netherlands and the United Kingdom have established procedures for quality assessment, e.g., the CNAA validation, the Association of Universities in the Netherlands (VSNU), and the Hoger Beroeponderwijs (HBO) Council visiting committees, while no formalized procedures of this kind exist in Germany. Although we do not want to suggest that because of the existence or non-existence of such procedures any conclusions can be formulated a priori regarding differences in quality among these countries, it became apparent that they have had marked effects on the availability of data. Both in the Netherlands and in the United Kingdom, more or less extensive data were available at the institutional level on both programmes (structure and contents), student achievements, and graduate follow-up studies (labour market related). In Germany, this kind of information proved to be harder to come by, and in particular, institutional level data turned out to be something of a problem. Or, phrased differently, there appeared to be less of a tradition of systematic data gathering at the institutional level in Germany. We therefore believe it fair to conclude, again without making any comments on the quality of institutional performance, that the existence of institutionalized quality assessment procedures results in the availability of process and output related data at the institutional level.

Another more practical problem was the language and transfer problem. Can all educational terms be translated into a sort of universal language, so that there will be no misunderstanding in the three countries about the descriptions of them? An innocuous example of this problem can be illustrated with the words course, subject, and unit.

\section{Preliminary Results of the Data}

We argued earlier that the performance indicator kind of data we attempted to collect would be used primarily as an input for the peer review process, and not for making direct comparisons. We still hold this opinion, but it should be somewhat qualified. Certainly at the systemlevel, data can be compared rather straightforwardly without the problem of contextual distortion. Based on the results of Stage 1, the following comparative statements can be made for the dimensions previously discerned, highlighting the similarities and differences between the three countries.

\section{Structure of the Systems}

With respect to primary and secondary education, one should note that in general Dutch children spend 14 years in school before enrolling at a university, while in Germany and in the United Kingdom, the number of years is 13. Also, British and Dutch students, because of the structure of the educational system, can enroll at the age of 18 , while in Germany, they are at least 19. German children start 


\section{John BRENNAN, Leo C.J. GOEDEGEBUURE, Tarla SHAH, Don F. WESTERHEIJDEN, and Peter J. M. WEUSTHOF}

their formal education at the age of six, while in the United Kingdom and the Netherlands they do so at the ages respectively of 5 and 4 .

With respect to pre-university secondary education, one can note that the British system leads to an earlier specialization in terms of subject fields than is the case in Germany and the Netherlands. In general, British pupils take their General Certificate of Secondary Education (GCSE) examinations at the age of 16 , after which they specialize in two or three fields for which they take the A-level examinations at the age of 18 . In the Netherlands, pupils take their final pre-university examinations (consisting of 7 subjects) at the age of 18 , while in Germany students take their final examinations (either a general or a subject-specific one) at the age of 19. No two-stage process exists in these countries.

With respect to the higher education structure, one should note that the British structure differs markedly from the Dutch and the German ones. In the United Kingdom, a distinction can be made between the bachelor's and the master's degree, whereby the bachelor's degree can be obtained after, on average, three years of study and can be followed by a master's degree after a further one or two years of study. The bachelor's degree is a full degree, in the sense that it is considered to be a final qualification which is recognized by the labour market. In the Dutch and German systems also, a distinction can be made in two phases, namely the propaedeutic and doctoral phases in the Netherlands and the Grundstudium and Hauptstudium in
Germany, but these are not considered to be final qualifications and are not recognized by the labour market. In Germany, the initial phase takes two years to complete; in the Netherlands, one year. The final phase takes three years to complete in the Netherlands and two to twoand-a-half years in Germany. Formally, therefore, not much difference can be observed in terms of length of study. However, in practice these differences are substantial.

\section{Input Features: Admission, Selection, and Age}

The basic difference between, on the one hand, the British system and, on the other hand, the Dutch and German systems, is the fact that British institutions can select their students, while in Germany and the Netherlands, a pre-university qualification procedure entitles a student to enroll at a university of his or her preference.

In the United Kingdom and the Netherlands, students generally enroll at a university or polytechnic more or less directly from secondary education. In general, therefore, students are under 19 years of age when they enroll. In Germany, however, the alternative routes to higher education are far more common. Approximately half the student population either accumulates working experience or combines work with education (Berufsbildung) before enrolling at a university. This possibility implies that the average age of first year students is substantially higher (21.7 years), a situation quite similar to that of students at the British polytechnics. 


\section{Process Features, Actual Length of Study, and Completion}

As indicated above, substantial differences can be observed regarding the actual amounts of time students take to complete their -university education. In the United Kingdom, a student takes either three or four years to complete the bachelor's degree, depending on the programme. Approximately 85 percent finish their degrees within this 3 to 4 year period. In contrast, both Germany and the Netherlands display a marked difference between formal and actual length of study. In the Netherlands, the average student takes some 5.7 years to complete the degree, while in Germany, the average length of study is between 7 and 7.5 years.

Data on completion rates are difficult to obtain, as output data have to be related to actual enrollment years. Most of the time such data cannot be obtained. Based on the limited data available for the three countries in this respect, it would seem that in the United Kingdom completion rates are somewhat higher than in the other two countries. However, such a conclusion has to be interpreted very carefully.

The above conclusions are, of course, not shocking. They are (or should be) known to those involved in comparative higher education research. Nevertheless, straightforward comparisons of this type have proved to be helpful as essential background information as well as starting points for formulating questions regarding the problem of comparability in peer review. As will be indicated in the next section, these structural differences and similarities featured prominently in the outcomes of the peer review process.

\section{STAGE 2: INTERNATIONAL PEER REVIEW}

Seventeen economists from the three countries attempted to compare the qualities of university economics programmes through an examination of the ten study programmes. The economists were partly internal and partly external to the institutions involved. The group also included a representation of the professional field outside higher education. The main conclusions of their report are summarized as follows:

i. Broad comparability exists between the content of economics course programmes to graduate level in the Netherlands, Germany, and the United Kingdom; this situation holds particularly true with regard to the core curriculum components of microand macro-economics and quantitative methods.

ii. Despite the similarities in content, differences in the length of programmes and in teaching and assessment methods are such as to suggest differences in learning outcomes. These could not be explored within the context of the peer review, but the panel recommended that this important issue be explored further using other methods.

iii. It did appear clear, however, that the Dutch and German programmes paid greater attention to statistical and quantitative methods, that the levels of stu- 
John BRENNAN, Leo C.J. GOEDEGEBUURE, Tarla SHAH, Don F. WESTERHEIJDEN, and Peter J. M. WEUSTHOF

dent achievements in these areas were felt to be higher in both countries than in the United Kingdom.

iv. There are differences of emphasis in the objectives of economics programmes between the Netherlands and Germany on the one hand and the United Kingdom on the other. In the latter, more importance was attached to economics as a vehicle for the general intellectual development of the student. Preparation of professional economists was reserved for a minority enrolled in masters' programmes, i.e., a further year of study. This appears not to be the case in Germany and the Netherlands. Graduates of the six Dutch and German course programmes would be regarded as professional economists and could expect to gain employment as such. Graduates of United Kingdom universities would not be in this position.

v. The above distinction suggested to some members of the panel that a United Kingdom master's programme in economics would have been a more suitable com. parator for the study.

vi. The different national contexts provide important "boundary conditions" in which teachers of economics must work. The nature and length of secondary education and the available routes into higher education represent one important boundary condition. The uses made of different educational qualifications in the labour market and the expectations of employers represent another. These affect study programmes in higher education through course aims and objectives and through the aspirations and expectations of entering students. Differences in learning outcomes are likely to result.

vii. The generally younger age of United Kingdom students is an important factor conditioning the design and delivery of programmes in that country. The greater structuring of programmes and support for students is probably necessary to achieve desired learning outcomes with low levels of dropout over the short three-year period. The broader experience and the greater maturity of Dutch and German students are likely to affect their capacity to learn and the benefits they obtain from their study programmes. Panel members with experience of teaching students from more than one of the three countries could vouch that there were real differences.

viii. The opportunity for students in the United Kingdom to study non-economics subjects beyond the foundation year appears to be much more limited than in the other countries. In Germany and the Netherlands, subjects such as law and political science have a continuing importance throughout the programme of study. 
ix. Important differences exist within countries with respect to the above factors. In particular, the extent to which there is comparability in the learning outcomes - both in terms of content and level - across individual national higher education systems must be open to question.

\section{PROBLEMS AND ISSUES}

\section{Problems and Alternative Methods}

A tentative conclusion here is that the strengths and weaknesses of peer review for international purposes are the same as its strengths and weaknesses generally. Its major strengths derive from the knowledge and experience which are brought to bear on the process and hence the authority which derives from the resultant judgments. The latter, we believe, have a robustness, credibility, and legitimacy which, for example, bureaucratic or performance indicator approaches are unlikely to attain. Equally, however, there is always danger that the judgments do not provide the kind of clear-cut picture of reality which decision-makers require. The peer review meeting also revealed another of the strengths of the method - its potential contribution to quality enhancement through the exchange of ideas and information.

The weaknesses evident were also the weaknesses of peer review more generally: the tendency for self-interests to intrude (whether personal, institutional, or, as in this case, national) and the difficulty of assessing learning outcomes and hence academic levels. The latter, we felt, was the major failure of peer review: the inability to reach the same firmness of conclusion about academic level as was achieved with respect to curriculum content. The need to augment peer review of this sort by methods which provide a more direct indication of outcomes and levels was a major conclusion of the review. Possible methods might include employer inputs, graduate feedback, external examiners, or perhaps blind marking of sample assessments from the three countries by another international panel.

In comparing quality in higher, education, ambiguity can often be found as to whether one is comparing programmes of study or the outcomes of those programmes, i.e., what graduates have learned. With regard to the latter, there are many extra-educational factors which get in the way in addition to the methodological problems to which reference has already been made. But in relation to the former, the international panel did reach a broad consensus about what a degree-level programme in economics should contain in general terms - at least in the three countries involved - and thereby provided a comparator against which other economics course programmes might be judged.

\section{The Future of Quality Assessment on a European Scale}

The present project is one of the first efforts to assess the quality of higher education on an international 


\section{John BRENNAN, Leo C.J. GOEDEGEBUURE, Tarla SHAH, Don F. WESTERHEIJDEN, and Peter J. M. WEUSTHOF}

European scale. ${ }^{10}$ The need for international quality comparison can be expected to grow, firstly within the Communities, as has already been indicated. With the continuing integration of the Common Market as concerns labour, the number of graduates with foreign education can be expected to grow in all member countries. The possibilities for international recruitment, for example, to obtain the best specialists for given jobs, will grow accordingly. Closer to the daily experience of higher education, we are witnessing increased mobility, both of students and of staff members, stimulated by several European Communities programmes such as ERASMUS and LINGUA. But Europe is larger than the European Communities, even if the number of European Communities countries may expand in the coming years (e.g., Sweden and Austria). Improved co-operation between the European Communities and the remaining European Free Trade Association countries is being discussed. Also the possibilities for free co-operation and mobility have grown tremendously in the last few years within Europe, with the Velvet Revolutions in the central and eastern European countries. Mobility be- tween the European Communities and some associated countries and the countries of central and eastern Europe is stimulated by the TEMPUS programme. The central and eastern European countries are engaged in large-scale processes of restructuring not in the last place in the higher education systems. Quality control on a European scale may be particularly relevant to these restructurings.

One, however, can rightly ask whether or not with the growing internationalization of the environment of higher education, the actors within the systems are aware of the need for comparative European quality assessments. There is, as yet, little demand for it. Latently, however, such demand is present: for example, such questions as "Who do we want in our ERASMUS network?", or more generally, "With whom do we want to co-operate?" are being regularly asked within higher education institutions in many European countries. Presently, such questions are answered in ways that can hardly be distinguished from answers, given at random, or the decisions are made from private hunches or the fortuitous acquaintances of certain professors. Such is not high quality

${ }^{10}$ Other recent projects of the same kind are the comparison of Business Studies in Sweden with selected study programmes in Germany, Finland, France, the Netherlands, and the United Kingdom; see EUROPEAN FOUNDATION FOR MANAGEMENT DEVELOPMENT, STRATEGIC AUDIT UNIT, Business Administration and Economics Programmes in Swedish Higher Education: An International Perspective (Brussels: EFMD, 1991) and the Programme Recognition Committee in Electronic Engineering, organized by the Association of Universities in the Netherlands (VSNU), results of which can be expected in 1992. For a fuller account of the present project, see J. BRENNAN, L. C. J. GOEDEGEBUURE, T. SHAH, D. F. WESTERHEIJEDEN, and P.J.M. WEUSTHOF, Towards a Methodology for Comparative Qualily Assessment in European Higher Education (London: CNAA/CHEPS/HIS, 1992). 
decision-making. More systematic knowledge of the quality of different higher education institutions in the European countries would, in such cases, help in making better informed decisions.

The kinds of questions addressed in the previous paragraph deal with the institutional level, and will in fact, more often than not, even be posed and answered at the level of faculties or of study programmes (e.g., a good partner for the economists of a given institution may not be a good partner for the physicists). These levels were chosen deliberately because one of the more general conclusions of this pilot project is that quality comparisons at national level are too general to be of much use. We do not want to deny that national, system level, circumstances deeply influence the quality of study programmes, but they remain boundary conditions, within which a large variety of qualities (on the different dimensions) can be realized. The latter assertion, of course, is borne out by the familiar knowledge that within each country, hierarchies of prestige - at least partly based on quality exist for study programmes or facul- ties. One might thus conclude that European quality control would need to be based at programme-level or at faculty-level.

How can quality assessment on a European scale be organized? At the moment, only national quality assessment systems exist (and not in all countries). It is neither politically feasible, nor desirable, to make quality assessment a task for the European Communities. And why should it be confined to European Communities countries only? The alternative, we would suggest, lies in a voluntary association of higher education institutions. The voluntary associations from which the accreditation system grew in the United States of America might serve as example. Of course, this system is not without problems. It may have developed into a bureaucratic system without much quality assurance in it. Apparently the threshold quality of the United States accreditation system is not much of a challenge any more. But, even if these problems do exist, the system did work well for a long time - and Europe still has to begin that long time. 


\section{INFORMATION}

\section{CEPES NEWS:}

The Oradea Statement on Policy Issues of Quality Assessment and Institutional Accreditation in Higher Education

In co-operation with the Ministry of Education of Romania and the University of Oradea, CEPES organized and held an International High-Level Consultation on Policy Issues of Quality Assessment and Institutional Accreditation in Higher Education which was particularly directed at the countries of central and eastern Europe. The Consultation, which took place in Oradea (Romania), from 5 to 7 May 1993, was attended by ministers of education from central and eastern European countries and by experts and representatives from different national and international centres for academic assessment and institutional accreditation in North America and Europe.

The main objective of the conference was to identify possibilities for the future development of cooperation at the European level in the domain of accreditation and quality assessment. In this context attention was paid to issues concerning mobility and the recognition of university diplomas and degrees.

The Statement adopted by the participants in this meeting is reproduced in full below with the hope that our readers will react to it by sending us their comments and suggestions as well as information relevant for the field of quality assessment and institutional accreditation in higher education.

Statement of the International HighLevel Consultation on Policy Issues of Quality Assessment and Institutional Accreditation in Higher Education

I. BACKGROUND

1. The International High-Level Consultation on Policy Issues of Quality Assessment and Institutional Accreditation in Higher Education took place at a moment when higher education systems, particularly those of the central and eastern European countries, are standing on the threshold of $a$ period of fundamental change. This change is expected to be as profound as the change which is affecting the values of the central and eastern European societies during the transition period. Indeed, the reform of higher education systems is being undertaken in all the countries in this part of Europe. As different from each other as they might be in terms of specific objectives and stages of implementation, these reforms have in common the fact that they are aiming at academic excellence as well as the enhancement of the contribution of universities to the development of the societies to which they belong and for the speeding up of the transition to pluralist democracies and prosperous market economies. 
2. In this period of reform, the higher education systems of the central and eastern European countries are faced with many challenges. Some of these have their roots in the recent past; others result from current developments, while still others are being shaped by efforts . to anticipate the future. Decrease of public financing, a tendency towards increased autonomy accompanied by requests for accountability, institutional diversification, new forms of educational governance and structure, curricula reform with an increased need for flexibility, a marked trend towards internationalization with international joint projects and mobility of students and staff, the appearance of private and other higher education institutions, the increase in the numbers of students in a period of scarcity of resources, the extensive changes in curricula, coupled to new demands for staff recruitment and development, the need for increased mobility of students and staff following the extensive internationalization of learning - these are only a few of the new challenges with which the higher education systems of the region are faced.

3. Quality is and should be the hallmark of all changes and developments in the higher education systems of the central and eastern European countries. The questions of how to assess, to assure, and to improve quality, and of which standards are to be considered as the benchmarks for the further development of existing higher education institutions and programmes of study are part and parcel of the current strategy to establish lines of development for the present and to envisage future trends. The need to define criteria and procedures for the accreditation of higher education institutions in the central and eastern European countries is an important priority.

4. The appearance of private higher education institutions and the creation of new faculties and specialities in the public institutions in the central and eastern European countries have contributed greatly to enhancing the importance of accreditation. What in fact should be the basic, minimal requirements for setting up a higher education institution? How should these requirements be differentiated according to type of institution? Should they be related to professional requirements? What are the procedures to be followed in order to meet basic requirements? Who should.be responsible for monitoring criteria and efforts in this regard? These questions and many more in a similar vein require careful answers before the process of accreditation can begin to function.

5. Given the trends and achievements resulting from the expanding academic mobility of staff and students, the prospects of increased mobility within the context of the ongoing internationalization of higher education, the search for standards of quality assessment and assurance, the ways and means of institution- 
al accreditation should be closely linked to the experience already accumulated in other countries, particularly in the EC countries and the United States of America, and to the co-operative projects envisaged or implemented there.

\section{RECOMMENDATIONS}

The participants in the International High-Level Consultation on Policy Issues of Quality Assessment and Institutional Accreditation in Higher Education, meeting in Oradea (Romania), from 5 to 7 May 1993:

- aware of the need to carry out reforms in the higher education systems of the central and eastern European countries;

- stressing the importance of quality assurance in higher education as an essential condition for the fulfilment of the academic and social mission of universities;

- considering the experiences acquired by other European and North-American countries in the domain of quality assurance and management of higher education; and

- taking into account the variety of collaborative initiatives undertaken by such international organizations as CEPES-UNESCO, the European Communities, $O E C D$, the Council of Europe, $C R E$;

- bearing in mind the efforts undertaken towards the elaboration of a joint UNESCO - Council of Europe Convention on academic recognition in Europe in which quality assurance and institution- al accreditation will constitute an important element; and

- acknowledging the existence of different cultural heritages which are reflected in national systems, and thus that approaches to assessment and accreditation may vary from system to system

- have formulated the following recommendations:

1. The issues of quality assurance, assessment, and improvement, as well as those of institutional accreditation are priorities in all central and eastern European systems of higher education and should be closely linked to the processes through which higher education systems and institutions are being reformed, by means of appropriate legislation, policies and mechanisms of implementation.

2. National authorities and representatives of the academic world are urged to co-operate closely in establishing national bodies, preferably of an intermediate "buffer" institution type, charged with quality assessment and/or institutional accreditation at country level.

3. In order to increase the comparability of criteria, practices, and procedures of quality assessment, the higher education systems and institutions of the central and eastern European countries are invited to launch pilot projects in the field, which should be similar to projects developed and implemented in other European systems of higher education. 
4. Such projects could be undertaken jointly and thus allow for a consideration of funding through, for example, the TEMPUS Programme, particularly the "complementary activities" type of funding.

5. The project proposal formulated by CEPES-UNESCO, The European Group on Academic Assessment (EGAA), which is focussed on the idea of developing a pan-European co-operation for the exchange of information and experience in the area of the quality of higher education was received with interest and gained the full support of the participants.

6. When implementing procedures for quality assurance and assessment in higher education, due consideration should be given to strategies and mechanisms for the internationalization of higher education institutions and systerns.

7. CEPES is urged to further organize workshops and training activities focussed on practical matters related to quality assurance and accreditation in higher education.

8. Exchanges of information and coordination should assure a degree of convergence in order to facilitate international comparability and co-operation.

(Source: The CEPES Documentation Centre, May 1993)

\section{MISCELLANEOUS:}

European Journalism Educators'
Conference Held in Timisoara,
Romania, on 29 and 30 April 1993

Sponsored by the Soros Foundation and the University of Timisoara and with the co-operation of the European Journalism Centre of Maastricht, the Netherlands, and the European Journalism Training Association, The European Journalism Educators' Conference met in Timisoara for two days at the end of April 1993. Its objective was to discuss the possibility of setting up an eastern European journalism training association and possibly an eastern European journalism centre, both to be initially funded by the Soros Foundation.

The immediate outcome of the Conference was the adoption of a Declaration which is reproduced in its entirety below:

\section{DECLARATION OF TIMISOARA}

\section{(30 April 1993)}

As a result of group discussions at the Conference of Journalism Educators from Central and East Europe in Timisoara, Romania, on April 29-30, 1993, participants agreed that the issues outlined below were of greatest importance in promoting the interests of journalism education in central and eastern Europe.

\section{INTRODUCTION}

Within each Central and East European country, there are different journalism education programs. Some have been in existence for decades and 


\section{INFORMATION}

are struggling to change; others are newly founded and are struggling to create new programs. Some are four or five year programs within university structures with an academic orientation. Others are of shorter duration and geared more towards the practical aspects of the journalism profession. Still others combine aspects of both.

These difference are a result of local conditions, traditions, and the existing possibilities within each country. Our goal is to learn from one another - as well as from colleagues outside our region. We hope to adapt features of models used in other countries to our own needs, rather than impose outside models outright.

Despite differences, we have many common goals. The most important of these are as follows:

\section{PRINCIPAL GOALS}

- to promote the overall democratization of journalism and communication in our societies;

- to upgrade the quality of journalism training and education;

- to improve facilities and conditions for training journalists;

- to prepare a more professional generation of communicators for tomorrow through the recurrent education and training of their teachers today;

- to introduce new technological infrastructures and to improve those which already exist;

To achieve these goals, we have identified these basic needs common to all our journalism. training institutions:

\section{$N E E D S$}

- greater assistance in the development of curricula and study programs;

- more experience of both instructors and students being trained abroad, primarily in the countries of Western Europe and North America;

- more scholarships and stipends being provided, ranging from short-term durations of one month or less to full semester to year-long or longer; such scholarships will meet at least two important needs which our future journalists now have - to improve their knowledge of foreign languages as well as to improve their professional skills;

- greater material assistance, both technical equipment and teaching materials. Computers and supporting equipment are direly needed, as is basic radio and television equipment; textbooks published in western countries for use as source books for future adaptations are needed, as well as literature with the most up-to-date information about journalism, for library and archival purposes. In addition, a limited number of subscriptions to selected important periodicals for journalism libraries is needed, as well as for student publications.

\section{COOPERATION}

We can also foresee that cooperation between East-East countries can be of immense value in furthering the achievement of the goals outlined above. We recognize the necessity of creating active networks that ensure 
the continuity of the flow of information and knowledge in our societies. Specifically, the forms that such cooperation can take could be as follows:

- exchanges of students and teachers within East-East countries (as well as East-West and West-East) as a feature of regular study programs and curricula;
- greater exchange of information both in journalism training as well as media and communication research through workshops, seminars, and summer schools;

- possible cooperation on joint academic, pedagogical, and scientific projects and issues identified as important by various parties.

(Source: European Journalism Educators' Conference, Timisoara, 30 April 1993) 


\section{CALENDAR OF EVENTS}

\section{MEETINGS ORGANIZED BY CEPES}

\section{September}

Workshop on "Structural Diversification in Higher Education: Sources and Trends (With particular emphasis on the binary system)", organized within the Project on Legislative Reform in Higher Education of the Council of Europe. Organizers: the Council of Europe, CEPES and Ministry of Education of Romania (Bucharest, Romania). For further information, please contact: $\mathrm{Mr}$. Lazar Vlasceanu, CEPES, 39, Stirbei Voda Street, R-70732 Bucharest, Romania.

\section{8-23 September}

1st Ukrainian International Conference on Higher Education Problems, organized by the Ukrainian Ministry of Education under the auspices of CEPES-UNESCO (Odessa, Ukraine). For further information, please contact: Mr. V. Bulgar, Polytechnic Institute, 1 Shevchenko Av., Odessa, Ukraine 270044.

\section{4}

4th Interregional Workshop for Staff Development in Higher Education. For further information, please contact: Mr. Oleg Kouptsov, CEPES, 39, Stirbei Voda Street, R-70732 Bucharest, Romania.
"National Identity and European Consciousness: Mentality, Education, Scholarship". Experts meeting on the evolution of European mentalities (Bucharest, Romania). For further information, please contact: Mrs. Stamenka Uvalic-Trumbic, CEPES, 39, Stirbei Voda Street, R70732 Bucharest, Romania.

\begin{tabular}{c}
\hline OTHER MEETINGS \\
\hline 9-13 August \\
\hline
\end{tabular}

"Institutional Management", Module VII of the European Higher Education Advanced Training Course (EHEATC) organized by the Consortium of Higher Education Researchers (CHER) (Turku, Finland). For further information, please contact: Mr. Kari Hyppönen, Head of Dept. of Academic and Student Affairs, University of Turku, SF-20500 Turku, Finland.

\section{5-18 August}

"Curriculum - Pedagogy - Technology". 4th Nordic Conference under the Nordic Forum for Computer Aided Higher Education (Aalborg, Denmark). For further information, please contact: Conference Secretariat. Conference Secretary Bente Vestergaard, TNP/Institute 12, Aalborg University, P.O. Box 159, DK-9100 Aalborg, Denmark. 


\section{5-18 August}

"Higher Education in a Changing Environment: Regional, National and Transnational Issues". 15th Annual Forum of the European Higher Education Society (EAIR) (Turku, Finland). For further information, please contact: Mrs. Jacinte van Schaik, EAIR Secretariat, c/o CHEPS, University of Twente, P.O. Box 217, 7500 AE Enschede, The Netherlands.

\section{9-20 August}

"Higher Education in a Crisis?" 5th Symposium on Higher Education Research organized by the Institute for Educational Research (Jyväskylä, Finland). For further information, please contact: Mauri Panhelainen, Institute for Educational Research, Dept. of Higher Education Research, P.O. Box 35, SF-40351 Jyväskylä, Finland.

\section{0-25 August}

"Tele Teaching '93. Learning and Working Independent of Time and Space". International conference and exhibition on telecommunications in education, training and work organized by the Norwegian Computer Society on behalf of The International Federation for Information Processing (Trondheim, Norway). For further information, please contact: Conference Secretariat, "TeleTeaching '93". Norwegian Computer Society, P.O. Box 6714 Rodelokka, N0503 Oslo, Norway.
30 August-3 September

8th World Conference on Co-operative Education, organized by the World Council and Assembly on Cooperative Education (Dublin, Ireland). For further information, please contact: Ms. Adrienne Joly, Conference Administrator, Dublin City University, Dublin 9, Ireland.

\section{August-5 September}

5th European Conference for Research on Learning and Instruction, organized by the European Association for Research on Learning and Instruction (EARLI) (Aix-enProvence, France). For further information, please contact: 5th EARLI Conference Secretariat, U.F.R. de Psychologie et Sciences de l'Education, Université de Provence, 29, Avenue Robert Schuman, 13621 Aix-en-Provence Cedex, France.

\section{6-8 September}

"Students and Employment: A Challenge for University Management". International seminar organized by IMHE Programme and Free University of Brussels (Brussels, Belgium). For further information, please contact: IMHE Programme, OECD, 2 rue André Pascal, 75775 Paris Cedex 16, France.

\section{0-24 September}

"Higher Education and European Developments", Module VIII of the European Higher Education Advanced Training Course (EHEATC) organized by the Consortium of Higher Education Researchers 
(CHER) (Florence, Italy). For further information, please contact: CHER Administrator, CHEPS, University of Twente, P.O. Box 217, 7500 AE Enschede, The Netherlands.

\section{1-24 September}

"Engineering Education '93. The Bridge between Teaching and Research". International symposium organized by IGIP - International Society for Engineering Education and FHTE - Fachhochschule für Technik Esslingen (Esslingen am Neckar, Germany). For further information, please contact: Prof. Dr. rer. nat. Günther Kurz, FHT Esslingen, Kanalstrasse 33, D-7300 Esslingen am Neckar, Germany.

\section{8-30 September}

"Quality Assurance in Open and Distance Learning: European and International Perspectives". First EDEN's Academic and Professional Section Conference (Downing College, Cambridge, United Kingdom). For further information, please contact: Mr Alan Tait, Roger Mills, EDEN A \& P Conference, Open University, 12 Hills Road, Cambridge, CB2 1PF, United Kingdom.

\section{0-13 November}

"Christian Universities and European Culture. Intellectual and Political Responsibilities". Internatioonal conference organized by the University College of St. Ignatius (UFSIA) and IFCU Center of Coordination of Research in Rome, under the auspices of "Antwerp, 1993 European Capital of Culture
(Antwerp, Belgium). For further information, please contact: Prof. G. Dierickx, Coordinator UFSIA, Faculteit PSW, Prinsstraat 13, 2000 Antwerpen, Belgium.

\section{1-25 November}

Fifty-second meeting of the IAU Administrative Board//Tenth IAU Round Table organized by the Internatioanl Association of Universities (Tokyo, Japan). For further information, please contact: Dr. Franz Eberhard, Secretary-General, IAU, 1, rue Miollis, 75732 Paris Cedex 15, France.

\section{3-25 November}

RIDE '93 Research in Distance Education (Deakin University, Geelong, Victoria, Australia. For further information, please contact: Terry Evans, RIDE '93 Seminar, Institute of Distance Education, Deakin University, Victoria 3217 , Australia.

\section{November - 2 December}

XIth General Assembly of AUPELFUREF (Yamoussoukro-Abidjan, Ivory Coast). For further information, please contact: AUPELF. UREF, Rectorate, B.P. succ. Côtedes-Neiges, H3S 2S7 Montréal, Québec, Canada.

\section{6-8 December}

"Quality Management and Quality Assurance in OECD Member Countries" International seminar (Paris, France). For further information, please contact: OECD, 2 rue 
André Pascal, 75775 Paris Cedex 16, France.

\section{9-11 December}

EDINEB: "Educational Innovation in Economics and Business Administration: the Case of Problem-Based Learning". Conference organized by the Faculty of Economics and Business Administration, University of Limburg (Maastricht, The Netherlands). For further information, please contact: Conference Secretary: Ms. M. van Zutphen, University of Limburg, P.O. Box 616, 6200 MD Maastricht, The Netherlands.

\section{4-16 December}

"Governments and the Higher Education Curriculum - Evolving Partnerships". Annual Conference of the Society for Research in Higher Education (SRHE) and the University of Sussex (Brighton, UK). For further information, please contact: Prof. Tony Becher, Conference Coordinator, EDB, University of Sussex, Falmer, Brighton BN1 9RG, United Kingdom.

1994

\section{7-10 February}

Annual Conference of the Association for the Advancement of International Education (San Francisco CA, USA). For further information, please contact: AAIE, Thompson House, Westminster College, New Wilmington PA 16172, USA.

\section{2-25 June}

"Comparative Issues in Access to Higher Education". International conference organized by the International Access Network (IAN) and hosted by the Learning Assistance Association of New England and the University of Southern Maine (Portland, Maine, U.S.A.). For further information, please contact: $\mathrm{Mr}$. Robert Lemelin, University of Southern Maine, 96 Falmouth Street, Portland, Maine 04103, USA.

\section{September}

"Educational Reforms: Appraisal and Perspectives with Special Emphasis on the 1974 Recommendation on International Education. 44th Session of The International Conference on Education (ICE) organized by the International Bureau of Education (Geneva, Switzerland). For further information, please contact: Intyernational Bureau of Education, P.O. Box 199, 1211 Geneva 20, Switzerland.

\section{5-7 September}

IMHE General Conference (Paris, France). For further information, please contact: OECD-IMHE, 2 rue André Pascal, 75775 Paris Cedex 16, France. 


\section{NOTES ON CONTRIBUTORS}

BARNETT, Ronald. Dr. , Senior Lecturer.

Address: University of London, Institute of Education, Centre for Higher Education Studies, 55-59 Gordon Square, London WC1H 0NT, United Kingdom.

BRENNAN, John. Dr., Head of Centre. Address: The Open University, Quality Support Centre (QSC), 344-354 Grays Inn Road, London WC1X 8BP, United Kingdom.

GELLERT, Claudius.

Address: European University Institute, Badia Fiesolana, Via dei Roccetti 5, 50016 San Domenico di Fiesole-Florence, Italy.

GOEDEGEBUURE, Leo C.J. Researcher.

Address: University of Twente, Centre for Higher Education Policy Studies, P.O. Box 217, 7500 AE Enschede, the Netherlands.

HÄYRYNEN, Yrjö-Paavo. Professor of Psychology.

Address: University of Joensuu, 80101 Joensuu, Finland.

HÄYRYNEN, Liisa.

Address: University of Joensuu, 80101 Joensuu, Finland.

KIVINEN, Osmo. Director.

Address: University of Turku, Research Unit for the Sociology of Education, Hämeenkatu 1, 20500 Turku, Finland.
KOGAN, Maurice. Professor.

Address: Brunel University, Department of Government, Centre for the Evaluation of Public Policy and Practice, (CEPPP), Uxbridge, Middlesex, UB8 3PH, United Kingdom.

KOZMA, Tamas. Dr., Director.

Address: Hungarian Institute for Educational Research, P.O. Box 427, 1395 Budapest, Hungary.

MIDDLEHURST, Robin.

Address: University of London, Institute of Education, Centrefor Higher Education Studies, 55-59 Gordon Square, London WC1H 0NT, United Kingdom.

MOSCATI, Roberto. Associate Professor of Sociology.

Address: Università degli Studi di Milano, Dipartimento di Sociologia, Via Conservatorio 7 , 20122 Milano, Italy.

PUGLIESE, Enrico. Professor of Sociology of Work.

Address: Università degli Studi di Napoli, Dipartimento $d i$ Sociologia, Corso Umberto 1, 80138 Napoli, Italy.

RINNE, Risto. Professor.

Address: University of Turku, Research Unit for the Sociology of Education, Hämeenkatu 1, 20500 Turku, Finland. 
SCHOMBURG, Harald. Researcher. Address: Gesamthochschule Kassel-Universität, Wissenschaftliches Zentrum für Berufs- und $\mathrm{Hochsch}$ ulforschung, Henschelstraße 4, 3500 Kassel, Germany.

SHAH, Tarla. Researcher.

Address: Hochschul-Informations-System (HIS), Goseriede 9, Postfach 2920, 3000 Hannover 1, Germany.

TEICHLER, Ulrich. Professor, Director of the Centre for Research on Higher Education and Work.
Address: Gesamthochschule Kassel-Universität, Wissenschaftliches Zentrum für Berufs- und $\mathrm{Hochschulforschung,}$ Henschelstraße 4, 3500 Kassel, Germany.

WESTERHEIJDEN, Don F. Researcher.

Address: University of Twente, Centre for Higher Education Policy Studies, P.O. Box 217, 7500 AE Enschede, the Netherlands.

WEUSTHOF, Peter J. M. Researcher.

Address: Hochschul-Informations-System (HIS), Goseriede 9, Postfach 2920, 3000 Hannover 1, Germany. 


\section{CEPES PUBLICATIONS}

\section{HIGHER EDUCATION IN EUROPE}

Quarterly review, in English, French, Russian

\section{STUDIES AND PAPERS}

CEPES publishes studies and shorter papers on specific issues of higher education, follow-up studies to meetings, and periodic statistical surveys. Their topics range from general problems of planning and management to the specific teaching, training, research and service functions of higher education, and its new roles for the advancement of modem society.

CEPES STUDIES

AACCESS TO HIGHER EDUCATION IN EUROPE (English, French, Russian, 1981, 90 p. ISBN 92-3-101942-2)

"INTERUNIVERSITY CO-OPERATION IN THE EUROPE REGION (English, French, Russian, 1981, 80 p. ISBN 92-3-101941-4)

DEFFICIENCY IN HIGHER EDUCATION (English, 1986, 149 p. ISBN 92-3-102350)

a PLANNING IN HIGHER EDUCATION (English, 1986, 120 p. ISBN 92-9069-101-8)

aHIGHER EDUCATION AND RESEARCH (English, 1986, 120 p. ISBN 92-9069-103-4)

a INTERNATIONAL DIRECTORY OF HIGHER EDUCATION RESEARCH INSTITUTIONS (English, 1987, 134 p. ISBN 92-3-002516-X)

QNEW INFORMATION TECHNOLOGIES IN HIGHER EDUCATION (English, 1989, 339 p. ISBN 92-9069-111-5)

' 'STATISTICS ON HIGHER EDUCATION' 1980 - 1985. (English, 1989, 167 p. ISBN 92-9069-112-3)

aTHE OPEN DOOR: PAN-EUROPEAN ACADEMIC CO-OPERATION (English, 1991, 150p. ISBN92-9069-115-8)

- HANDBOOK OF HIGHER EDUCATION DIPLOMAS IN EUROPE (KG. Saur, 1992, 304 p. ISBN 3-598-11073-1)

To order: K. G. SAUR VERLAG \& CO., Postfach 7016, D-8000 München 70, Germany.

PAPERS ON HIGHER EDUCATION

a TRENDS, DEVELOPMENTS, AND NEEDS OF THE HIGHER EDUCATION SYSTEMS OF THE CENTRAL AND EASTERN EUROPEAN COUNTRIES (English, 1992,48 p.ISBN92-9069-119-X)

aASSISTING HIGHER EDUCATION IN CENTRAL AND EASTERN EUROPE. ACTIVITIES OF INTERNATIONAL ORGANIZATIONS - A SURVEY (English, 1992, 31 p. ISBN 92-9069-120-4)

ICEPES - 20 YEARS OF SERVICE (English, 1992, 40 p. ISBN 92-9069-121-2)
BIBLIOGRAPHY ON ACADEMIC RECOGNITION AND MOBILITY - EUROPE REGION (English, 1992, 123 p. ISBN' 92-9069-122-0)

-ACCREDITATION AND QUALITY ASSURANCE IN HIGHER EDUCATION (English, 1992, 85 p. ISBN 92-9069-123-9)

$\square$ ACADEMIC FREEDOM AND UNTVERSITY AUTONOMY. Proceedings of the International Conference, 5-7 May 1992, Sinaia (English, 1992, 52 p. ISBN 92-9069-124-7)

\section{MONOGRAPHS}

The series of monographs is intended to cover the national systems of higher education in Europe and North America. The monographs follow a standard structure identifying the main features and explaining the functions of the national systems, while also facilitating easy cross reference and comparison among them. The monographs appear in English, except as otherwise noted.

aHIGHER EDUCATION IN ALBANIA $(1986,51$ p. ISBN 92-9069-104-2)

a HIGHER EDUCATION IN BULGARIA (1983, 114 p. ISBN 92-3-102185-0)

口HIGHER EDUCATION IN THE BIELORUSSIAN SSR (1983, 72 p. ISBN 92-3-102187-7)

IHIGHER EDUCATION IN FINLAND (1988, 91 p. ISBN $951-47-2071-7)$

\HIGHER EDUCATION IN THE GERMAN DEMOCRATIC REPUBLIC (1983, 77 p. ISBN 92-3-102186-9)

aHIGHER EDUCATION IN HUNGARY (1985, 108 p. ISBN 92-9069-102-6)

aHIGHER EDUCATION IN THE NETHERLANDS $(1989,88 \mathrm{p}$.)

aHIGHER EDUCATION IN NORWAY $(1992,94$ p. ISBN 92-9069-118-2)

aHIGHIER EDUCATION IN POLAND (1987, 90 p. ISBN 92-9069-107-7)

aHIGHER EDUCATION IN SWITZEREAND (1984, 80 p. ISBN 92-3-102292-X)

aHIGHER EDUCATION IN TURKEY (1990, ISBN' 92-9069-114-X)

aHIGHER EDUCATION IN THE UKRAINIAN SSR (1985, 79 p. ISBN 92-3-102369-1)

WHIGHER EDUCATION IN THE UNITED STATES (1982, 83 p. ISBN 92-3102045-5)

aHIGHER EDUCATION IN THE USSR (1990, ISBN 92-9069-109-3)

Forthcoming:

Studies:

-MULTILINGUAL LEXICON OF HIGHER EDUCATION (Commercial publishing)

- Order should be placed with the publisher 


\section{Order Form}

Your Subscrlber Number:

Involce to be sent to:

(If you have already subscribed) (if different trom that of the subscriber)

Your References

No. of Order

Name:

Title/Function:

Institution:

Address:

Country:

Telophone:

Telefax:

Telex:

- I would like to subscribe (to renew my subscription) to the quarterly review "Higher Education In Europe" , English or French versions:

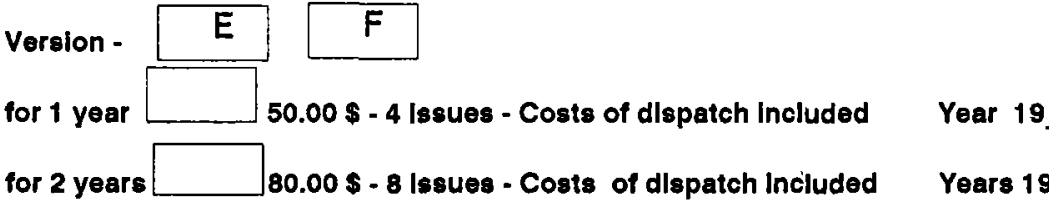

Number of coples

- I would like to order the following publication(s) (see the list overleaf) at the price of:

$5.00 \$$ per CEPES Paper on Higher Education

$15.00 \$$ per Monograph or Study

(Cosis of dispatch Included)

Title(s) of the publlcatlon / Author

Please send the Order Form to the following address:

CEPES UNESCO, 39 Stirbel Vodä Street, Bucharest, Romanla R-70732

Payment: After receipt of our invoice, please send back a cheque in US \$ in the name of CEPES UNESCO to the above address.

Very Important: Please mention your number as a subscriber.

Date Signature 


\section{STIL AVAILABLE! ORDER NOW!}

\section{Higher Education in International Perspective: A Survey and Bibliography}

by Philip G. Altbach and David H. Kelly

(London: Mansell, 1985)

The European Centre for Higher Education wishes to inform the readers of Higher Education in Europe that it still has on hand a few copies of this classic work, one which has withstood the test of time. They can be ordered directly from CEPES for the low price of $\$ 25.00$. In order to obtain your copy, please write to CEPES as per the instruction given on the order form at the end of this volume.

\section{NEW ADDITION TO THE CEPES MONOGRAPH SERIES ON THE HIGHER EDUCATION SYSTEMS OF THE COUNTRIES OF THE EUROPE REGION OF UNESCO}

CEPES would like to announce the recent publication of Higher Education in Norway. Compiled by Anne-Marie Fetveit of the Norvegian Ministry of Education, Research, and Church Affairs, this study supersedes the earlier study on Norvegian higher education which appeared in this series in 1983.

Interested readers are invited to order this new publication, which costs only $\$ 15.00$, directly from CEPES, making use of the order form at the end of this volume. 


\begin{tabular}{|c|}
\hline $\begin{array}{l}\text { CEPES PAPERS ON HIGHER EDUCATION } \\
\text { The European Centre for Higher Education is pleased to inaugurate a new series of } \\
\text { publications on higher education designed to deal with and to present to the interested } \\
\text { public specific issues and problems in higher education with which the Centre is dealing. } \\
\text { Each volume in the series is written either by CEPES staff members or by invited specialists, } \\
\text { experts in their respective fields. }\end{array}$ \\
\hline The series currently includes six titles, all of them published during 1992: \\
\hline $\begin{array}{l}\text { CEPES - } 20 \text { YEARS OF SERVICE } \\
\text { (Leland Conlcy Barrows) }\end{array}$ \\
\hline $\begin{array}{l}\text { BIBLIOGRAPHY ON ACADEMIC RECOCNITION AND MOBILITY - EUROPE REGION } \\
\text { (Cecilia Preda) }\end{array}$ \\
\hline $\begin{array}{l}\text { ACADEMIC FREEDOM AND UNIVERSITY AUTONOMY } \\
\text { (Procedings of the International Conference, } 5 \text { - } 7 \text { May 1992, Sinaia, Romania) }\end{array}$ \\
\hline $\begin{array}{l}\text { ACCREDITATION AND QUALITY ASSURANCE IN HIGHER EDUCATION } \\
\text { (Paul Enache Stcrian) }\end{array}$ \\
\hline $\begin{array}{l}\text { ASSISTING HIGHER EDUCATION IN CENTRAL AND ASTERN EUROPE: } \\
\text { ACTIVITIES OF INTERNATIONAL ORGANIZATIONS - A SURVEY } \\
\text { (Stamenka Uvalic-Trumbic) }\end{array}$ \\
\hline $\begin{array}{l}\text { TRENDS, DEVILOPMENTS, AND NEEDS OF THE HIGHER EDUCATION SYSTEMS } \\
\text { OF THE CENTRAL AND EASTERN EUROPEAN COUNTRIES } \\
\text { (Lazar Vlasceanu) }\end{array}$ \\
\hline $\begin{array}{l}\text { studies directly from CEPES at the very low price of } \\
\text { as per the instructions given on the order form at the }\end{array}$ \\
\hline
\end{tabular}




\section{Forthcoming Issues:}

3-93

Policy Issues of Quality Assessment and Institutional Accreditation

4-93

Careers for Women at European Universities: Obstacles and Opportunities

$1-94$

Trends, issues, and New Laws in Higher Education

2-94

Counselling and Orientation of Students in Higher Education

Note for contributors

Contributors who wish to publish in the review should send their manuscripts to: The Senior Editor, CEPES, 39 Stirbei Vodã Street, R-70732 Bucharest, Romania, or through:

The Bucharest CEPES pouch, UNESCO, 7 place de Fontenoy, 75700 Paris, France.

Articles should be typed double-spaced with ample margins and should not exceed 3000 words. Notes and bibliography should be presented separately. The bibliography should give the full name of the author, dates of publication, full original title (with English, French or Russian translation, if appropriate), publisher and place of publication, number of pages. Charts, drawings (done in black ink), and tables should be presented on separate pages; their respective positions should be indicated in the text. References in the text should only indicate the

author's surname, date of publication, and page number, if necessary.

CEPES would be grateful to receive the article not only in English, but also in French and Russian, if possible.

The article should be preceded by an abstract of approximately 250 words. The author's name, address, and a brief biography should be stated on a separate sheet of paper.

Manuscripts will not be returned.

\section{CEPES invites contributors to send their manuscripts on diskettes.}

The CEPES information processing system can receive WANG or IBM compatibles, 5.25 or 3.5 diskettes, preferably on double density.

Please indicate type of word processing software used. 